San Jose State University

SJSU ScholarWorks

Mineta Transportation Institute Publications

$3-2020$

\title{
Crime and Harassment on Public Transportation: A Survey of SJSU Students Set in International Context
}

\author{
Asha Weinstein Agrawal \\ San Jose State University, asha.weinstein.agrawal@sjsu.edu \\ Anastasia Loukaitou-Sideris \\ University of California, Los Angeles \\ Cristina Tortora \\ San Jose State University \\ Yajing Hu \\ Stanford University
}

Follow this and additional works at: https://scholarworks.sjsu.edu/mti_publications

Part of the Community-Based Research Commons, Social Control, Law, Crime, and Deviance Commons, and the Transportation Engineering Commons

\section{Recommended Citation}

Asha Weinstein Agrawal, Anastasia Loukaitou-Sideris, Cristina Tortora, and Yajing Hu. "Crime and Harassment on Public Transportation: A Survey of SJSU Students Set in International Context" Mineta Transportation Institute Publications (2020). https://doi.org/10.31979/mti.2020.1810

This Report is brought to you for free and open access by SJSU ScholarWorks. It has been accepted for inclusion in Mineta Transportation Institute Publications by an authorized administrator of SJSU ScholarWorks. For more information, please contact scholarworks@sjsu.edu. 


\section{SJSU}

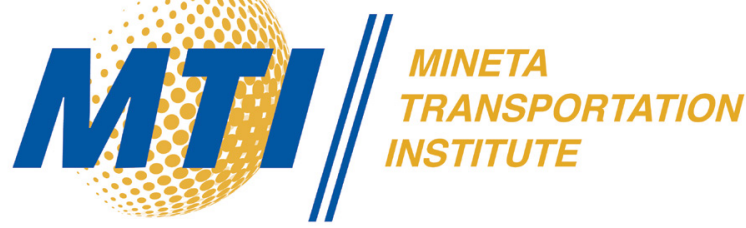

Crime and Harassment on Public Transportation: A Survey of SJSU Students Set in International Context

Asha Weinstein Agrawal, Ph.D.

Anastasia Loukaitou-Sideris, Ph.D.

Cristina Tortora, Ph.D.

Yajing Hu, Ph.D.

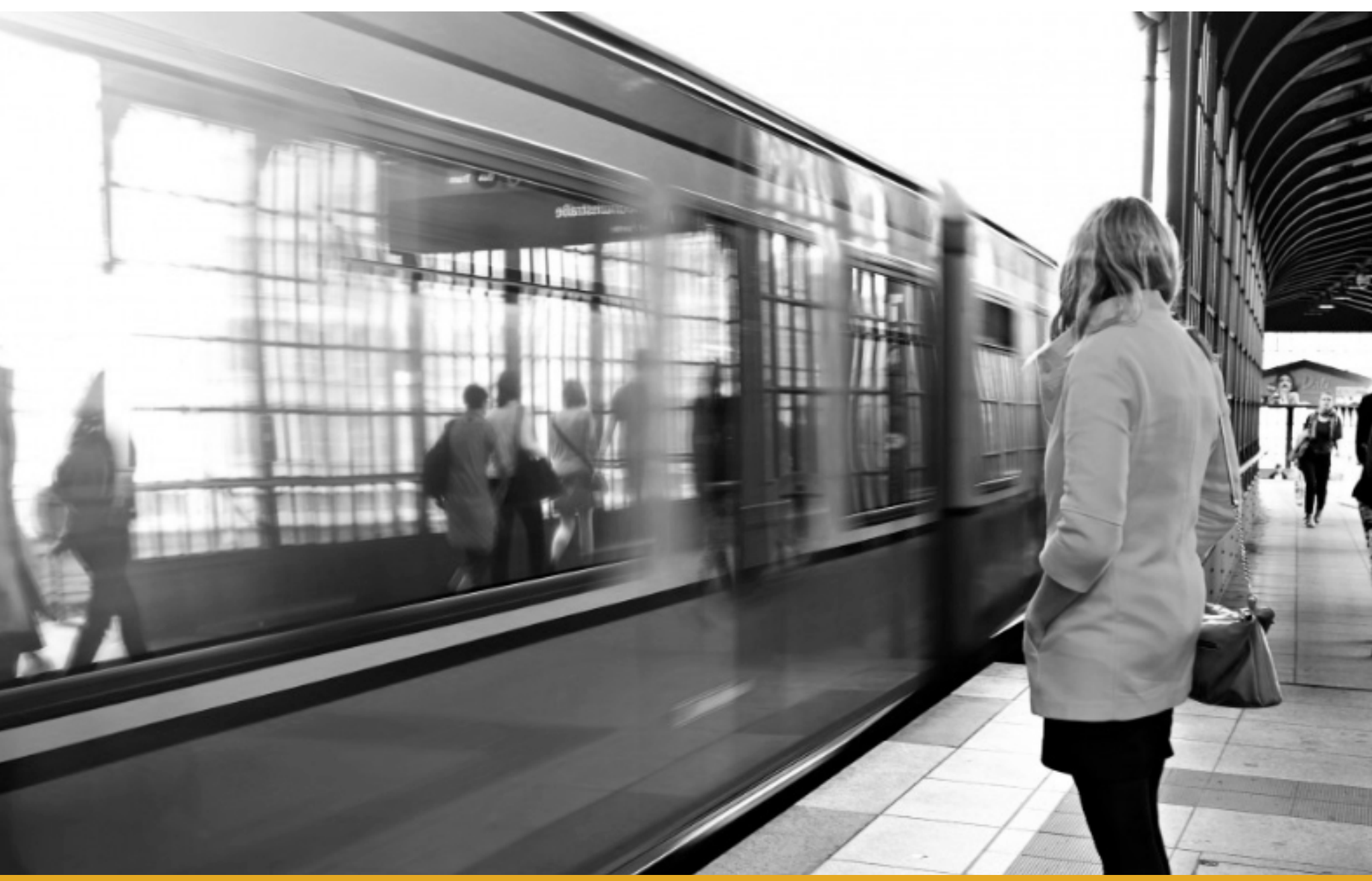




\section{MINETA TRANSPORTATION INSTITUTE \\ LEAD UNIVERSITY OF \\ Mineta Consortium for Transportation Mobility}

Founded in 1991, the Mineta Transportation Institute (MTI), an organized research and training unit in partnership with the Lucas College and Graduate School of Business at San José State University (SJSU), increases mobility for all by improving the safety, efficiency, accessibility, and convenience of our nation's transportation system. Through research, education, workforce development, and technology transfer, we help create a connected world. MTI leads the four-university Mineta Consortium for Transportation Mobility, a Tier I University Transportation Center funded by the U.S. Department of Transportation's Office of the Assistant Secretary for Research and Technology (OST-R), the California Department of Transportation (Caltrans), and by private grants and donations.

MTl's transportation policy work is centered on three primary responsibilities:

\section{Research}

MTI works to provide policy-oriented research for all levels of government and the $P$ rivate sector to foster the development of optimum surface transportation systems. Research areas include: bicycle and pedestrian issues; financing public and private sector transportation improvements; intermodal connectivity and integration; safety and security of transportation systems; sustainability of transportation systems; transportation / land use / environment; and transportation planning and policy development. Certified Research Associates conduct the research. Certification requires an advanced degree, generally a Ph.D., a record of academic publications, and professional references. Research projects culminate in a peer-reviewed publication, available on TransWeb, the MTI website (http://transweb.sjsu.edu).

\section{Education}

The Institute supports education programs for students seeking a career in the development and operation of surface transportation systems. MTI, through San José State University, offers an AACSBaccredited Master of Science in Transportation Management and graduate certificates in Transportation Management,Transportation Security, and High-Speed Rail Management that serve to prepare the nation's transportation managers for the 2 I st century. With the active assistance of the California Department of Transportation (Caltrans), MTI delivers its classes over a state-of-the-art videoconference network throughout the state of California and via webcasting beyond, allowing working transportation professionals to pursue an advanced degree regardless of their location. To meet the needs of employers seeking a diverse workforce, MTl's education program promotes enrollment to under-represented groups.

\section{Information and Technology Transfer}

MTI utilizes a diverse array of dissemination methods and media to ensure research results reach those responsible for managing change. These methods include publication, seminars, workshops, websites, social media, webinars, and other technology transfer mechanisms. Additionally, MTI promotes the availability of completed research to professional organizations and journals and works to integrate the research findings into the graduate education program.MTI's extensive collection of transportation- related publications is integrated into San José State University's world-class Martin Luther King, Jr. Library.

\section{Disclaimer}

The contents of this report reflect the views of the authors, who are responsible for the facts and accuracy of the information presented herein. This document is disseminated in the interest of information exchange. The report is funded, partially or entirely, by a grant from the U.S. Department of Transportation's University Transportation Centers Program. This report does not necessarily reflect the official views or policies of the U.S. government, State of California, or the Mineta Transportation Institute, who assume no liability for the contents or use thereof. This report does not constitute a standard specification, design standard, or regulation. 
REPORT 20-09

\title{
CRIME AND HARASSMENT ON PUBLIC TRANSPORTATION: A SURVEY OF SJSU STUDENTS SET IN INTERNATIONAL CONTEXT
}

\author{
Asha Weinstein Agrawal, Ph.D. \\ Anastasia Loukaitou-Sideris, Ph.D. \\ Cristina Tortora, Ph.D. \\ Yajing Hu, Ph.D.
}

March 2020 


\section{TECHNICAL REPORT DOCUMENTATION PAGE}

1. Report No. 20-09

4. Title and Subtitle

Crime and Harassment on Public Transportation:

A Survey of SJSU Students Set in International Context

3. Recipient's Catalog No.

5. Report Date

March 2020

6. Performing Organization Code

8. Performing Organization Report CA-MTI-1810

Asha Weinstein Agrawal, Ph.D. 0000-0003-2328-0263

Anastasia Loukaitou-Sideris, Ph.D. 0000-0003-0186-4751

Cristina Tortora, Ph.D. 0000-0001-8351-3730

Yajing Hu, Ph.D. 0000-0001-9738-0457

9. Performing Organization Name and Address

Mineta Transportation Institute

College of Business

San José State University

San José, CA 95192-0219

12. Sponsoring Agency Name and Address

U.S. Department of Transportation

Office of the Assistant Secretary for

Research and Technology

University Transportation Centers Program

1200 New Jersey Avenue, SE

Washington, DC 20590

15. Supplemental Notes

10.31979/mti.2020.1810

\section{Abstract}

Communities around the world are gradually becoming aware that transit riders, and especially women, are often victims of a wide range of offenses of a sexual nature that happen on buses and trains, and at bus stops and train stations. Better understanding the extent and nature of sexual harassment on transit is a critical issue for transit operators and society at large. If fear of sexual crime limits if and how people ride transit, the result is reduced mobility for certain segments of the population, as well as lost ridership for transit agencies.

For this study, we surveyed 891 students at San José State University (SJSU), a large public university in the San Francisco Bay Area. The survey explored in detail whether and how student riders experience sexual harassment, as well as how fear of such harassment influences their transit use. Recognizing that transit trips are complex, multi-phased activities, the survey asked separately about harassment experiences waiting for the bus or train, on the transit vehicle, and walking to/from the transit stop.

Key findings include that sexual harassment during transit trips is a common experience (63\% of respondents reported having been harassed), the experience of sexual harassment leads students to limit their use of transit, many take safety precautions when using transit, and very few report experiences of harassment to anyone at all, much less to authorities.

Although the SJSU survey was designed as a stand-alone research project, we are able to situate the results in a global context because the study was embedded in an international effort, with a near-identical survey administered to students at universities in 18 cities across six continents. The SJSU experience is typical of students around the world, though SJSU's students were particularly likely to report feeling unsafe after dark.

17. Key Words

Transit; sexual harassment; safety; security; surveys

\section{Distribution Statement}

No restrictions. This document is available to the public through The National Technical Information Service, Springfield, VA 22161
19. Security Classif. (of this report) Unclassified
20. Security Classif. (of this page)

Unclassified
21. No. of Pages

103 


\title{
Copyright $\odot 2020$ \\ by Mineta Transportation Institute \\ All rights reserved
}

\author{
Mineta Transportation Institute \\ College of Business \\ San José State University \\ San José, CA 95192-0219
}

Tel: (408) 924-7560

Fax: (408) 924-7565

Email: mineta-institute@sjsu.edu

transweb.sjsu.edu 


\section{ACKNOWLEDGMENTS}

The authors thank the following people for their important contributions to this project:

- Student research assistants Hao Ding, who helped with the literature review, and Morgan Frankel, who helped with the literature review and data preparation;

- Scott Heil and John Briggs, from San José State University's Institutional Effectiveness \& Analytics Office, who administered the survey;

- Vania Ceccato, who co-led with Anastasia Loukaitou-Sideris the global project into which this study fits-a comparative look across six continents at how university students experience sexual crimes when using public transit;

- Editing Press, for editorial services; and

- MTI staff, including Executive Director Karen Philbrick, Ph.D.; Deputy Executive Director Hilary Nixon, Ph.D.; Research Support Assistant Joseph Mercado; and Executive Administrative Assistant Jill Carter. 


\section{TABLE OF CONTENTS}

Executive Summary

$\begin{array}{ll}\text { Study Methods } & 1\end{array}$

Study Findings $\quad 2$

Implications for Policy $\quad 3$

$\begin{array}{ll}\text { I. Introduction } & 5\end{array}$

$\begin{array}{lr}\text { II. Literature Review } & 8\end{array}$

Extent of Sexual Harassment on Transit $\quad 8$

Spatial and Temporal Patterns of Harassment $\quad 9$

Socio-Demographic Characterists of Victims 10

$\begin{array}{ll}\text { Sexual Harassment Impacts } & 10\end{array}$

$\begin{array}{ll}\text { Reporting } & 11\end{array}$

Effectiveness of Anti-Harassment Strategies $\quad 12$

$\begin{array}{ll}\text { Conclusion } & 13\end{array}$

$\begin{array}{ll}\text { III. Study Methods } & 15\end{array}$

About SJSU and its Students 15

Global Context for the SJSU Survey 16

Questionnaire Design 16

Sampling and Survey Administration 17

$\begin{array}{ll}\text { Analysis Procedures } & 17\end{array}$

$\begin{array}{ll}\text { IV. Findings } & \mathbf{2 0}\end{array}$

Socio-Demographics and Travel Behavior of Respondents 20

Do Students Feel Unsafe Riding Transit, and Why? 23

What Factors Prevent Students from Using Transit More? 33

How Many Students Experienced Harassment? 35

To What Extent Is Harassment Witnessed and Reported? 42

What Safety Precautions Do Students Take? 44

What Changes Do Students Recommend to Improve Safety? 47

V. Conclusions $\quad 52$

Summary of Findings $\quad 52$

Implications for Policy and Action $\quad 54$

Study Limitations and Recommendations for Future Research 55 
Appendix A: Survey Questionnaire and Topline Results 57

$\begin{array}{ll}\text { Appendix B: Data Tables From the Statistical Significance Tests } & 77\end{array}$

Do Students Feel Unsafe Riding Transit, and Why?

How Many Students Have Experienced Sexual Harassment Riding Transit? 80

To What Extent Do Victims Report Sexual Harassment on Transit? 81

What Safety Precautions Do Students Take When Riding Transit?

What Changes Do Students Recommend to Improve Safety on Transit? 82

Appendix C: Data Tables From the Regression Modeling 85

Likelihood of Being Victimized $\quad 85$

$\begin{array}{ll}\text { Perceived Safety } & 86\end{array}$

$\begin{array}{ll}\text { Abbreviations and Acronyms } & 88\end{array}$

$\begin{array}{lr}\text { Bibliography } & 89\end{array}$

$\begin{array}{lr}\text { Endnotes } & 95\end{array}$

$\begin{array}{ll}\text { About the Authors } & 102\end{array}$

$\begin{array}{lc}\text { Peer Review } & 103\end{array}$ 


\section{LIST OF FIGURES}

1. Public Transit Routes and Stops near the SJSU Campus 16

2. Home Location of the Survey Respondents 23

3. Percent of Bus and Train Riders Feeling "Always" or "Often" Safe, by Gender 25

4. Percent of SJSU Students Feeling "Always" or "Often" Safe after Dark on the Bus, as Compared to Other Countries

5. Percent of SJSU Students Feeling "Always" or "Often" Safe after Dark on the Train, as Compared to Other Countries

6. Onboard Safety Concerns Identified by Female vs. Male Bus Riders

7. Onboard Safety Concerns Identified by Female vs. Male Train Riders

8. Perceived Safety Concerns on the Bus by Bus Riders Who Had and Had Not Been Harassed

9. Perceived Safety Concerns at the Bus Stop by Bus Riders Who Had and Had Not Been Harassed

10. Perceived Safety Concerns on the Train by Riders Who Had vs. Had Not Been Harassed

11. Perceived Safety Concerns at the Platform by Train Riders Who Had or Had Not Been Harassed

12. Comparison of Factors Preventing Bus Riders from Using the Bus More Often, by Gender

13. Comparison of Factors Preventing Train Riders from Using the Train More Often, by Gender

14. Factors Preventing Bus and Train Riders from Using Transit More Often, by Gender

15. Percent of SJSU Students Experiencing Harassment on the Bus, as Compared to Other Countries

16. Percent of SJSU Students Experiencing Harassment on the Train, as Compared to Other Countries

17. Percent of LGBTQI and non-LGBTQI SJSU Students Experiencing Harassment on the Bus, as Compared to Other Countries 
18. Percent of LGBTQI and non-LGBTQI SJSU Students Experiencing Harassment on the Train, as Compared to Other Countries

19. Percent of SJSU Students Reporting Harassment, as Compared to Other Countries

20. Precautions that Bus Riders Take, by Gender 46

21. Precautions that Train Riders Take, by Gender 47

22. Safety Recommendations from Bus Riders, by Gender 48

23. Safety Recommendations from Train Riders, by Gender 49

24. Safety Recommendations from Bus Riders, by Harassed vs. Not Harassed 50

25. Safety Recommendations from Train Riders, by Harassed vs. Not Harassed 


\section{LIST OF TABLES}

1. Variables Used in the Multivariate Regression Analysis 18

2. Socio-Demographic Characteristics of the Respondents 21

3. Travel Behavior of the Respondents 22

4. Percentage of Transit Riders Feeling Unsafe, by Transit System Setting and Mode

5. Percentage of Bus and Train Riders Considering Different Factors

"A Significant Problem," by Transit System Setting 28

6. Factors Preventing Bus and Train Riders from Using Transit More Often 34

7. Percent of Riders Experiencing Different Types of Harassment, by Transit System Setting and Mode

8. Percent of LGBTQI Riders Experiencing Different Types of Harassment, by Transit System Setting and Mode

9. Reporting by Students Who Self-Identified as a Victim of Harassment

10. Victim Reports of How Witnesses Reacted to the Crime

11. Types of Precautions that Riders Take during Bus and Train Trips

12. Percentage of Women vs. Men Feeling Always or Often Safe Riding Bus and Rail

13. Onboard Safety Concerns Identified by Female vs. Male Bus and Train Riders 77

14. Safety Concerns Identified by Bus Riders Who Had vs. Had Not Been Harassed 78

15. Safety Concerns Identified by Train Riders Who Had vs. Had Not Been Harassed

16. Factors Preventing Transit Riders from Using the Bus/Train More Often for Female vs. Male Riders

17. Factors Preventing Transit Riders from Using the Bus/Train More Often for Riders Who Had and Had Not Been Harassed

18. Female vs. Male Riders Who Were Victims of Harassment during Bus/ Rail Travel, by Mode 
19. Percent of Women and Men Reporting Harassment

20. Precautions Riders Take Using Buses and Trains, by Gender

21. Precautions Riders Take Using Buses and Trains, by Riders Who Had and Had Not Been Harassed

22. Recommended Safety Improvements from Bus Riders, by Gender

23. Recommended Safety Improvements from Train Riders, by Gender

24. Recommended Safety Improvements from Bus Riders Who Had vs. Had Not Been Harassed

25. Recommended Safety Improvements from Rail Riders Who Had vs. Had Not Been Harassed

26. Logistic Regression for Model of Bus Riders Who Had Been Victimized, by Type of Victimization

27. Logistic Regression for Model of Train Riders Who Had Been Victimized, by Type of Victimization

28. Ordered Logistic Regression Model for Safety Perception on the Bus, Showing Odds Ratios for Significant Explanatory Variables

29. Ordered Logistic Regression Model for Safety Perception on the Train, Showing Odds Ratios for Significant Explanatory Variables 


\section{EXECUTIVE SUMMARY}

In 2017, the Washington Post published an article titled "Why the \#MeToo Movement is a Public Transportation Issue." The article observed that "For many, it's a depressing but foregone conclusion: if you're a woman who rides public transportation, you're almost guaranteed to experience the kinds of demeaning or threatening encounters that fit squarely within the bounds of the \#MeToo conversation."1

The Washington Post article expressed a blunt truth. Transit riders, and especially women, are often victims of a wide range of offenses of a sexual nature that happen on buses and trains, as well as at bus stops and train stations. Sexual harassment offenses fall into three categories: verbal, non-verbal, and physical. Verbal offenses include sexual comments, kissing noises, whistling, or even being asked to have sex. Non-verbal harassment includes indecent exposure, being shown pornographic images, and stalking. Physical harassment includes groping a person's body or playing with her hair, or unwanted kissing, as well as the most serious crimes of sexual assault and rape.

Understanding the extent and nature of sexual harassment on transit and responding to it is a critical issue for transit operators and society at large. If fear of sexual crime limits whether and how people ride transit, the result is reduced mobility for certain segments of the population, as well as lost ridership for transit agencies.

Occasionally, transit agencies ask transit riders in onboard surveys about their experience with harassment. From such surveys and from the scholarly literature, we know that sexual harassment in transit environments is significantly underreported. Thus, it remains largely invisible. But how can transit operators and their community planners to effectively combat an unknown problem? Our study was designed to help fill that gap in knowledge.

\section{STUDY METHODS}

Findings in this study are drawn from an online survey of 891 students at San José State University (SJSU), a large public university in the San Francisco Bay Area. SJSU is located in the downtown core of the city and is served by local and regional bus and rail services.

The survey explored in detail whether and how student riders experience sexual harassment, as well as how fear of such harassment influences their transit use. Recognizing that transit trips are complex, multi-phased activities, the survey asked separately about harassment experiences waiting for the bus or train, on the transit vehicle, and walking to/from the transit stop.

Although the SJSU survey was designed as a stand-alone research project, we are able to situate the results in a global context because the study was embedded in an international effort. ${ }^{2}$ Teams of researchers on six continents administered a near-identical survey to students at universities in 18 cities. 


\section{STUDY FINDINGS}

\section{Sexual Harassment is Common on Transit}

Sadly, the survey results reveal that sexual harassment and assault is a commoneven routine-experience for SJSU student transit riders, whether they ride the bus or train. Almost two-thirds (63\%) of respondents who rode transit had experienced some form of harassment while using transit. Verbal harassment was the most common form of harassment, with $41 \%$ experiencing "obscene/harassing language" and $26 \%$ being subjected to sexual comments. Among non-verbal types of harassment, $22 \%$ had been stalked and $18 \%$ had been victims of indecent exposure. Physical harassment was less common, but still, $11 \%$ of students had experienced groping or inappropriate touching.

\section{Sexual Harassment Creates Fear and Reduces Transit Use}

The survey also found that students' fear of sexual harassment reduces their transit use. When asked if they felt safe using transit, only half of riders reported feeling always or often safe, and sexual harassment was a clear factor making some students feel unsafe on transit. Depending on the transit setting, from one quarter to one third of riders considered sexual harassment to be a significant problem.

Students responded to these concerns either by avoiding transit or by taking precautions when riding. A quarter of riders said that sexual harassment prevented them from using transit more often. Among those students taking precautions, many took precautions that limited their mobility, include traveling only during the daytime, waiting for transit only at well-lit places, and avoiding certain bus or train stops. Students who had been prior victims of harassment were much more likely to report feeling unsafe using transit, to consider sexual harassment a problem, to report reduced use of transit, and to take precautions when riding transit.

\section{Sexual Harassment Affects Both Genders, but Far More Women}

Concern about harassment was much more common among women than men. For example, women were less likely than men to report feeling safe. Twice as many women as men saw harassment as a problem, and $45 \%$ of female bus riders but only $7 \%$ of male riders said that fear of sexual harassment led them to reduce use of the bus. Roughly twice as many women as men reported all types of harassing behaviors-verbal, nonverbal, and physical. Finally, women were also much more likely than men to take safety precautions when using transit, such as limiting travel to daytime hours or carrying a selfdefense spray.

Although sexual harassment affects more women than men, the study clearly shows that men are also affected: many male survey respondents reported having been victims and worrying about harassment, and in a few cases men reported reducing transit use in response to that concern. 


\section{Sexual Harassment Remains Largely Unreported}

Fewer than one quarter of victims reported the harassment they had experienced to anyone at all, and those students who reported the experiences mostly did so to friends or family rather than to police or transit operators.

\section{The SJSU Student Experience is a Global Experience}

The rates of victimization for SJSU bus and train riders are generally in line with the results from the surveys conducted at other cities around the world. As in most other cities, more than half of SJSU's female student transit riders experienced harassment on the bus or train, far more women than men are harassed, and harassment was rarely reported to authorities. However, as compared to students in the other cities in the global study, SJSU students were less likely to feel "always" or "often" safe after dark on the bus or on the train.

\section{IMPLICATIONS FOR POLICY}

Although sexual harassment is a problem that stems from cultural and social factors far beyond any transit operator or community control, there are many ways that operators can proactively address the problem to reduce its severity. Based on the study findings, we suggest the following actions.

Educate the public about harassment. Transit operators, police, and other responsible public agencies can instigate widespread educational campaigns against sexual harassment. Such campaigns, through ads and posters on transit vehicles and in transit settings, can raise awareness about the problem and encourage victims and bystanders to report sexual harassment incidents. A related finding is that many victims did not explicitly identify sexual crimes as such, so awareness campaigns should also educate the public about what behaviors constitute sexual crimes.

Institutionalize onboard surveys. Transit operators can better understand the problem and extent of harassment on their systems if they conduct systematic surveys that ask passengers about their experiences with harassment. Questions should inquire about experiences not only onboard the transit vehicle but also at transit stops and on the way to/from transit.

Make reporting of harassment easy. The finding that almost none of the SJSU student victims officially reported the crime underscores the need for transit operators to make reporting easy for transit riders. Smartphone apps and dedicated phone lines can help victims and bystanders report harassment and other crimes in real time.

Give attention to the physical environment. Respondents made clear that poorly maintained and dark transit environments made them fearful, a finding that points to the value of keeping transit settings well-lit and well-maintained. 
Safeguard against antisocial behaviors. Many respondents also indicated that they would use transit more if they did not fear antisocial behaviors like drunkenness and obscene language. Survey respondents called for more police patrols and security cameras on both platforms and transit vehicles to reduce antisocial behavior.

Learn from industry best practices. Of course, the complexities of transit operations may require solutions that are different from what passengers ask for. To better understand feasible and tested actions, operators also have a great deal to learn from the practices of transit operators that have prioritized efforts to reduce sexual crimes, including antiharassment campaigns, training of transit vehicle operators, request-a-stop policies, and use of digital technologies to report harassment events. 


\section{INTRODUCTION}

In 2017, the Washington Post published an article titled "Why the \#MeToo Movement is a Public Transportation Issue." The article observed that, "For many, it's a depressing but foregone conclusion: if you're a woman who rides public transportation, you're almost guaranteed to experience the kinds of demeaning or threatening encounters that fit squarely within the bounds of the \#MeToo conversation." ${ }^{3}$ Growing evidence supports that conclusion. For example, a 2018 survey of passengers on the Los Angeles Metro system found that one-quarter of women riding buses and one-third of women riding rail had been victims of sexual harassment within the preceding six months. ${ }^{4}$

This study adds to the small but growing literature about problems of sexual harassment and assault against transit riders with findings from a survey that explored in detail the experiences San José State University (SJSU) students have had with sexual harassment and assault, as well as the ways those concerns affect their choices about using transit.

The terms "sexual harassment" and "sexual assault" are used in this study to distinguish two types of sex crimes that differ in their degree of seriousness. Sexual harassment, broadly defined, is "any unwanted attention including lewd comments, leering, sexual invitations, threats, displaying pornographic material, being followed or pictured, and public masturbation," while sexual assault refers to situations "when someone is threatened, coerced, or forced into non-consensual sexual acts." Scholars identify three categories of sexual harassment crimes in public spaces and transit environments: verbal, non-verbal, and physical. ${ }^{6}$

Understanding the extent and nature of sexual crimes and harassment on transit is a critical issue for public transit agencies, as well as society more broadly. When fear of sexual crime limits whether and how people ride transit, the result is reduced mobility for individual travelers and lost ridership for transit agencies.

Transit ridership has been mostly declining since 2007 , despite significant investment in transit infrastructure in California over the last 15 years, ${ }^{7}$ and it is possible that fear of sexual crimes is one factor reducing ridership. Studies point to a variety of factors influencing transit use, such as service quality, fare costs, and perceived transit safety. Some researchers have argued that the perception of personal safety can have a significant influence on travel patterns, ${ }^{8}$ and concern over safety is a common reason why many choose not to use transit. ${ }^{9}$ Fear for their safety leads some transit riders to take precautionary measures that range from adopting behavioral mechanisms when in public (e.g., sitting close to a passenger who does not look threatening), to choosing specific routes, travel modes, and transit environments over others, to completely avoiding particular settings and activities such as walking. ${ }^{10}$

One factor largely missing from these discussions about declining transit ridership, however, is fear of sexual crimes in particular, even though researchers find that women riders are more fearful than men about victimization while travelling. ${ }^{11} \mathrm{~A}$ particular concern of women transit riders is the threat of offenses of a sexual nature that happen on buses and trains, and at bus stops and train stations around the world. ${ }^{12}$ Although public discussion 
about sexual harassment as one possible cause of declining ridership is growing, agency attention to the matter is still rare. The omission may be explained by recent studies finding that sexual harassment in transit environments often goes unreported, and thus it remains largely invisible to transit operators (see Chapter 2).

Surveys of transit operators in the U.S. have found that operators are largely genderneutral in their policies, leading to a frequent and significant mismatch between female riders' security needs and the security strategies adopted. For example, a 2006 survey of 131 large transit operators found that they do not perceive a particular need for womenfocused safety programs. ${ }^{13}$ But this gender-blind approach to passenger safety can create a "gender gap" in mobility and causes transportation inequity, since women are typically more reluctant to walk, bike, or use public transit due to safety concerns. ${ }^{14}$ This also counteracts many cities' desire to promote greener travel modes and transit agencies' aspirations for increased transit ridership.

The above-mentioned studies focus on the general public, and it is not clear if similar patterns hold true among college students, a group with particularly high potential to use transit. College students are less likely to travel alone by private car, as they typically have lower incomes and car ownership rates than the general public, and they seek residences near the campus. Universities often encourage transit ridership for students, offering them free or very inexpensive transit passes. SJSU, for example, gives every student a free pass to ride on local bus and light rail services provided by the Santa Clara Valley Transportation Authority (VTA).

This study examines the safety concerns of college students with respect to sexual harassment and assault: how these may vary by gender; how the concerns affect their choices about using transit; and what type of precautions and behavioral and travel adaptations college students adopt in the face of these concerns. The motivation of the study is not only to identify challenges that may affect transit use by college students, but also to propose policy responses to overcome them.

Findings in this study are drawn from an online survey that the authors administered to 891 students at San José State University (SJSU), a large public university in the San Francisco Bay Area. SJSU is located in the downtown core of the city and is served by local and regional bus and rail services. The survey asked students about their experiences with harassment in transit settings, as well as their concerns with using public transit. Recognizing that transit trips are complex, multi-phased activities, the survey asked separately about harassment experiences waiting for the bus or train, on the transit vehicle, and walking to/from the transit stop.

Although the SJSU survey was designed as a stand-alone research project, we are able to situate the results in a global context because the study was embedded in an international effort. ${ }^{15}$ Teams of researchers on six continents administered a near-identical survey to students at universities in 18 cities. 
The remainder of the report is organized as follows. Chapter 2 summarizes the literature that traces the extent and impact of sexual harassment in transit environments. Chapter 3 describes the study methods, Chapter 4 discusses the survey findings, and Chapter 5 concludes with a summary of findings, policy recommendations, and recommendations for future research. Appendices present detailed data tables and the full questionnaire. 


\section{LITERATURE REVIEW}

Buses, bus stops, trains, and train stations represent a unique category of public space, as they are populated by thousands of anonymous riders on the move. Because of their anonymity and relative openness, transit environments are often difficult to control ${ }^{16}$ and so both generate and attract crime. ${ }^{17}$ At the same time, transit environments are spatially confined settings populated by transit riders with rather predictable behaviors.

Literature on women in public spaces has found that, in general, women are more afraid than men of being victimized in public settings, ${ }^{18}$ even though intersectional characteristics such as age, race/ethnicity, sexual orientation, or disability may also influence levels of fear. ${ }^{19}$ As indicated in the previous paragraph, transit settings represent a subset of public spaces. While a significant literature examines crime at bus stops, station platforms, and transit vehicles, one specific type of transit crime, sexual harassment, has received relatively less attention. Scholarly research on sexual harassment on public transit only emerged in the 1980 s. ${ }^{20}$ Prior to that time, studies on public transport were "gender-blind." However, in the last decade an increasing number of studies and reports have started focusing on crimes of sexual nature against women in transit. ${ }^{21}$

Scanning the literature on sexual harassment in transit environments, we find only a few academic studies in North America and Europe. On the other hand, there has been a proliferation of literature on sexual harassment on transit in some cities of the Global South, especially after the brutal gang rape and subsequent death of a young woman on a bus in Delhi in 2012. While this literature from the Global South is important, we ultimately decided not to review it extensively in this report. Some of the documented impacts of sexual harassment on victims in these countries-curtailed education, early marriage, hindered development ${ }^{22}$ —are different and more severe from those in the Global North. These differences explain our decision to confine our analysis to the Global North. However, recognizing that strategies and interventions from the Global South may be helpful for the Global North, we did expand our search to include a few articles from the Global South that focused on responses to harassment.

The following sections give a brief overview of the literature.

\section{EXTENT OF SEXUAL HARASSMENT ON TRANSIT}

Despitean increasing awareness about crimes of sexual harassment in publictransportation, the extent of their prevalence still has not been explored with large-scale, systematic data collection. ${ }^{23}$ Official data is problematic both because victims rarely report the crimes, and because official crime reporting statistics often do not specify when harassment was sexual in nature. ${ }^{24}$

In a 2007 survey of 1,790 New York City subway riders, 63\% of respondents reported having been sexually harassed on the subway. A little less than half (44\%) reported having witnessed an incident of sexual harassment, and nearly 1 out of $10(9 \%)$ had witnessed an incident of sexual assault. Of these witnesses, the vast majority (93\%) reported that the victim was female, and almost all (98\%) said that the perpetrator was male. ${ }^{25}$ A 2017 
smaller-scale survey of 140 female college students conducted by researchers in New York City found that almost 4 out of $5(77 \%)$ had experienced or witnessed sexual harassment in transit environments. ${ }^{26}$

Passenger on-board surveys undertaken by transit agencies in different U.S. regions have found smaller percentages of victimization. A 2018 onboard passenger survey conducted by the Los Angeles County Metropolitan Transportation Authority (not reporting the number of passengers surveyed) found that $26 \%$ of female riders and $21 \%$ of male riders had experienced sexual harassment during their transit rides over the six prior months. ${ }^{27}$ Similarly, a 2018 online survey of 1,000 Washington Metropolitan Area Transit Authority riders found that about 1 out of $5(21 \%)$ respondents had experienced sexual harassment on public transportation, and that women were nearly twice as likely as men to be the victim. ${ }^{28}$ In London, a 2012 study survey of 523 women found that about 1 out of 5 had been harassed on public transportation. ${ }^{29}$ Another telephone survey of 1,000 Londoners by Transport for London in 2012-2013 found that $12 \%$ to $15 \%$ of women had experienced sexual harassment in transit environments. ${ }^{30}$

The aforementioned studies indicate that sexual harassment on transit is a common phenomenon, even though the reported percentages of victimization vary. The variation is likely caused by methodological differences as well as difference in actual crime rates. For one thing, different studies use different definitions of sexual harassment; some ask about lifetime victimization experiences, while others inquire about experiences only over a specific timeframe. Additionally, it is likely that the context (bus or train, bus stop or train station) matters; onboard surveys undertaken by transit agencies focus only on experiences on the transit vehicle, while some academic studies examine the broader transit environment and rider experience throughout the whole transit journey.

\section{SPATIAL AND TEMPORAL PATTERNS OF HARASSMENT}

The few studies that have explored the spatial patterns of sexual harassment in transit environments find that the problem is pervasive at stops and stations, as well as onboard vehicles. For example, a 2018 study led by the Washington Metropolitan Area Transit Authority found that approximately two-thirds of transit riders who were sexually harassed experienced harassment onboard trains, about 3 out of 5 in rail stations, 2 out of 5 onboard buses, and about the same at bus stops. ${ }^{31}$ A study of women's everyday mobility in Austria found that about 2 out of $5(39 \%)$ sexual harassment offenses took place in transit settings, of which most were inside the vehicles $(71 \%)$ as compared to $29 \%$ at transit stops. ${ }^{32}$ The aforementioned study of female college students in New York City found that patterns of victimization were extensive during all stages of their subway commute to and from college: $46 \%$ experienced harassment while walking, $49 \%$ at stations, and $61 \%$ onboard transit vehicles. ${ }^{33}$

Studies find that sexual harassment in transit environments often concentrates temporally during peak traffic hours, when transit environments are overcrowded, but that rape and sexual assault tend to happen in late night or early morning hours. ${ }^{34}$ For example, the 2007 study of New York City subway users found that almost 3 out of 5 of those harassed had experienced the incident during rush hours. ${ }^{35}$ 
On the other hand, fear of victimization tends to be higher during the very early morning or late evening hours, when it is dark, and when transit settings are typically desolate and lack the natural surveillance of bystanders or other transit riders. Studies in the UK have found that women feel particularly unsafe at transit settings after dark. ${ }^{36}$

\section{SOCIO-DEMOGRAPHIC CHARACTERISTS OF VICTIMS}

Despite the variations in the extent of sexual harassment in transit environments, studies show that women are disproportionately more victimized than men. According to a 2004 report by the Department for Transport in the UK, the risk of experiencing sexual harassment for women is four times more than for men. ${ }^{37}$ Likely for this reason, studies find that women perceive higher risks of victimization, exhibit higher levels of anxiety over personal safety, and feel less safe in public transportation environments than men; such perceptions have impacts on women's travel behavior and are likely to limit women's mobility. ${ }^{38}$

While it is important to examine nuances among female transit users, only a handful of studies have examined issues of intersectionality and very few have begun to look at gender categories beyond the binary men/women classification. In terms of age, a 2017 study found that younger women are more likely to be harassed than older women. ${ }^{39}$ Race may also be key factor in the differential experiences of women, as non-white women often experience higher levels of fear than white women. ${ }^{40}$ Income also seems to affect feelings of fear over victimization. Studies of bus stop crime in Los Angeles found that low-income women are more fearful of crime than higher-income women, partly because they live in high-crime and unsafe neighborhoods. ${ }^{41}$ Women with disabilities are also more likely to be harassed in public transit environments. Reviewing a limited literature, ludici, et al., concluded that the rate of physical and sexual aggression experienced by women with disabilities on transit is double that of women without disabilities. ${ }^{42}$

\section{SEXUAL HARASSMENT IMPACTS}

The review of the literature shows that sexual harassment in transit environments may have impacts on individual riders, particularly women, as well as impacts on the ridership of transit systems. Impacts on transit riders include anxiety and fear, avoidance, and risk management behaviors. These impacts lead women who have access to private modes of transportation to desert public transit, which counteracts larger municipal or regional efforts for a greener transportation system.

\section{Anxiety and Fear}

Studies find that women exhibit higher levels of anxiety over personal safety and feel more unsafe in public transportation environments than men, and such feelings have impacts on their travel behavior and mobility. ${ }^{43}$ Experiences of being a victim or simply witnessing sexual harassment can generate fear of transit environments. ${ }^{44}$ Indeed, studies find that prior sexual victimization affects women's perception of safety in transit environments to a greater extent than men's. ${ }^{45}$ At the same time, the already higher rates of sexual harassment experienced by women in transit settings contribute and amplify their perception of insecurity, which reinforces their higher levels of fear. 


\section{Avoidance}

Fear of harassment can lead to avoidance of transit use. A survey of 824 MetroLink weekday riders in St. Louis found that among groups with different demographic and trip characteristics, young females and riders using transit stations with higher crime rates were more likely to express doubt over their future use of transit. ${ }^{46} \mathrm{~A}$ recent survey in Los Angeles showed that the transit ridership of a newly-built light rail line was significantly lower among women partly because of safety concerns. ${ }^{47}$ In the Île-de-France region of Paris, a survey of 3,188 female transit riders found that $48 \%$ of those who had reported feeling unsafe in transit environment considered avoiding using transit after dark, avoiding certain transit settings, or changing their means of transportation. ${ }^{48}$ Another impact that fear may have on women's behavior is partial avoidance, namely avoiding using the bus or the train during certain times (time-based avoidance) or avoiding certain transit stations or lines (space-based avoidance). ${ }^{49}$ Time-based avoidance usually happens after dark and during other times when fewer people are around, which is also when more serious sex crimes like assault and rape tend to happen. ${ }^{50}$

\section{Risk Management}

In response to the risk of sexual harassment, some riders are found to exercise risk management, adopting certain behavioral mechanisms to minimize risk. A study focusing exclusively on sexual harassment of female transit riders, found that women who relied on transit to get to work or school, and who were unable to change transportation modes after being harassed, exercised behavioral adaptations, such as sitting and standing only near women passengers, or strategically placing their bag or backpack to avoid being touched. ${ }^{51}$ Other studies find that additional measures that women transit riders adopt to reduce the risk of harassment include dressing carefully to avoid clothing that can be perceived as provocative, travelling accompanied by their dog, and even carrying some sort of repellant or weapon. ${ }^{52}$

Fear, avoidance, and even risk management behaviors that stem from the risk of sexual harassment constrain mobility. As the more vulnerable group to sexual crimes and harassment in transit environments, women are disproportionately affected and can be adversely impacted in their access to essential urban amenities and opportunities such as jobs, healthcare, or recreation. ${ }^{53}$ As a number of scholars have also found, avoidance behaviors also hurt the bottom lines of transit operators as they reduce transit ridership, which in turn negatively affects efforts to reduce greenhouse gas emissions in cities and promote more sustainable transportation modes than the private automobile. ${ }^{54}$

\section{REPORTING}

An early study in the New York City subway system pointed out that sex crimes are probably underreported to a greater extent than other crimes. ${ }^{55}$ Some have estimated that underreporting by women of threatening behavior or actual assault on transit may be as high as $90 \% .{ }^{56}$ Empirical data from transit-rider surveys confirm that high percentages of sexual harassment and assault crimes are not reported and remain largely invisible in crime statistics. A 2014 passenger survey by the Los Angeles County Metropolitan 
Transportation Authority found that about 1 in 5 passengers experienced sexual harassment during rides, of which the majority were female passengers, and yet only 99 official reports were received in the whole year. ${ }^{57}$ The aforementioned 2007 survey on the New York City subway system found that only $4 \%$ of respondents who were sexually harassed reported to the police and/or transit agency. Reporting rates for sexual assault were somewhat higher, but still very low: $14 \%$ of victims reported the assault to the police and/or transit agency, while only $9 \%$ of witnesses reported the crime. ${ }^{58}$

Researchers find several reasons for underreporting. One is that the experience of sexual harassment and assault is traumatizing, and the victim often chooses to avoid reliving it by filing a police report. Further, victims may fear that police officers will lack empathy during the interview process. Another reason is distrust of the police, and the extent of underreporting is found to be higher among recent and possibly undocumented immigrant women. ${ }^{59}$ The embarrassment felt by victims of sexual harassment due to social and cultural pressure may also result in underreporting. ${ }^{60}$

There is a small evidence that transit riders' reluctance to report sexual harassment may be changing as a result of the \#MeToo movement. A recent study of bystander perceptions to sexual harassment in transit environments in the UK found that participants attributed blame to the perpetrator rather than the victim. ${ }^{61}$

\section{EFFECTIVENESS OF ANTI-HARASSMENT STRATEGIES}

Transit agencies and municipal departments may use a variety of interventions that range from physical solutions and Crime Prevention through Environmental Design (CEPTD) interventions, to technological solutions, to education and awareness-raising campaigns, ${ }^{62}$ as well as the deployment of transit policing, and even "women-only" transit vehicles. However, the literature lacks systematic "before and after" evaluations and metrics of the effectiveness of different interventions and strategies. ${ }^{63}$

Notable in recent years is the introduction of new digital technologies in the fight against sexual harassment. These include smartphone apps that riders can use to report sexual harassment in real time and request help, such as the DigiPolice App launched by the Tokyo Metropolitan Police. Victims can activate the app, which immediately starts shouting "Stop it!," while the message "There is a molester!" appears on the smartphone screen. ${ }^{64}$ Smartphone apps that allow individuals to report where they have been harassed have also been launched in many cities of the world by the nonprofit Hollaback. Similarly, the HarassMap37 website in Egypt encourages victims to anonymously report the place and type of their victimization in transit settings and other public spaces. This information reveals to the authorities and the public the hot spots which they should police or avoid, respectively. ${ }^{65}$ Finally, the Safetipin App in India provides a safety audit of public environments in nine Indian cities, measuring nine parameters including lighting, the condition of walkways and paths, the presence of people and specifically women on the streets, etc., and the app computes a Safety Score. ${ }^{66}$ Evidence is limited on the effectiveness of these new technologies, such as online platforms and smartphone apps, to encourage reporting and raise awareness. Yet there is some tentative early evidence that such measures may help increase reporting, as evidenced by the growing number of women using online platforms to share their harassment experiences. ${ }^{67}$ 
With respect to policy interventions, campaigns aimed at raising public awareness about sexual harassment and encouraging reporting are believed to be promising. ${ }^{68}$ For example, Massachusetts Bay Transport Authority (MBTA) reported higher reporting rates and higher arrest rates in the four years after the launch of an anti-harassment advertising campaign. ${ }^{69}$ A recent evaluation of the "Report It To Stop It" campaign, launched in London to encourage reporting of sexual harassment incidents to police, found no difference in attitudes towards reporting between those who had seen the campaign and those who had not, yet an increase in crime reporting was observed after the launch of the campaign. ${ }^{70}$ In Brazil, the São Paulo metro initiated in 2014 the "You are not alone" program, which includes more resources for security personnel and security technology, training of transit personnel, and a campaign to encourage incident reporting. Researchers evaluating this program found mixed results: the program has increased reporting but victims cannot be helped in real time. ${ }^{71}$

Another intervention aiming to reduce harassment is the introduction of women-only transportation vehicles, which have been introduced in many countries, such as Mexico, Brazil, Egypt, India, Indonesia, Iran, Japan, Malaysia, Russia, South Korea, Thailand, and the United Arab Emirates. Women-only transit vehicles have received both positive ${ }^{72}$ and negative evaluations in the context of the Global South. ${ }^{73}$ In the U.S., such schemes have raised concerns that they may generate greater gender inequality and perpetuate genderbased discrimination. ${ }^{74}$

\section{CONCLUSION}

While the evidence in the literature is conclusive about the widespread presence of sexual harassment on transit, its reported extent varies because of inconsistent definitions of the term and methodological inconsistencies among the various studies. While some transit agencies have started asking about sexual harassment in their onboard passenger surveys, large-scale studies and surveys of transit riders are still rare, and thus there are gaps in our knowledge of how sexual harassment affects different sub-groups of women differently. We also know little about the perpetrators and their patterns of perpetration in cases of sexual harassment: what emboldens and motivates or counteracts their behavior.

On the other hand, the literature is definitive about the existence of a very significant underreporting of sexual harassment and assault crimes in transit settings. Victims and bystanders are reluctant to report especially the less serious offences because of embarrassment, perceived inaction by authorities, and sometimes fear of police. However, we know little about the factors that trigger or inhibit reporting and supportive responses by bystanders.

The literature also indicates that none of the elements of a transit system (the transit vehicles, transit stations, bus stops, and routes to and from the transit station or stop) is immune to the incidence of harassment, though there is no consensus as to which of these settings is more vulnerable, since environmental and contextual factors can also be at play. A small set of studies examines the spatial and temporal characteristics of transit settings that relate to higher incidence of harassment. Different types of harassment are more encouraged in some settings than others: bus overcrowding, for example, may 
enable improper touching, while sexual assault is more likely to take place at a desolate than a crowded bus stop.

Lastly, we need more studies that evaluate the effectiveness and outcomes of different anti-harassment interventions and strategies: what works and what doesn't, where and for whom. 


\section{STUDY METHODS}

We administered the survey online to a random sample of SJSU students enrolled in the fall of 2018. This chapter first describes SJSU's geographic location, public transit services, and regional population characteristics to put the findings in content. The next section discusses the larger global project into which the survey fits, and the remaining sections describe the content of the survey questionnaire and survey administration process.

\section{ABOUT SJSU AND ITS STUDENTS}

SJSU, a public university with both undergraduate and graduate programs, had 32,828 students in 2018. ${ }^{75}$ Many students attend the university part-time and work off campus either part-time or full-time. The student population is highly diverse. For example, $42 \%$ of students identify as Asian and $18 \%$ as Hispanic, and many are born outside the United States. ${ }^{76}$ The student population is also diverse economically. Although some students come from affluent or middle-class households, the campus struggles to serve its many homeless and food-insecure students.

SJSU is located in the city of San José, California, in the United States. With a population just over one million, San José is the third largest city in California and the tenth largest in the country. Located at the southern end of the San Francisco Bay Area, San José bills itself as "the Capital of Silicon Valley." The city's population is racially and ethnically diverse, with the largest groups being Asian/Asian-American (35\%), Hispanic/Latino (32\%), and white/ non-Hispanic (26\%). By U.S. standards, the population of San José is comparatively well educated ( $41 \%$ of adults 25 and older have at least a bachelor's degree) and higher income (median household income is $\$ 97,000$ ). However, there are also many people struggling to make ends meet. According to the Census Bureau, $10 \%$ of residents live in poverty. ${ }^{77}$

In terms of the built environment, much of San José and its surrounding communities are sprawling and low-density, with residents typically relying on personal automobiles for travel. However, many residents are also unable to drive and so rely on public transportation. While transit services are sparse in most of the region, the university itself is located in a downtown core served by numerous local and regional transit options (Figure 1). The VTA runs buses, light rail, and paratransit services, and transit operators based in other counties operate regional bus and rail services that run into downtown San José. The latter include buses and three rail services (Caltrain, Altamont Commuter Express, and Amtrak Capitol Corridor). 


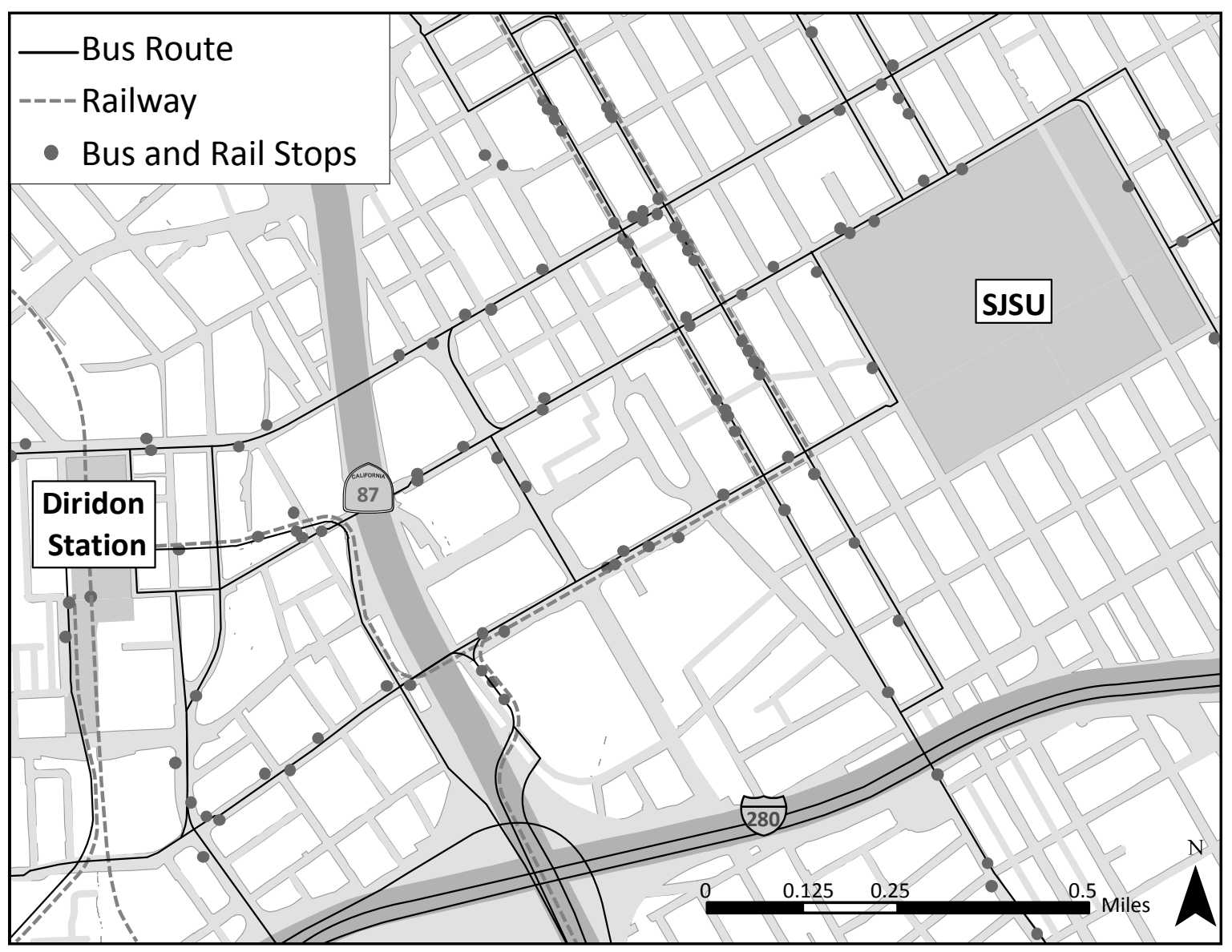

Figure 1. Public Transit Routes and Stops near the SJSU Campus

Source: Map by Clelia Busados.

\section{GLOBAL CONTEXT FOR THE SJSU SURVEY}

The SJSU survey was designed as a stand-alone research project embedded in an international effort. ${ }^{78}$ For the global project, teams of researchers around the world administered a near-identical survey to university students, examining how the nature, type, settings, and extent of victimization on public transport among university students varies in different city and country contexts. Contributing surveys were fielded to university students on six continents: San José, Los Angeles, Vancouver, and Mexico City in North America; Bogota, São Paolo and Rio Claro in Brazil, South America; London, Paris, Milan, Lisbon, Stockholm, and Huddinge in Europe; Tokyo, Guangzhou, and Manila in Asia; Lagos in Africa; and Melbourne in Australia.

\section{QUESTIONNAIRE DESIGN}

The heart of the survey questionnaire asked respondents about their experiences related to sexual crimes when using public transit: if they had been the victim of such crimes, if they had witnessed such crimes against others on the transit system, how safe they felt using transit during daytime and nighttime, and what safety precautions they took when using public transit. In addition, respondents were asked questions about what travel modes they typically use, age, gender, and race/ethnicity. 
The questionnaire was designed to be as similar as possible to one that had been implemented internationally at other universities, to facilitate comparison among campuses. For this study at SJSU, minor modifications were made to an English-language version of the questionnaire that had been previously administered at UCLA. The changes were made to more accurately reflect the public transit options at SJSU, add answer options to questions where the large numbers of UCLA respondents had all written in the same answer for an "Other: please describe" question, and collect slightly different travel behavior and socio-demographic information.

Appendix A reproduces the full text of the online questionnaire distributed at SJSU.

\section{SAMPLING AND SURVEY ADMINISTRATION}

We chose an online survey, with an emailed invitation, as the best way to reach a random sample of students. Because all students at SJSU are required to use email and other online applications for classes and administrative matters, there was no risk that some students could not be reached by email. (By contrast, many students do not regularly update the postal address on file with the campus.)

The online survey was administered by staff from SJSU's Office of Institutional Analytics and Effectiveness (IAE). IAE staff emailed a survey invitation to a sample of 8,000 students who had been randomly selected to participate. Because women were expected to have higher response rates, the invitation went to 4,800 men and 3,200 women. As an incentive, students were offered the chance to enter a random drawing for gift cards usable at campus stores.

The survey was fielded from October 21 to November 3, 2018. A total of 1,070 students responded, with 891 providing data usable for analysis, for an adjusted response rate of $11 \%$.

\section{ANALYSIS PROCEDURES}

For each theme, we compared the results for different subgroups, using the test of two proportions to check for statistically significant differences. For all themes analyzed, the report compares the findings for women versus men. Additionally, when the data permitted and where appropriate to the type of data, the report also compares the findings for bus and rail riders, as well as for riders who did and did not report having been harassed. We had intended to systematically compare findings for riders who did and did not self-identify as LGBTQI, but too few respondents identified as such to make such analysis meaningful for most questions.

Where it was logical to assume dependency among variables, we used a regression analysis to determine which variables significantly affected whether a respondent had been harassed and the respondent's perception of safety on transit. Perception of safety was measured by asking respondents to evaluate if they feel safe on a scale from 1 to 5 , with separate questions asked for day and nighttime, and for walking to/from the stop or station, waiting for the bus or train to arrive, and riding the transit vehicle. ${ }^{79}$ 
Depending on the characteristics of the dependent variable, we used either logistic regression or ordered logistic regression models. When the dependent variable is binary (i.e., yes or no), we used a logistic regression model. ${ }^{80}$ When the dependent variable is ordinal but not continuous (i.e., the values are not numerical but they have an order), we used an ordered logistic regression model. ${ }^{81}$

Table 1 shows the dependent and independent variables for the four models we ran. In both models, we first tested which of many independent variables significantly affected the dependent variable and then kept in the final models only those with a significant impact.

Table 1. Variables Used in the Multivariate Regression Analysis

\begin{tabular}{ll}
\hline Dependent variables & Independent variables \\
\hline Likelihood of having been a victim of harassment & Gender \\
Any type & LGBTQI \\
Verbal & Ethnicity \\
Non-verbal & Age \\
Physical & Train/bus frequency \\
& Commute time \\
& Takes the train/bus at night \\
\hline Safety perception a & Gender \\
On the bus/train during the day & LGBTQI \\
Waiting for the bus/train during the day & Age \\
On the bus/train at night & Train/bus frequency \\
Waiting for the bus/train at night & Have been harassed \\
& Takes the train/bus at night \\
& Takes precautions \\
\hline
\end{tabular}

a Questions 3 to 6 for bus riders and 14 to 17 for train riders.

The coefficients of each significant dependent variable can be interpreted using the odds ratio, which is the odds of observing a phenomenon $A$ (e.g., harassment) in the presence of a second "event" $B$ (e.g., being female). When the odds ratio is one, the two events are independent. A positive odds ratio implies that event $B$ increases the probability of observing event $A$, and vice versa for a negative odds ratio.

The overall goodness of fit of the models was measured using the pseudo- $\mathrm{R}^{2}$ index. For all the models the goodness of fit was quite low, which indicates that there may be variables not measured in the survey that affect the phenomena or that there may be no variables that can predict the phenomena.

Before performing the regression analyses, the data were pretreated to account for missing values; each missing value was imputed using a function of the other responses. The missing values can have a big impact on the analysis, and multiple imputation is generally recommended..$^{82}$ With multiple imputation, each missing value is imputed several times, obtaining several completed datasets. The procedure starts imputing all the missing values with a simple technique, like mode or mean imputation. It then selects one variable 
for which it deletes the imputed values and re-imputes the values using linear models, where the dependent variable is the one selected, and the independent variables are the other variables in the dataset. All the missing values for the other variables are imputed using the same technique, one variable at a time. The starting point affects the resultsstarting from a different variable produces different imputations. Therefore, multiple runs of the same algorithm can produce different datasets, where the difference concerns only the imputed values. We used five different complete datasets to create the final dataset used for analysis. In other words, we ran the algorithm five times, obtaining five regression models, one per dataset, and reported the overall results.

The analysis was performed using the software $R$ (Development Core Team, 2016). For multiple imputation we used the package $\mathrm{MICE},{ }^{83}$ and for regression we used the function glm from the STATS package. 


\section{FINDINGS}

This chapter presents the SJSU survey findings. The first section describes the respondents' socio-demographic and travel behavior characteristics, and the remaining sections present the survey findings organized into the following themes:

1. Do students feel unsafe riding transit, and why?

2. What factors prevent students from using transit more often?

3. How many students experienced sexual harassment on transit?

4. To what extent is harassment witnessed and reported?

5. What safety precautions do students take when riding transit?

6. What changes do students recommend to improve safety on transit?

For each theme, we looked at the results for all respondents and then compared the results for different subgroups, using the analysis procedures described in the preceding chapter. In all cases, we compared the findings for men versus women. However, we do not systematically report how students' experiences varied by other socio-demographic characteristics such as race/ethnicity and LGBTQI status because there are too few respondents for some categories. However, the report compares the findings for bus versus rail riders, or for riders who do versus do not report having been harassed, where such comparisons are appropriate to the type of data and number of data points.

Finally, the discussion sets the SJSU student experience into international context for those themes for which we have comparative data available from the larger international project.

\section{SOCIO-DEMOGRAPHICS AND TRAVEL BEHAVIOR OF RESPONDENTS}

Table 2 presents basic socio-demographic characteristics for the full sample of 891 students, as well as comparing the characteristics of female and male respondents. The sample is roughly representative of the larger SJSU student body in terms of gender, race/ethnicity, and age characteristics, though an exact comparison cannot be made because the survey and SJSU collect socio-demographic data using different categories. Just over half $(51 \%)$ of the respondents were female. In terms of race/ethnicity, $45 \%$ of the respondents identified as Asian/Asian-American (compared to 42\% for SJSU), $20 \%$ as Hispanic or Latino/a ( $28 \%$ for SJSU), and $28 \%$ as white ( $17 \%$ for SJSU). ${ }^{84}$ Smaller percentages of respondents identified as Black/African-American (3\%) or mixed race (7\%). Turning to age, $85 \%$ of respondents were between 18 and 29 years old, a figure also comparable to the overall student body. The mean age of SJSU students in 2018 was 22 years for undergraduate and 29 years for graduate students. 
Table 2. Socio-Demographic Characteristics of the Respondents

\begin{tabular}{lccc}
\hline Characteristic & All respondents (\%) & Women (\%) & Men (\%) \\
\hline Gender & 51 & - & - \\
Female & 47 & - & - \\
Male & 3 & - & - \\
Other & 9 & 10 & 7 \\
LGBTQI & 26 & 29 & 22 \\
Of Hispanic/Latino origin/descent & & & \\
Race & 59 & 57 & 62 \\
Asian or Asian-American & 28 & 30 & 27 \\
White & 6 & 6 & 6 \\
Other, including multiple & 3 & 4 & 2 \\
Black or African-American & 2 & 1 & 3 \\
Native Hawaiian or Pacific Islander & 1 & 2 & 1 \\
American Indian or Alaska Native & & & 89 \\
Age (years) & 88 & 87 & 8 \\
$18-29$ & 9 & 9 & 2 \\
$30-39$ & 3 & 4 & \\
$40+$ & & & \\
\hline
\end{tabular}

Note: $\mathrm{N}$-values for "all respondents" are as follows: $\mathrm{N}=864$ for gender, $\mathrm{N}=858$ for the LGBTQI question, $\mathrm{N}=852$ for the ethnicity question, $\mathrm{N}=673$ for the race question, and $\mathrm{N}=859$ for the age question.

a People who answered Hispanic/Latino and no other race were counted as "missing" when we calculated the percentage by race.

The survey asked respondents about their typical travel mode choices (Table 3). Sixty-one percent reported riding transit of some kind, with $53 \%$ riding the bus and $46 \%$ riding light rail. In terms of frequency, $30 \%$ of the respondents indicated riding buses frequently (three or more days per week), but only $12 \%$ said that they use rail frequently. There were only small differences between men and women; the difference by gender is at most seven percentage points, and usually much less. 
Table 3. Travel Behavior of the Respondents

\begin{tabular}{|c|c|c|c|}
\hline Frequency of travel, by mode & $\begin{array}{c}\text { All respondents } \\
(\%)\end{array}$ & $\begin{array}{c}\text { Women } \\
(\%)\end{array}$ & $\begin{array}{l}\text { Men } \\
(\%)\end{array}$ \\
\hline \multicolumn{4}{|l|}{ Days per week riding a public bus } \\
\hline 0 days & 47 & 48 & 52 \\
\hline Less than one day per week & 12 & 13 & 14 \\
\hline $1-2$ days & 11 & 10 & 11 \\
\hline $3-4$ days & 16 & 16 & 18 \\
\hline $5+$ days & 14 & 13 & 14 \\
\hline \multicolumn{4}{|l|}{ Days per week riding a train } \\
\hline 0 days & 54 & 54 & 54 \\
\hline Less than one day per week & 18 & 17 & 19 \\
\hline $1-2$ days & 10 & 11 & 8 \\
\hline $3-4$ days & 10 & 12 & 9 \\
\hline $5+$ days & 8 & 6 & 10 \\
\hline \multicolumn{4}{|c|}{ Travel by private vehicle at least once a week } \\
\hline As a driver & 59 & 62 & 61 \\
\hline As a passenger & 65 & 69 & 63 \\
\hline \multicolumn{4}{|l|}{ Days per week biking } \\
\hline 0 days & 36 & 37 & 37 \\
\hline Less than one day per week & 9 & 9 & 9 \\
\hline $1-2$ days & 3 & 2 & 5 \\
\hline $3-4$ days & 2 & 0 & 4 \\
\hline $5+$ days & 2 & 1 & 3 \\
\hline Do not own bike & 45 & 50 & 42 \\
\hline \multicolumn{4}{|c|}{ Frequency of using ride-hailing services (Lyft, Uber, etc.) } \\
\hline Never & 26 & 23 & 30 \\
\hline A few times per year & 34 & 35 & 34 \\
\hline A few times per month & 25 & 26 & 26 \\
\hline At least once a week & 12 & 14 & 9 \\
\hline \multicolumn{4}{|l|}{ Frequency of using taxis } \\
\hline Never & 78 & 79 & 79 \\
\hline A few times per year & 12 & 11 & 13 \\
\hline A few times per month & 6 & 5 & 6 \\
\hline At least once a week & 3 & 4 & 2 \\
\hline
\end{tabular}

Note: For all respondents $N=891$, for female respondents $N=437$, and for male respondents $N=403$.

a Values do not add up to $100 \%$ because some respondents indicated that they are both a driver and a passenger. Twenty-two percent of students reported that they had neither driven nor ridden as a passenger.

The majority of respondents lived in San José and nearby communities, although some students traveled from 40 or 50 miles away (Figure 2). 


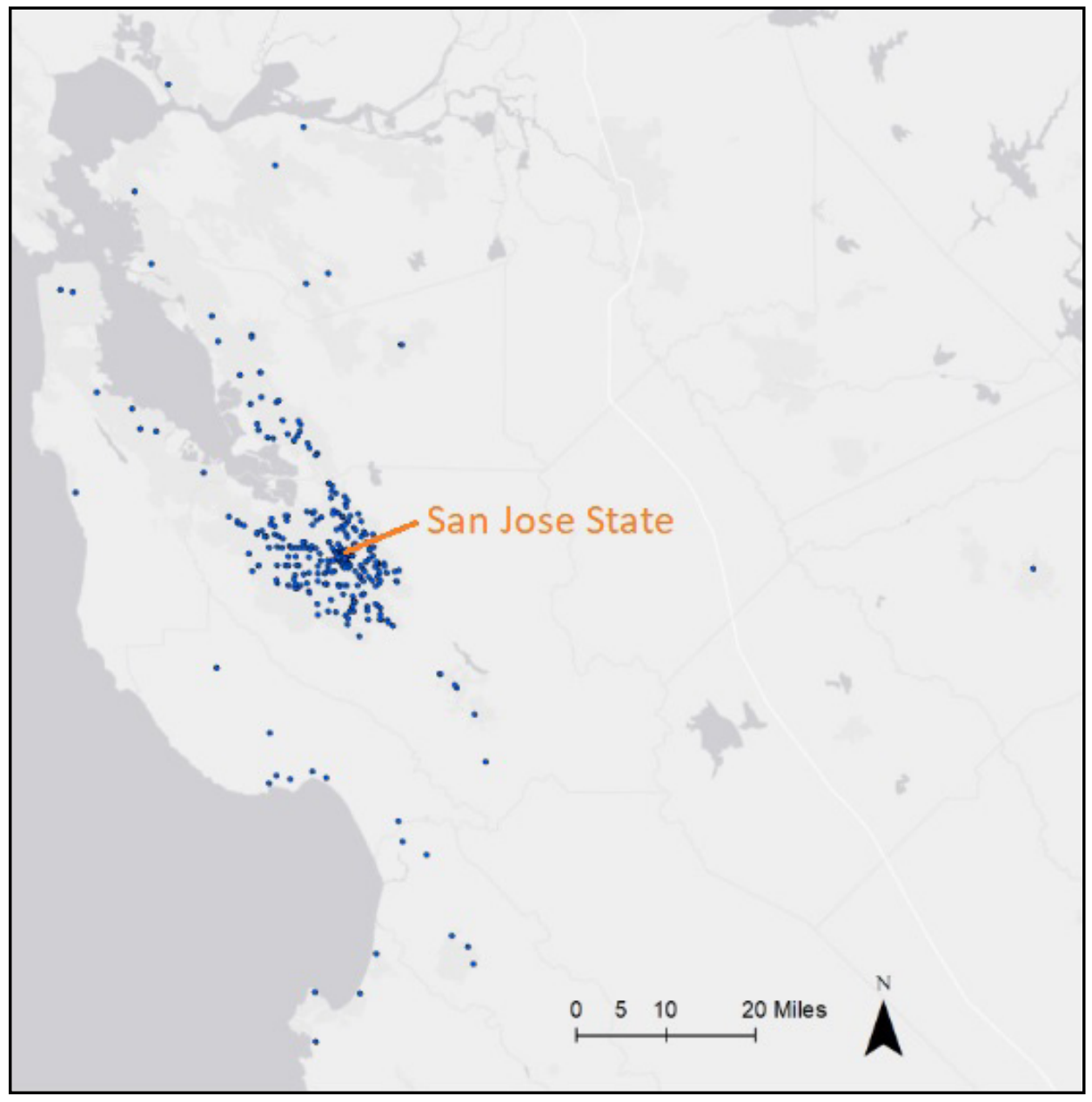

Figure 2. Home Location of the Survey Respondents

Source: Map by Benson Kwong and Johnny Luna.

Note: Locations shown for the 525 respondents who provided the names of two streets intersecting near their home.

\section{DO STUDENTS FEEL UNSAFE RIDING TRANSIT, AND WHY?}

The survey asked two sets of questions that, collectively, explored if and why students may feel unsafe riding transit. Respondents were asked both if they felt safe using the transit system, as well as what factors they considered "a significant problem" on transit systems.

\section{Do Students Feel Unsafe?}

The survey asked respondents directly whether or not they felt safe during different stages of the transit journey: waiting for the bus or train, walking to/from transit stop/stations, and on the transit vehicle. The survey asked about perceived safety when travelling by transit during the day as well as at night.

One unsurprising result from the descriptive results is that considerably more riders felt often or always safe during the daytime than at night, for both bus and rail travel (Table 4). 
Table 4. Percentage of Transit Riders Feeling Unsafe, by Transit System Setting and Mode

\begin{tabular}{|c|c|c|c|c|c|c|c|c|}
\hline \multirow[b]{2}{*}{ Feeling safe } & \multicolumn{2}{|c|}{ Bus: daytime } & \multicolumn{2}{|c|}{ Bus: after dark } & \multicolumn{2}{|c|}{ Train: daytime } & \multicolumn{2}{|c|}{ Train: after dark } \\
\hline & $\begin{array}{c}\text { Waiting } \\
(\%)\end{array}$ & $\begin{array}{c}\text { Onboard } \\
(\%)\end{array}$ & $\begin{array}{l}\text { Walking to/ } \\
\text { from stop } \\
\text { and waiting } \\
(\%)\end{array}$ & $\begin{array}{c}\text { Onboard } \\
(\%)\end{array}$ & $\begin{array}{c}\text { Waiting } \\
(\%)\end{array}$ & $\begin{array}{c}\text { Onboard } \\
(\%)\end{array}$ & $\begin{array}{c}\text { Walking to/ } \\
\text { from stop } \\
\text { and waiting } \\
(\%)\end{array}$ & $\begin{array}{c}\text { Onboard } \\
(\%)\end{array}$ \\
\hline Always & 22 & 24 & 3 & 3 & 28 & 30 & 6 & 7 \\
\hline Often & 43 & 50 & 14 & 15 & 45 & 46 & 14 & 18 \\
\hline Sometimes & 28 & 22 & 23 & 30 & 22 & 19 & 30 & 32 \\
\hline Rarely & 6 & 2 & 24 & 19 & 3 & 3 & 20 & 18 \\
\hline Never & 1 & 1 & 13 & 11 & 2 & 2 & 10 & 9 \\
\hline
\end{tabular}

There are statistically significant differences between how female and male riders perceived safety during their transit travel. Figures $3 \mathrm{a}$ and $3 \mathrm{~b}$ compare feelings of safety for women versus men, by mode and time of day. Significantly more male than female transit riders felt "always" or "often" safe for every step of the transit journal, time of day, and mode.

The regression models confirmed that being female is a statistically significant predictor of feeling less safe for both bus and rail riders (Appendix B, Table 28 and Table 29). Four different regression models were estimated for each transit mode. The regression models show that there are differences in perception by gender; women feel less safe than men on the bus at all times and on the train at night. Having been harassed is also a significant predictor of feeling safe for both bus and train, night and day. 

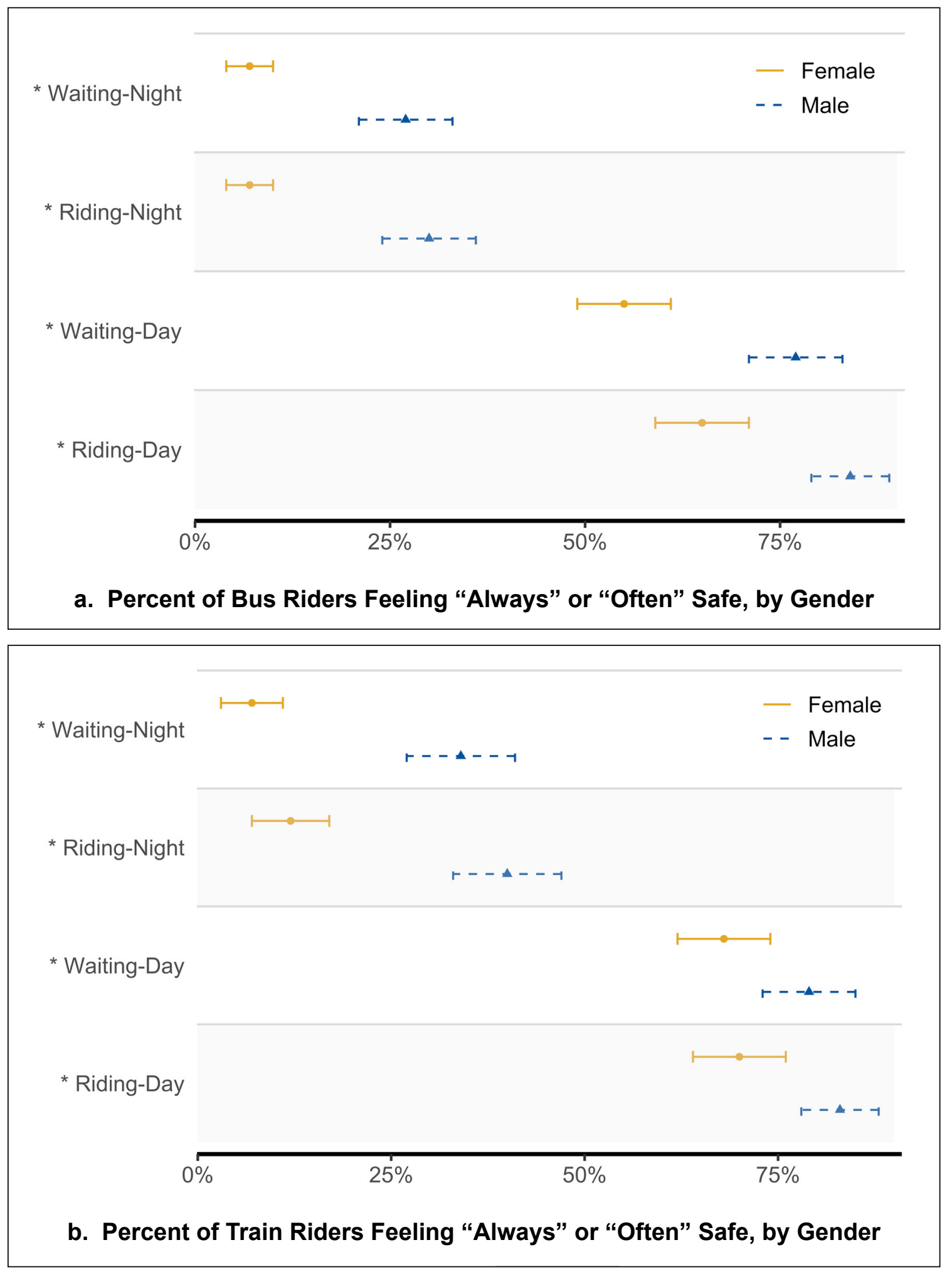

Figure 3. Percent of Bus and Train Riders Feeling "Always" or "Often" Safe, by Gender

Notes:

- Asterisks indicate a statistically significant difference at $p<0.05$, and the bars represent the $95 \%$ confidence intervals.

- For Figure 3a, there were 229 female and 212 male bus riders. For Figure 3b, there were 200 female and 186 male train riders. To review the results of this analysis in table form, including p-values, see Table 12 in Appendix B. 
As compared to students in the other cities in the global study, SJSU students were less likely to feel "always" or "often" safe after dark on the bus or on the train (Figure 4 and Figure 5). Only Mexico City and Rio Claro have smaller percentages of female students who feel safe after dark on the bus, and for train travel only Mexico City has a smaller percent of male students feeling safe. This difference may be explained by the fact that the streets and transit vehicles in San José and its surrounding communities are mostly empty during the late evening hours, in contrast to many European and Asian cities that have considerable activity on the streets and transit systems after dark.

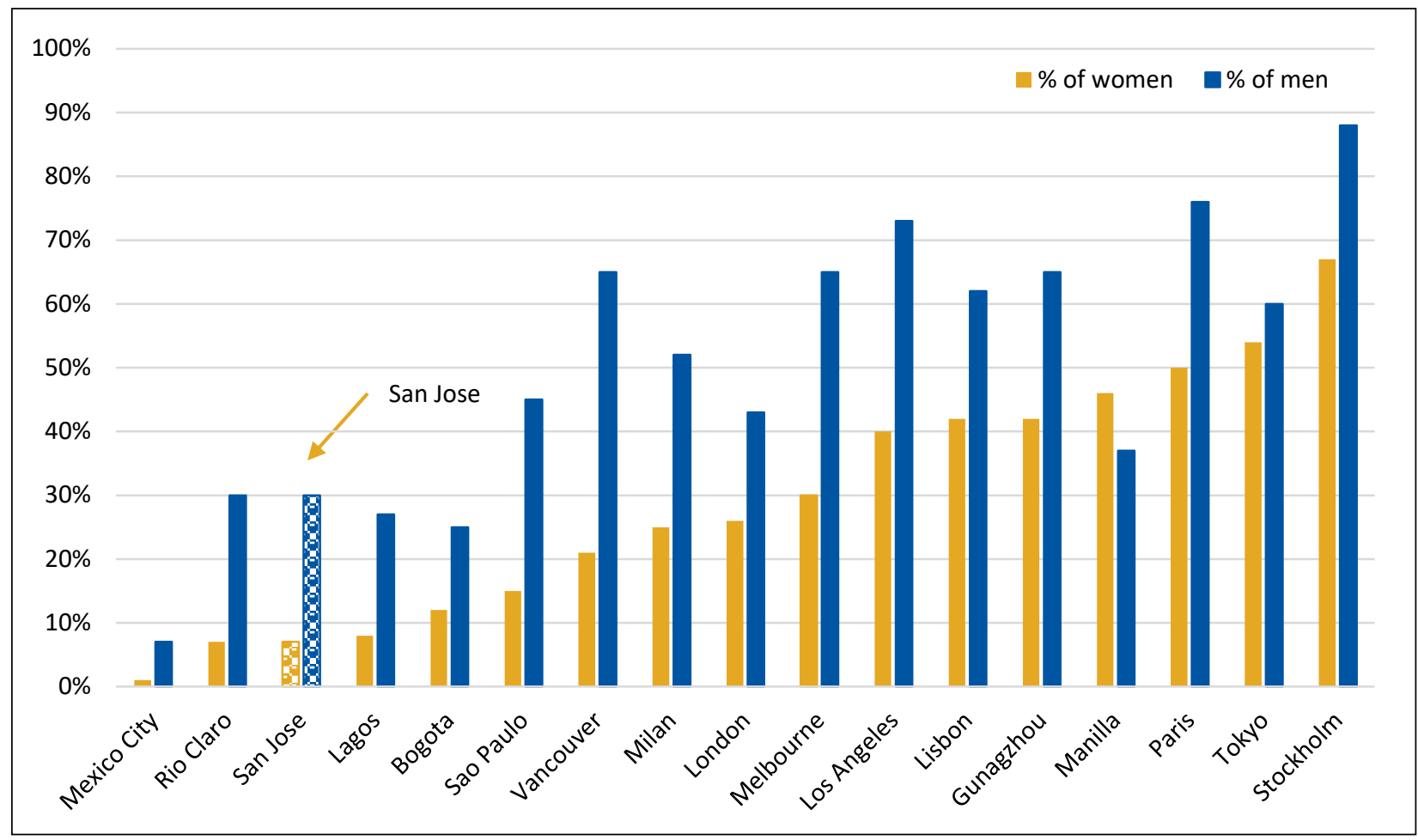

Figure 4. Percent of SJSU Students Feeling "Always" or "Often" Safe after Dark on the Bus, as Compared to Other Countries 


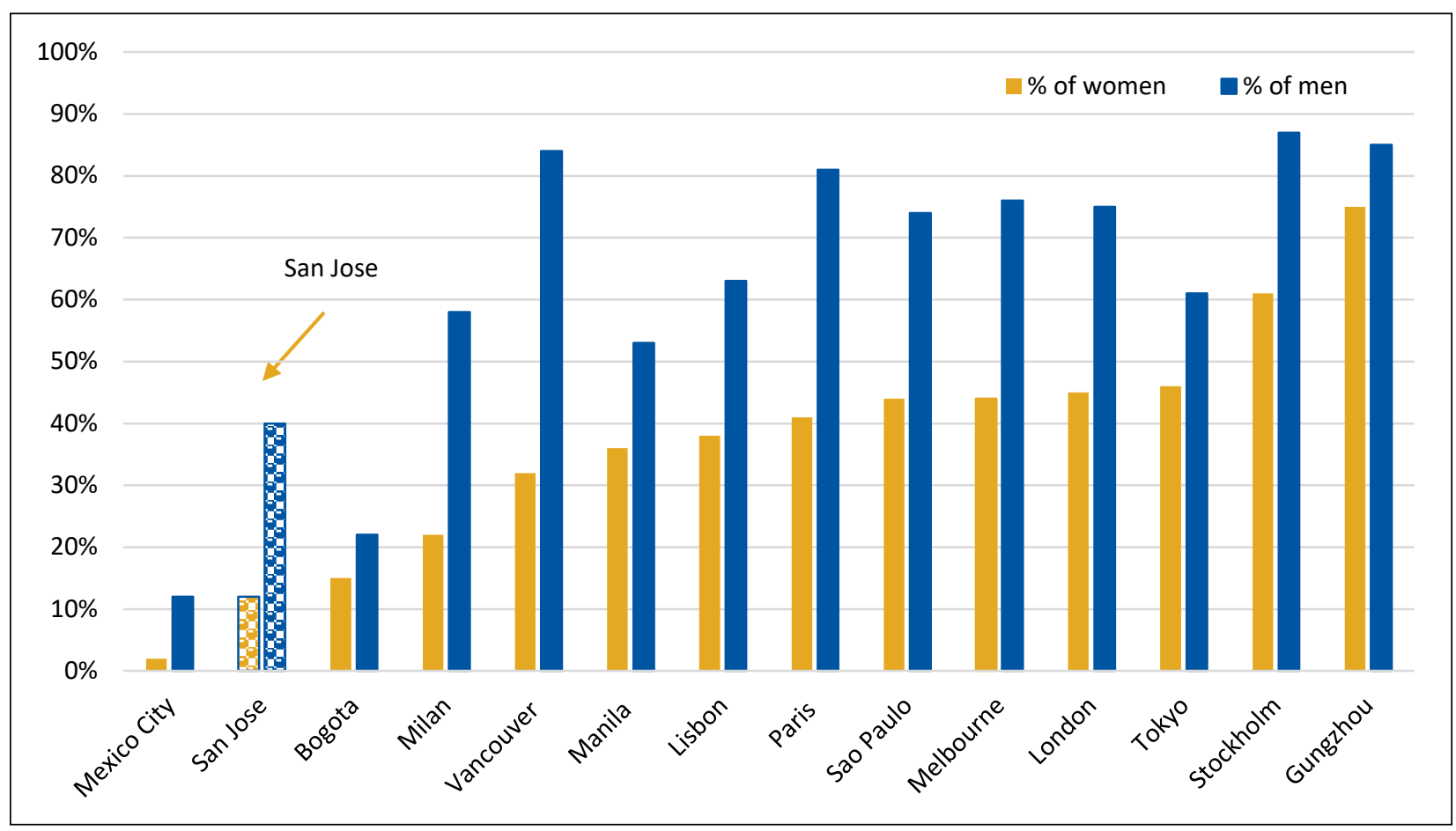

Figure 5. Percent of SJSU Students Feeling "Always" or "Often" Safe after Dark on the Train, as Compared to Other Countries

\section{What Factors Pose a "Significant Problem"?}

To explore the reasons why students may feel unsafe, another set of questions asked riders what specific factors they considered as "a significant problem" when riding transit. The questionnaire asked about both environmental factors and criminal behaviors. The environmental factors tested were poorly designed, poorly illuminated, and poorly guarded facilities, as well as "vandalism/litter." The criminal behaviors listed included "sexual harassment," plus nonsexual behaviors and crimes such as panhandling, drunkenness, pickpocketing, violent crime, and robbery.

Table 5 compares the percentages of riders considering each factor a significant problem, by transit system setting. In all settings, from one-third to one-half of respondents worried about the behavioral factors of obscene language, drunk people, and verbal/physical threats. Of concern to almost as many people was sexual harassment, with more than a quarter of respondents concerned in every transit setting. (The specific values range from $28 \%$ to $35 \%$.) The environmental problems also concerned many riders, with the percentages concerned ranging from $9 \%$ to $55 \%$, in most cases being near or above $20 \%$. Concerns onboard the vehicle were roughly similar for bus and train riders; the differences are no more than ten percentage points and usually less than five percentage points. 
Table 5. Percentage of Bus and Train Riders Considering Different Factors "A Significant Problem," by Transit System Setting

\begin{tabular}{|c|c|c|c|c|}
\hline \multirow[b]{2}{*}{ Problems } & \multicolumn{2}{|c|}{ Onboard } & \multirow{2}{*}{$\begin{array}{l}\text { Bus: traveling to/ } \\
\text { from or waiting } \\
\text { at stop }(\%)\end{array}$} & \multirow{2}{*}{$\begin{array}{l}\text { Train: at the } \\
\text { platform (\%) }\end{array}$} \\
\hline & Bus (\%) & Train (\%) & & \\
\hline \multicolumn{5}{|l|}{ Behavioral } \\
\hline Obscene language & 46 & 39 & 46 & 35 \\
\hline Drunk people & 45 & 47 & 57 & 48 \\
\hline Verbal/physical threats & 38 & 31 & 45 & 35 \\
\hline Sexual harassment & 29 & 28 & 35 & 28 \\
\hline Pickpocketing & 26 & 19 & 31 & 23 \\
\hline Robbery & 24 & 21 & 39 & 27 \\
\hline Drug use/sales & 19 & 18 & 36 & 27 \\
\hline Violent crime (aggravated assault, murder) & 19 & 17 & 32 & 24 \\
\hline Panhandling & 17 & 19 & 35 & 29 \\
\hline Jewelry snatching & 17 & 15 & 25 & 20 \\
\hline \multicolumn{5}{|l|}{ Environmental } \\
\hline Vandalism, litter & 38 & 33 & 55 & 39 \\
\hline Poorly designed & 18 & 13 & 45 & 18 \\
\hline Poorly guarded/empty most of the day & 18 & 28 & 46 & 40 \\
\hline Poorly illuminated & 16 & 9 & 51 & 22 \\
\hline Other & 1 & 1 & 1 & $<1$ \\
\hline
\end{tabular}

Note: $\mathrm{N}$-values are 472 for bus riders and 410 for train riders.

Women and men had roughly similar perceptions of the problems, with the exception of harassment, which concerned far more women (Figure 6, Figure 7, and Table 13). Sizable numbers of both women and men considered harassment a significant problem in transit settings, but the issue concerned twice as many women as men: $38 \% \mathrm{vs.} 18 \%$ onboard the bus, and $38 \%$ vs. $17 \%$ onboard trains. For all the other problems, more women than men were concerned, but the differences are usually no more than five percentage points.

We found statistically significant differences between respondents who had or had not been harassed when using transit (Figure 8, Figure 9, Figure 10, Figure 11, Table 14, and Table 15). Specifically, people who had been previously harassed were statistically significantly more likely to consider each of the physical and environmental issues listed in Table 5 as a significant problem. This finding holds across both modes and different stages of a transit trip. The magnitude of the differences was greater at bus or train stops than on the transit vehicle. 


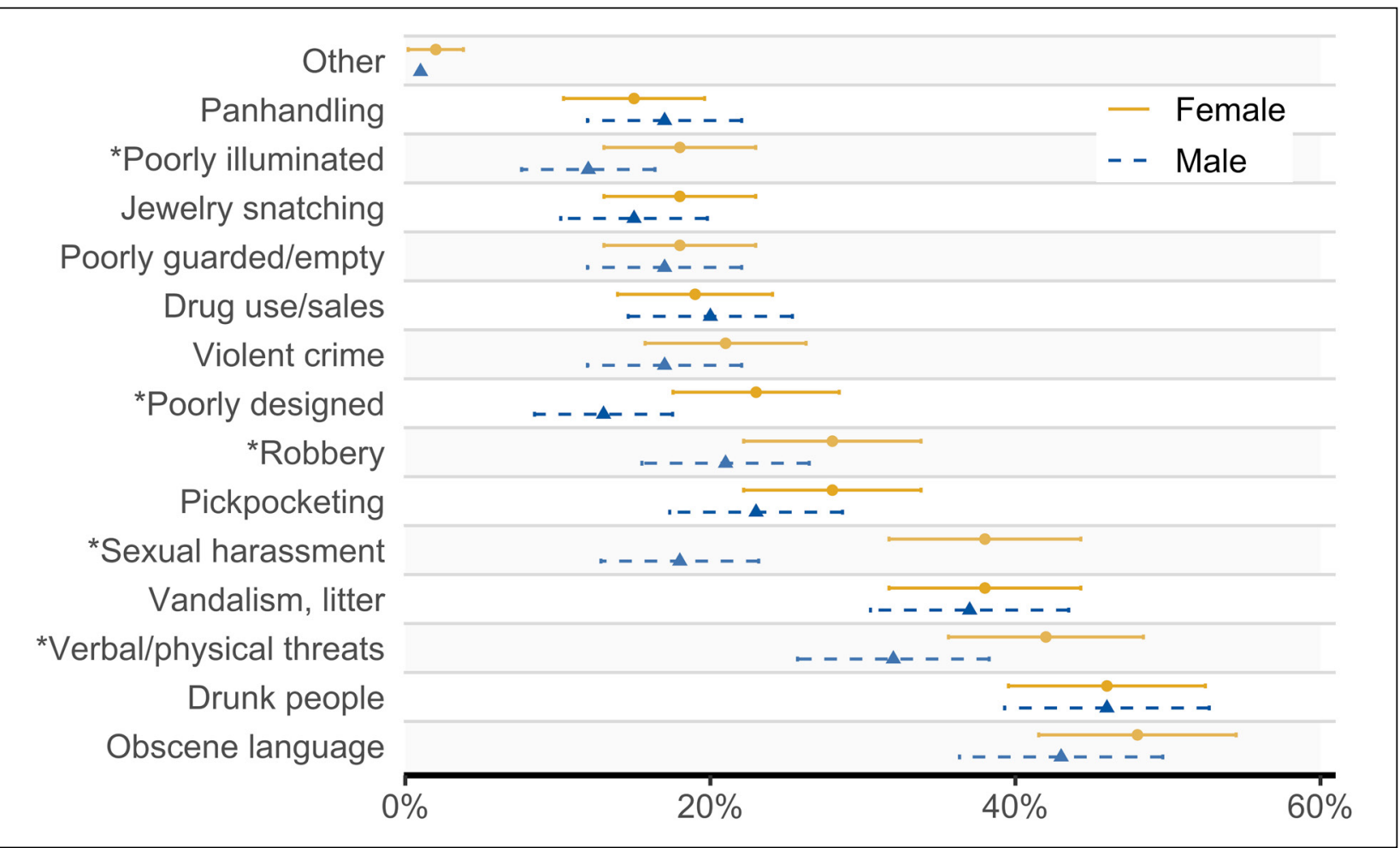

Figure 6. Onboard Safety Concerns Identified by Female vs. Male Bus Riders

Notes: Asterisks indicate a statistically significant difference at $p<0.05$. There were 472 bus riders (229 female and 212 male). To review the results of this analysis in table form, see Table 13 in Appendix B.

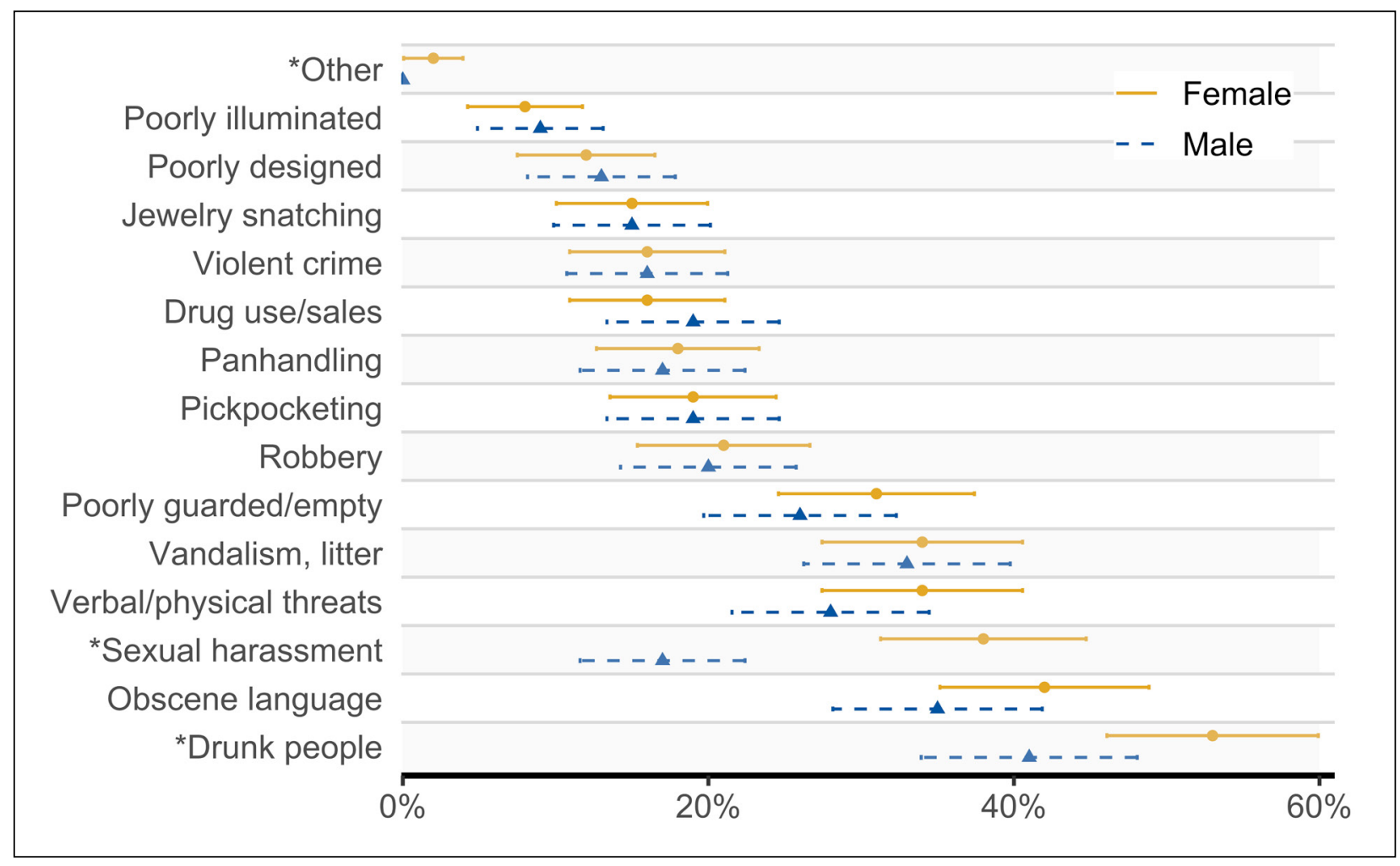

Figure 7. Onboard Safety Concerns Identified by Female vs. Male Train Riders

Notes: Asterisks indicate a statistically significant difference at $p<0.05$. There were 410 rail riders $(200$ female and 186 male). To review the results of this analysis in table form, see Table 13 in Appendix B. 


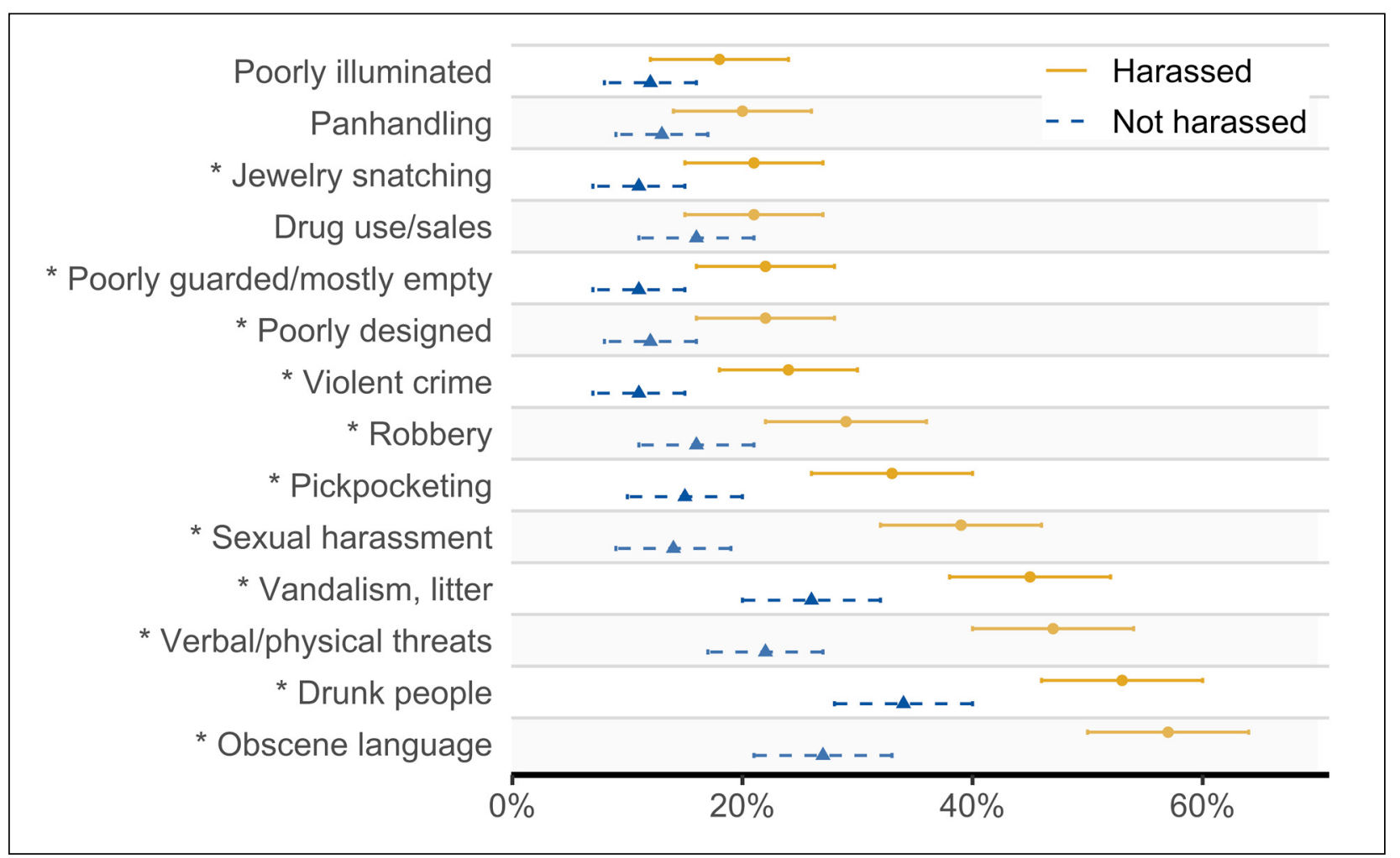

Figure 8. Perceived Safety Concerns on the Bus by Bus Riders Who Had and Had Not Been Harassed

Notes: Asterisks indicate a statistically significant difference at $p<0.05$. There were 289 bus riders who reported being harassed and 183 bus riders who were not. To review the results of this analysis in table form, see Table 14 in Appendix B. 


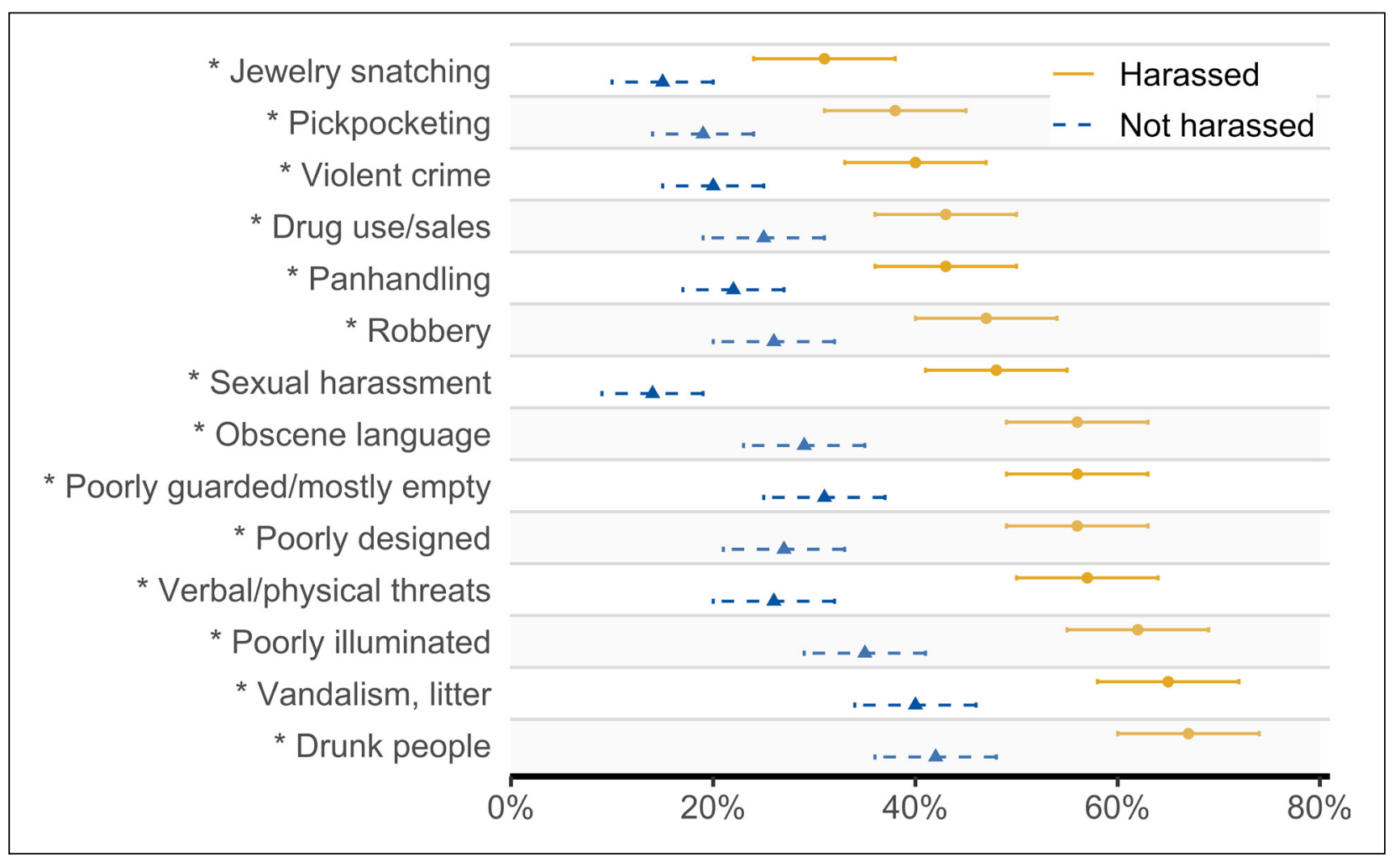

Figure 9. Perceived Safety Concerns at the Bus Stop by Bus Riders Who Had and Had Not Been Harassed

Notes: Asterisks indicate a statistically significant difference at $p<0.05$. There were 289 bus riders who reported being harassed and 183 bus riders who were not. To review the results of this analysis in table form, see Table 14 in Appendix B. 


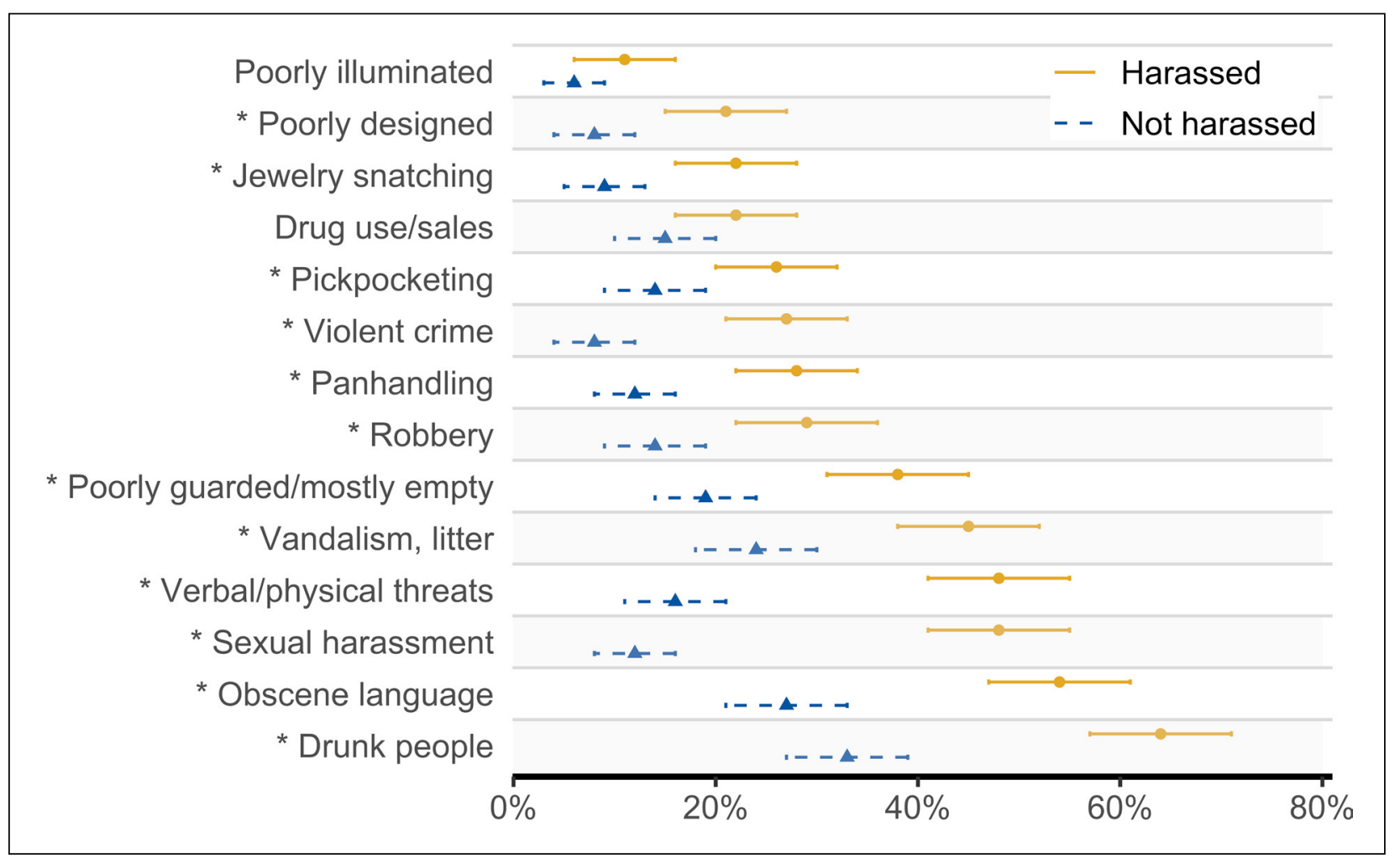

Figure 10. Perceived Safety Concerns on the Train by Riders Who Had vs. Had Not Been Harassed

Notes: Asterisks indicate a statistically significant difference at $p<0.05$. There were 184 rail riders who reported being harassed and 226 who did not. To review the results of this analysis in table form, see Table 15 in Appendix B. 


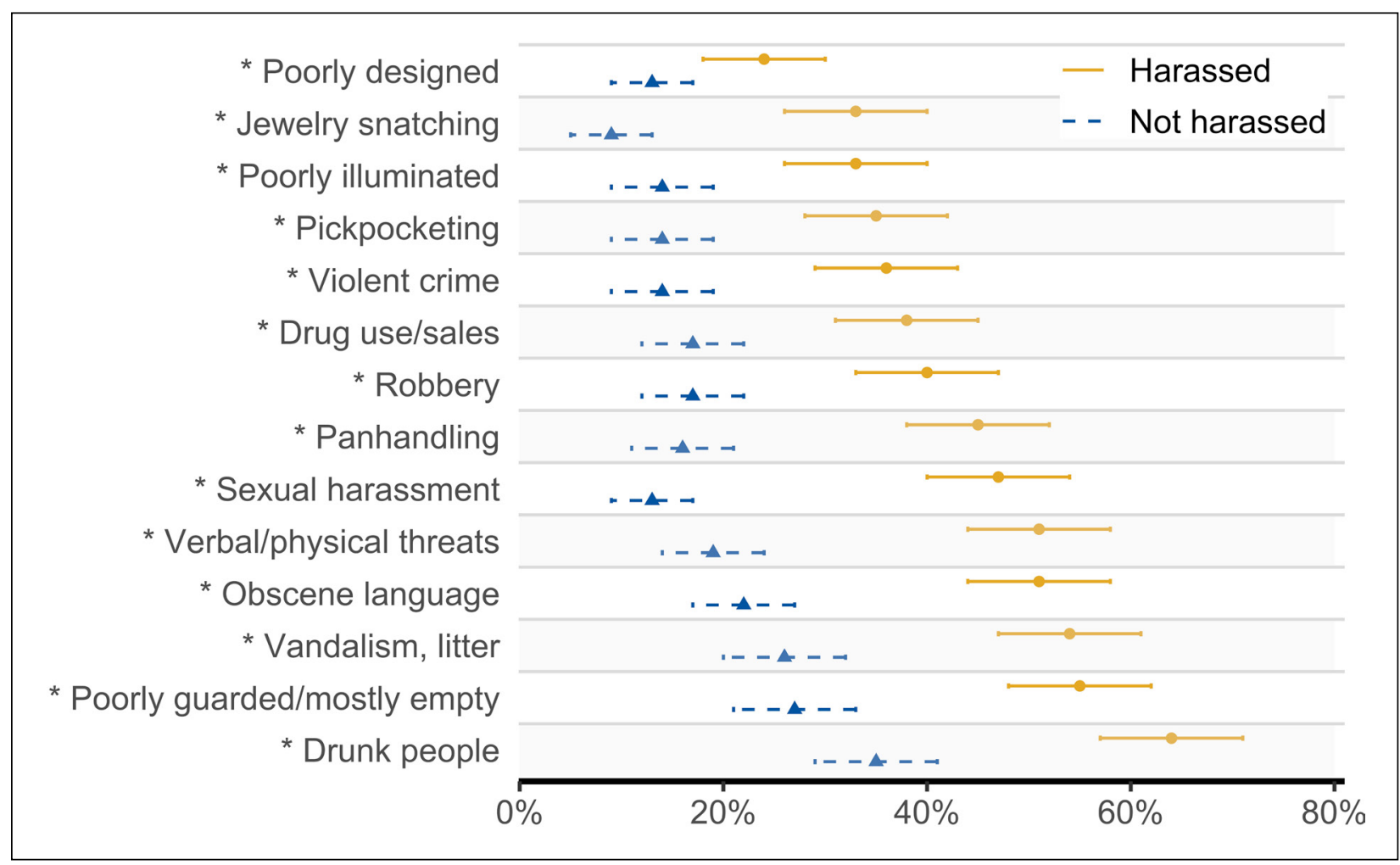

Figure 11. Perceived Safety Concerns at the Platform by Train Riders Who Had or Had Not Been Harassed

Notes: Asterisks indicate a statistically significant difference at $p<0.05$. There were 184 rail riders who reported being harassed and 226 who did not. To review the results of this analysis in table form, see Table 15 in Appendix B.

\section{WHAT FACTORS PREVENT STUDENTS FROM USING TRANSIT MORE?}

The survey asked students who rode the bus and the train whether certain factors prevented them from using that mode more often. The factors listed included environmental conditions (e.g., dirty environment), behaviors (e.g., fear of sexual harassment), and service characteristics (e.g., slow journey times). As Table 6 shows, almost half of bus riders and $40 \%$ of train riders were concerned about the general category "antisocial behavior of others." Fear of sexual harassment, in particular, was reported by $27 \%$ of bus riders and $23 \%$ of train riders.

Looking at gender, Figure 12 and Figure 13 show that women and men responded similarly for service-related factors but differently with respect to concerns about the behavior of others. There was little difference between women and men on factors like trip length, ontime performance, crowding, and fare cost. For example, slow journey times discouraged $42 \%$ of women and $43 \%$ of men from using the bus more often. However, factors related to antisocial behavior saw major differences by gender, often 20 percentage points or more. This gender difference was most stark with respect to fear of sexual harassment. This concern prevented $45 \%$ of female bus riders but only $7 \%$ of male bus riders from using buses more often. The pattern was very similar for rail riders: $39 \%$ of women but only $6 \%$ of men said that concern about sexual harassment prevented them from riding the train more often. 
Table 6. Factors Preventing Bus and Train Riders from Using Transit More Often

Factor preventing transit use

Bus riders (\%) Train riders $(\%)$

Fear of antisocial behavior of others (drinking, cursing, smelling badly, etc.)

Slow journey times

Fear of victimization waiting on at the stop/platform

Fear of victimization walking to the stop/station

Fear of victimization while on the bus/train

Dirty environment on the bus/train (trash, graffiti)

Fear of sexual harassment on the bus/train

Unreliable service

Overcrowded buses/trains

Dirty environment during the walk to the bus stop/train station

Many transfers

Lack of information about bus/train schedules

Cost of tickets

Fear of terrorist attack

Other

Fear of traffic crashes/accidents

Don't understand how to buy train fare
49

42

40

$37-29$

$37 \quad 26$

$31 \quad 28$

$31 \quad 27$

$27 \quad 23$

$27 \quad 16$

$26 \quad 21$

$25 \quad 22$

$21 \quad 11$

$19 \quad 16$

$12 \quad 18$

99

96

$6 \quad 10$

15

Note: $\mathrm{N}$-values are as follows: $\mathrm{N}=472$ for bus riders and $\mathrm{N}=410$ for train riders.

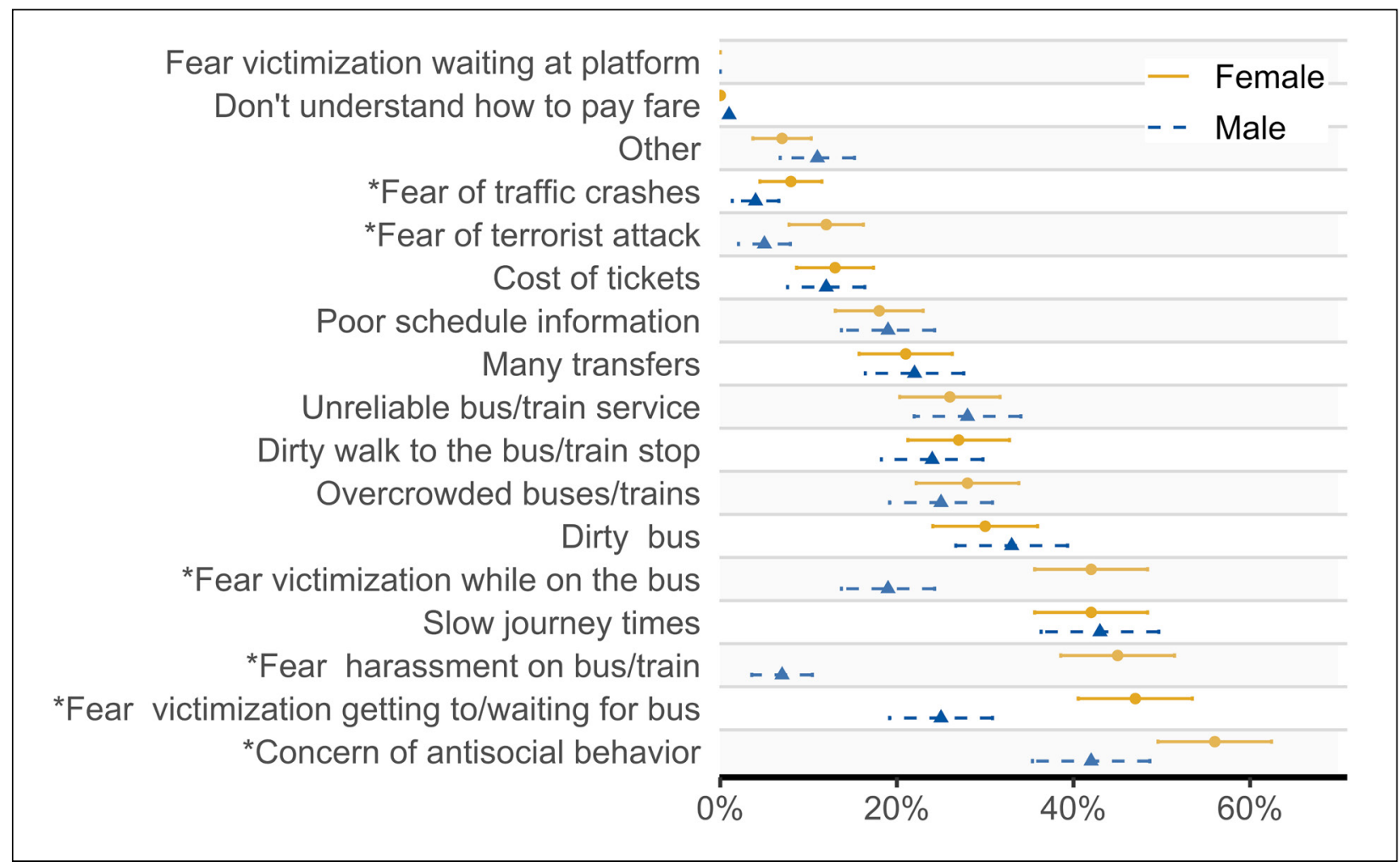

Figure 12. Comparison of Factors Preventing Bus Riders from Using the Bus More Often, by Gender

Notes: Asterisks indicate a statistically significant difference at $p<0.05$, and the bars represent the $95 \%$ confidence intervals. $\mathrm{N}=472$ for all bus riders, 229 for female bus riders, and 212 for male bus riders To review the results of this analysis in table form, see Table 16 in Appendix B. 


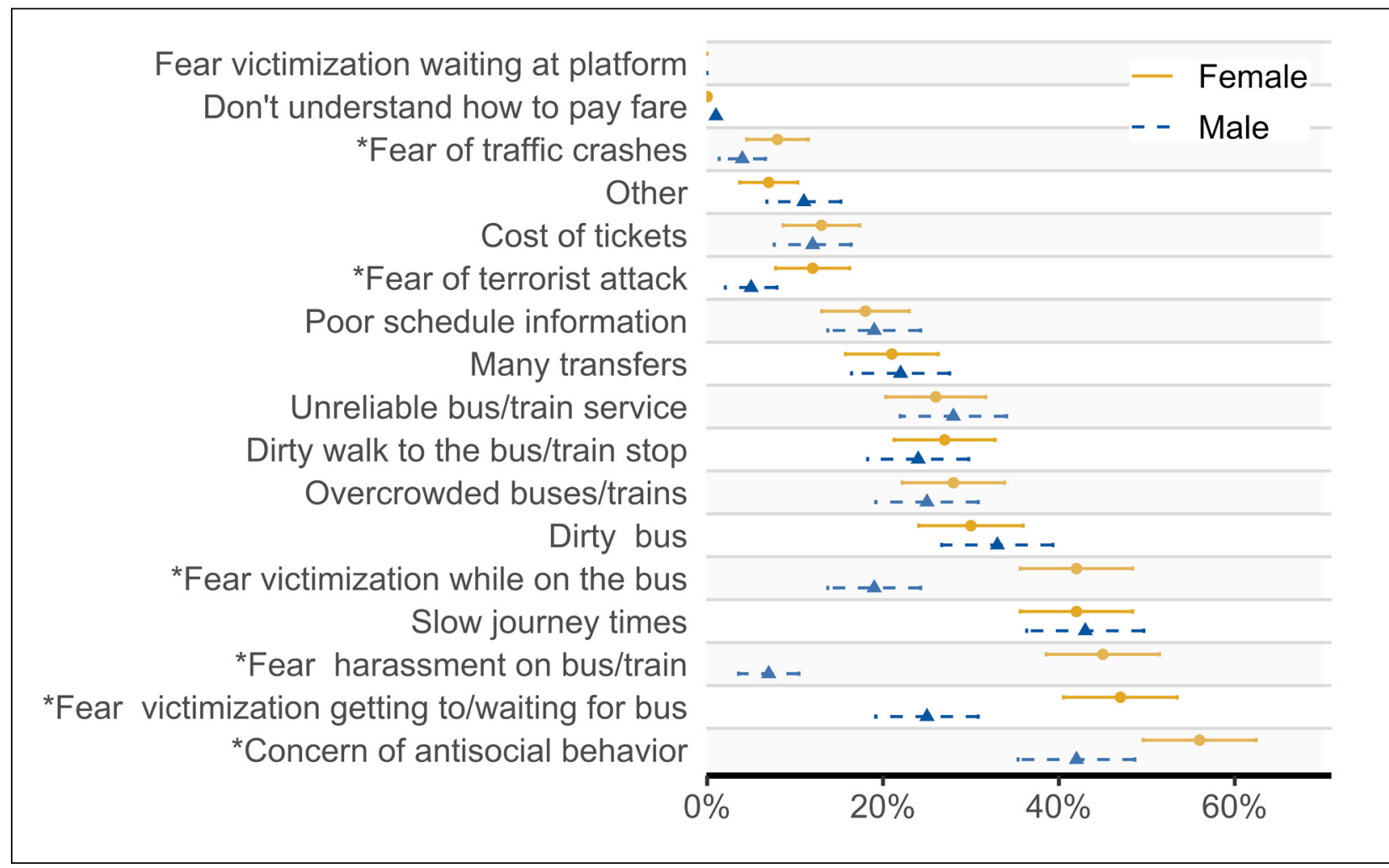

\section{Figure 13. Comparison of Factors Preventing Train Riders from Using the Train More Often, by Gender}

Notes: Asterisks indicate a statistically significant difference at $p<0.05$, and the bars represent the $95 \%$ confidence intervals. For train riders, $\mathrm{N}=410$ for all riders, 200 for female riders, and 186 for male riders. To review the results of this analysis in table form, see Table 16 in Appendix B.

\section{HOW MANY STUDENTS EXPERIENCED HARASSMENT?}

To determine how many students had been victimized, the survey asked about experience with sexual harassment in two different ways. One set of questions asked students if, in the last three years, they had experienced any of 16 different harassment behaviors in any of three settings: on the transit vehicle ${ }_{\perp}$ heading to/from the bus stop or station, and waiting at the bus stop or station platform. In addition, later in the survey students were asked if they had "been a victim of sexual assault, harassment, or other crime" while using transit.

The two different question approaches produced very different results. Only $23 \%$ of students reported experiencing "sexual assault, harassment, or other crime" when asked that general question (Table 9). However, almost three times as many students reported being harassed $(63 \%)$ from their answers to the series of questions asking whether they had been victims of any of a list of behaviors that fall under the general categories of sexual harassment or assault (Table 7).

Sexual harassment is, sadly, a routine experience for SJSU student transit riders, whether they ride the bus or train. Table 7 shows the experiences reported by bus and rail riders, showing for each where in the transit journey students experienced harassment, as well as specific types of harassment reported. Almost two-thirds of riders $(63 \%)$ reported 
experiencing at least one type of harassment behavior during some part of the transit journey, whether traveling to/from stops, waiting, or onboard the vehicle. By far the most common form of harassment was verbal, with $41 \%$ experiencing "obscene/harassing language." Forms of physical harassment were among the least common types, though even here a startling $11 \%$ had experienced groping or inappropriate touching.

Comparing the results for bus and rail, differences by mode are almost all trivial, with most differing by just a few percentage points. The only double-digit difference is that 14 percentage point more bus riders $(47 \%)$ than train riders $(33 \%)$ had experienced at least one kind of harassment while waiting at the stop.

Figures $14 \mathrm{a}$ and $14 \mathrm{~b}$ shows findings for women versus men, with the behaviors grouped into three categories: verbal harassment, nonverbal, and physical harassment. In all cases, more women than men report being harassed, and the differences are statistically significant in all cases except for physical harassment on the train. The difference by gender is the starkest for verbal harassment. 
Table 7. Percent of Riders Experiencing Different Types of Harassment, by Transit System Setting and Mode

\begin{tabular}{|c|c|c|c|c|c|c|c|}
\hline \multirow[b]{2}{*}{ Type of harassment } & \multicolumn{2}{|c|}{ Onboard } & \multicolumn{2}{|c|}{ Waiting } & \multicolumn{2}{|c|}{ Traveling to/from } & \multirow{2}{*}{$\begin{array}{l}\text { At least one location, } \\
\text { either mode }(\%)\end{array}$} \\
\hline & Bus (\%) & Train (\%) & Bus (\%) & Train (\%) & Bus (\%) & Train (\%) & \\
\hline At least one kind of harassment & 42 & 35 & 47 & 33 & 40 & 31 & 63 \\
\hline \multicolumn{8}{|l|}{ Verbal harassment } \\
\hline Using obscene/abusive language & 27 & 21 & 28 & 20 & 19 & 17 & 41 \\
\hline Calling you babe, honey, sweetheart & 12 & 12 & 16 & 13 & 15 & 13 & 26 \\
\hline Sexual comments & 12 & 9 & 17 & 10 & 15 & 10 & 26 \\
\hline Whistling & 9 & 10 & 17 & 12 & 17 & 13 & 24 \\
\hline Unwanted sexual teasing, remarks & 10 & 8 & 13 & 8 & 12 & 11 & 21 \\
\hline Making kissing sounds & 6 & 5 & 8 & 6 & 9 & 7 & 14 \\
\hline Asking personal questions about sexual life & 7 & 7 & 7 & 7 & 6 & 7 & 14 \\
\hline Asked to have sex by a stranger & 3 & 3 & 4 & 4 & 4 & 4 & 8 \\
\hline \multicolumn{8}{|l|}{ Non-verbal harassment } \\
\hline Unwanted sexual looks or gestures & 14 & 12 & 18 & 12 & 15 & 12 & 26 \\
\hline Stalking (a stranger following you) & 8 & 6 & 10 & 9 & 14 & 12 & 22 \\
\hline Indecent exposure & 7 & 7 & 10 & 7 & 8 & 6 & 18 \\
\hline Masturbating in public & 4 & 5 & 3 & 5 & 3 & 5 & 11 \\
\hline Showing pornographic images & 4 & 4 & 4 & 4 & 1 & 3 & 8 \\
\hline \multicolumn{8}{|l|}{ Physical harassment } \\
\hline Groping, touching inappropriately & 7 & 4 & 4 & 4 & 3 & 4 & 11 \\
\hline Pulling or playing with your hair & 4 & 3 & 3 & 3 & 2 & 3 & 7 \\
\hline Unwanted kissing by a stranger & 3 & 2 & 2 & 3 & 2 & 3 & 6 \\
\hline
\end{tabular}

Note: A total of 472 respondents reported riding the bus, 410 reported using rail, and 540 reported riding either bus or rail. 
Finally, we looked at the experience of harassment by respondents who self-identified as LBGTQI (Table 8). Among bus riders, 74\% had experienced some kind of harassment at some point during their transit trips, slightly higher than the $60 \%$ for non-LGBTQI bus riders. As for rail riders, $50 \%$ of LGBTQI riders had experienced some form of harassment at some point during a train journey, as compared to $56 \%$ for non-LGBTQI riders.

Table 8. Percent of LGBTQI Riders Experiencing Different Types of Harassment, by Transit System Setting and Mode

\begin{tabular}{|c|c|c|c|c|c|c|c|c|}
\hline \multirow[b]{2}{*}{ Type of harassment } & \multicolumn{2}{|c|}{ Onboard } & \multicolumn{2}{|c|}{ Waiting } & \multicolumn{2}{|c|}{ Travelling to/from } & \multicolumn{2}{|c|}{ At least one location } \\
\hline & Bus $(\%)$ & Train (\%) & Bus (\%) & Train (\%) & Bus (\%) & Train (\%) & Bus (\%) & Train (\%) \\
\hline Any kind & 55 & 46 & 57 & 39 & 49 & 41 & 74 & 50 \\
\hline Verbal & 40 & 37 & 53 & 33 & 45 & 35 & 66 & 43 \\
\hline Non-verbal & 36 & 33 & 34 & 28 & 32 & 33 & 49 & 43 \\
\hline Physical & 19 & 11 & 11 & 7 & 6 & 9 & 21 & 15 \\
\hline
\end{tabular}

Note: A total of $47 \mathrm{LGBTQ}$ respondents reported riding the bus and 46 reported using rail. 
* Physical

$$
1-\rightarrow-\urcorner
$$

* Non-Verbal

$$
r--\Delta--7
$$

* Verbal

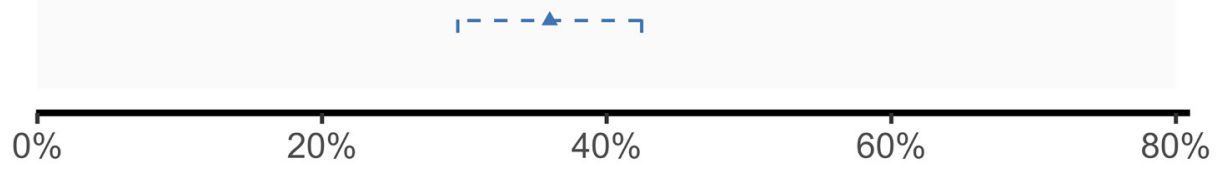

a. Percent of Bus Riders Experiencing Different Types of Victimization, by Gender

Physical

$$
1--\Delta-\neg
$$

${ }^{*}$ Non-Verbal

$$
1---1---\urcorner
$$

*Verbal

\begin{tabular}{llll}
\hline $0 \%$ & $20 \%$ & $40 \%$ & $60 \%$
\end{tabular}

b. Percent of Train Riders Experiencing Different Types of Victimization, by Gender

Figure 14. Factors Preventing Bus and Train Riders from Using Transit More Often, by Gender

Notes:

- Asterisks indicate a statistically significant difference at $p<0.05$, and the bars represent the $95 \%$ confidence intervals.

- For Figure 13a, there were 229 female bus riders and 212 male bus riders. For Figure 13b, there were 200 female train riders and 186 male riders.

- To review the results of this analysis in table form, see Table 18 in Appendix B. 
The rates of victimization for SJSU bus and train riders are generally in line with the results from the surveys conducted at other cities around the world (Figure 15 and Figure 16). Like most other cities, more than half of SJSU's female students experienced harassment on both the bus and train. Also, rates for SJSU women were considerably higher than for men, the same pattern found in almost all the other cities.

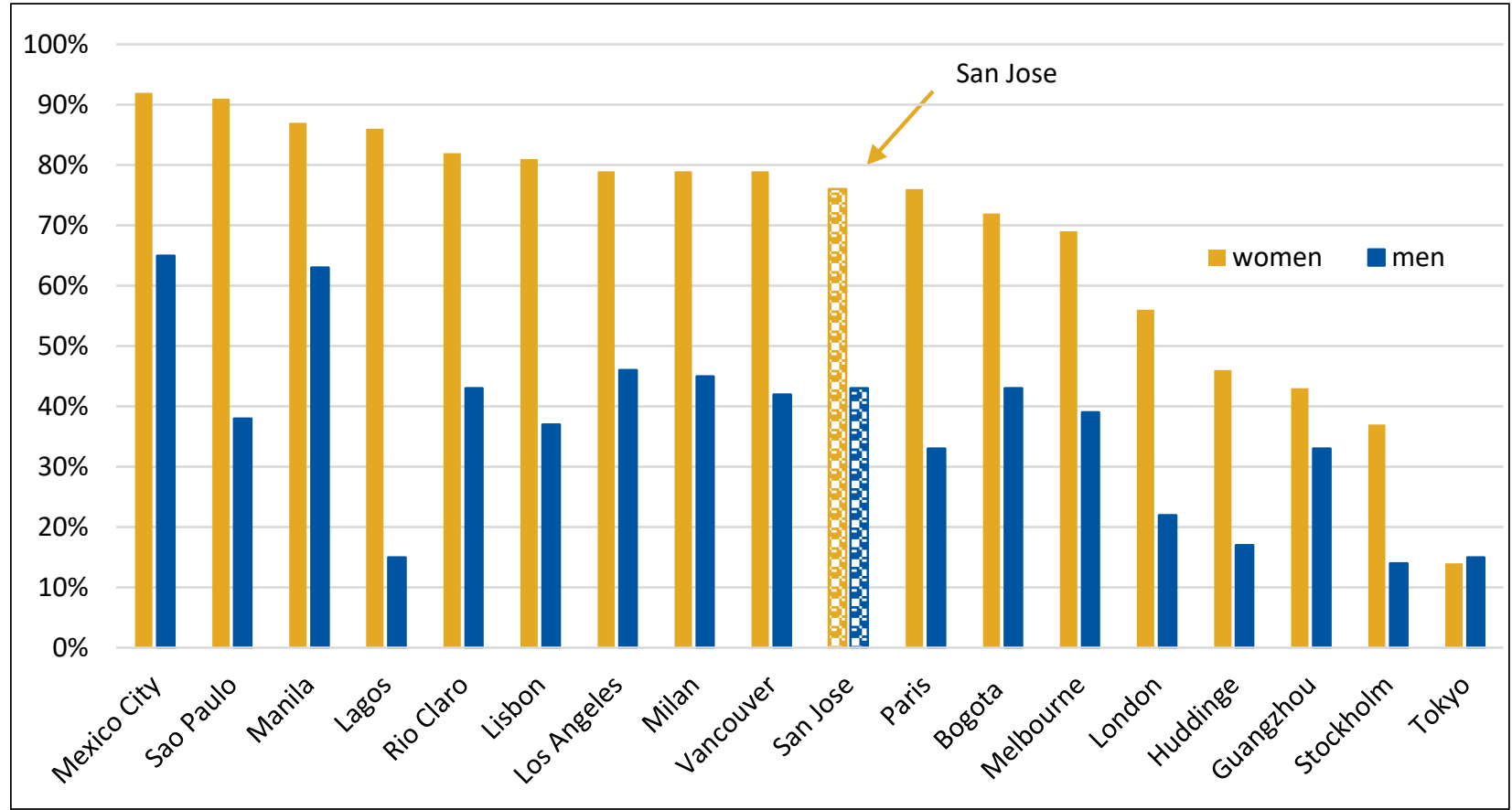

Figure 15. Percent of SJSU Students Experiencing Harassment on the Bus, as Compared to Other Countries

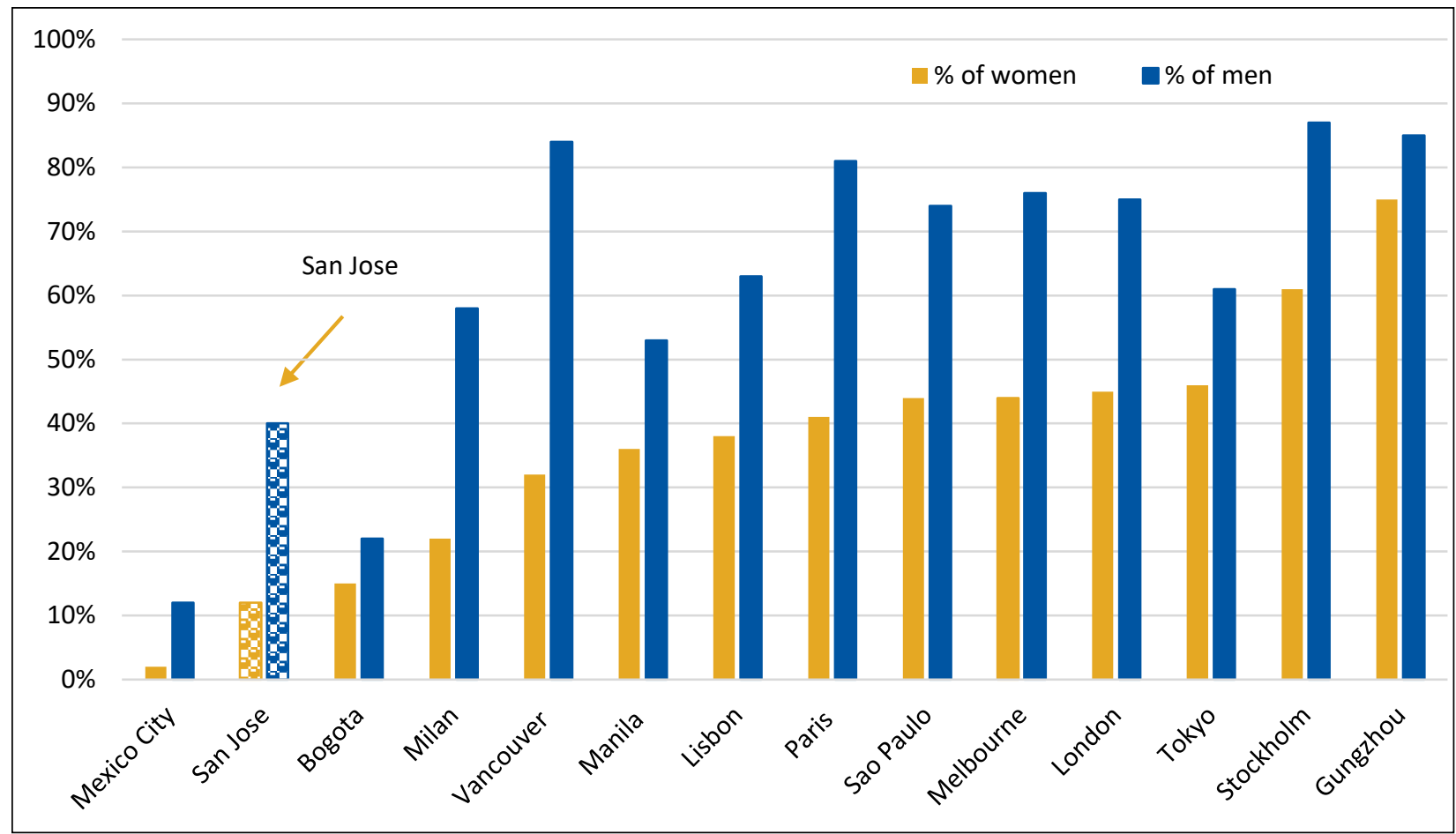

Figure 16. Percent of SJSU Students Experiencing Harassment on the Train, as Compared to Other Countries 
In San José, as in most cities, LGBTQI students reported somewhat higher rates of victimization on the bus than non-LGBTQI students, with the pattern reversed for train riders. However, these differences at SJSU were not statistically significant (Figure 17 and Figure 18).

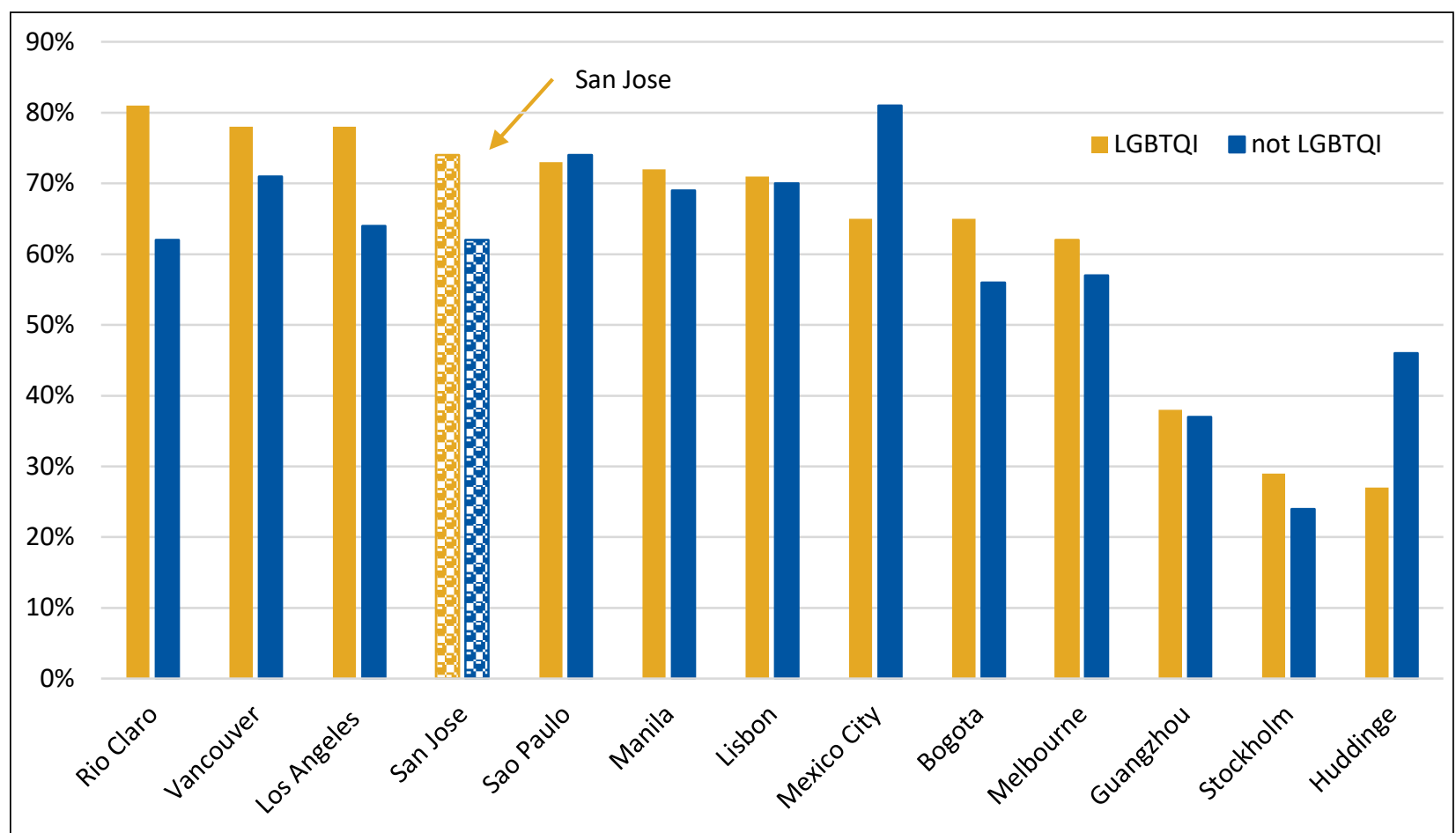

Figure 17. Percent of LGBTQI and non-LGBTQI SJSU Students Experiencing Harassment on the Bus, as Compared to Other Countries 


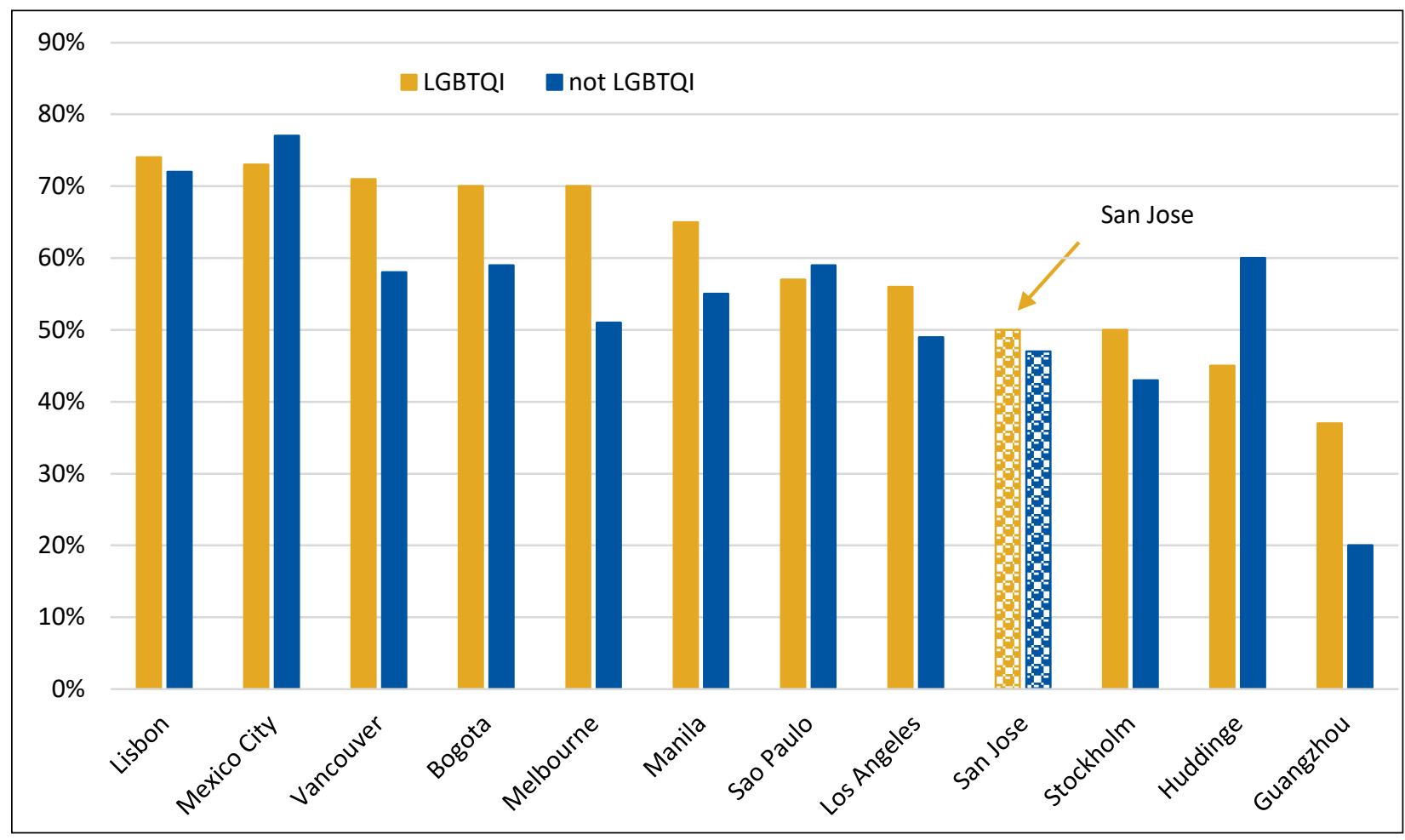

Figure 18. Percent of LGBTQI and non-LGBTQI SJSU Students Experiencing Harassment on the Train, as Compared to Other Countries

\section{TO WHAT EXTENT IS HARASSMENT WITNESSED AND REPORTED?}

Respondents were asked whether they had reported crimes of which they were a victim, as well as to whom they reported the crime (if they did) or the reasons they did not report (if they did not). Another question asked how witnesses had responded during the incident.

As Table 9 shows, only $23 \%$ of victims reported the crime to anyone at all. Victims most commonly reported crimes informally to friends or family, rather than formally to police, the transit authority, or SJSU personnel. 
Table 9. Reporting by Students Who Self-Identified as a Victim of Harassment ${ }^{a}$

\begin{tabular}{lcccc}
\hline & All (\%) & Female (\%) & Male (\%) & p-value \\
\hline Reported the crime to at least one person & 23 & 20 & 32 & 0.07 \\
Person to whom victims reported the crime & & & \\
Friends & & & & 0.44 \\
Bus driver or train operator & 16 & 15 & 21 & 0.13 \\
Police & 13 & 13 & 16 & 0.18 \\
Parents & 11 & 10 & 16 & 0.14 \\
Spouse & 10 & 9 & 8 & 0.27 \\
Transit agency & 5 & 5 & 8 & 0.27 \\
Other family members & 5 & 5 & 5 & 0.50 \\
San José State University & 5 & 5 & 8 & 0.27 \\
Other & 5 & 5 & 3 & 0.25 \\
Victims' reasons for not reporting a crime & 1 & 1 & & \\
I did not think the crime was serous & & & 32 & 0.03 \\
To avoid more trouble & 42 & 48 & 29 & 0.36 \\
I did not believe that they will catch the criminal & 32 & 32 & 18 & 0.05 \\
I did not wish to remember this & 27 & 30 & 16 & 0.44 \\
I was embarrassed & 17 & 17 & 5 & 0.04 \\
I was afraid of the police & 12 & 13 & 5 & 0.40 \\
Other & 4 & 4 & 13 & 0.08 \\
\hline
\end{tabular}

a The victims were self-identified in the previous question on the survey.

b The $p$-value for the test on the difference between proportions of men and women.

c Victims could select multiple people to whom they reported the crime, so the values sum to more than $23 \%$. Note: There were 190 victims, of whom 132 were female and 38 were male.

Another question asked students how witnesses had reacted during the crime, if there were any. A quarter of the students who identified as being a victim of harassment said that there were witnesses (Table 10). Among witnesses, the most common responses were pretending not to see what was happening (38\%) or watching from a distance $(19 \%)$. Very few talked to the offender (15\%) or the victim (13\%).

Table 10. Victima Reports of How Witnesses Reacted to the Crime

\begin{tabular}{lccc}
\hline Reaction of witnesses & All (\%) & Female (\%) & Male (\%) \\
\hline Pretended not to see what was happening & 31 & 35 & 27 \\
Watched at a distance what was happening & 19 & 21 & 18 \\
Talked to the offender & 15 & 15 & 18 \\
Other & 15 & 12 & 27 \\
Came forward and talk to victim & 13 & 15 & 9 \\
Came forward but did not say anything & 2 & 3 & 0 \\
\hline
\end{tabular}

a The victims were self-identified in the previous question on the survey.

Note: Of the 190 respondents who reported being a victim, only $25 \%$ (48 people) reported that someone witnessed the sexual assault, harassment, or other crime. Of these, 34 were female and 11 were male. 
SJSU was similar to most universities in that few students $(22 \%)$ indicated that they had reported incidents of sexual harassment (Figure 19).

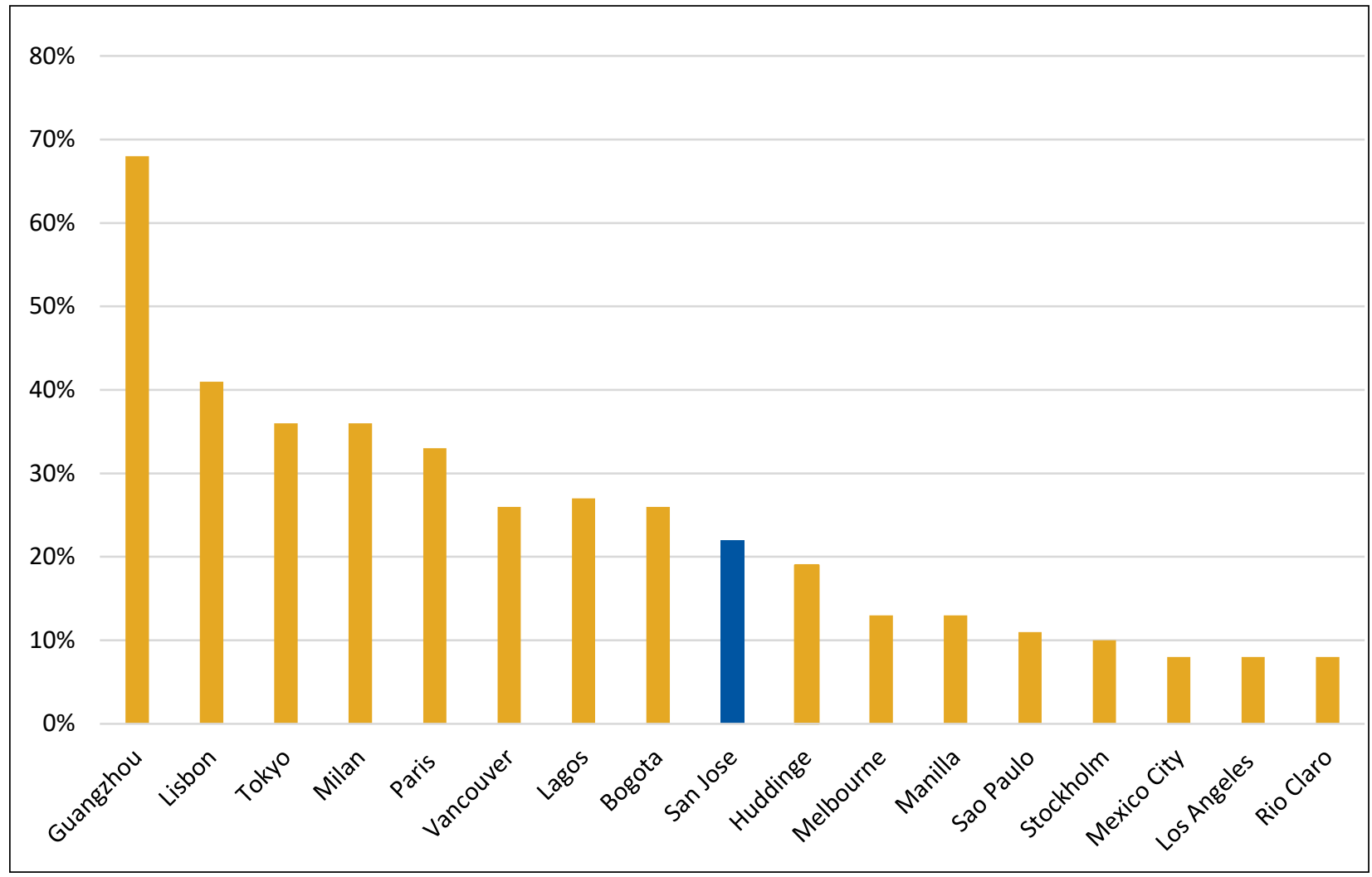

Figure 19. Percent of SJSU Students Reporting Harassment, as Compared to Other Countries

Note: The results are not broken down by gender because the differences were not statistically significant.

\section{WHAT SAFETY PRECAUTIONS DO STUDENTS TAKE?}

Students who rode the bus or train were asked what safety precautions, if any, they take during transit trips. The options presented included modifying the way they used transit (i.e., not riding after dark), self-presentation (i.e., not wearing jewelry), and carrying selfdefense equipment. Table 11 shows the precautions taken for both bus and rail. Overall, $61 \%$ of bus riders and $45 \%$ of train riders reported taking at least one precaution. Looking at the specific types of precautions, among the most common are behavior modifications that limit students' ability to use transit: traveling only during the daytime, waiting for transit only at well-lit places, and avoiding certain bus or train stops. In terms of changing one's self-presentation, the most common response was to "dress in a certain" way ( $21 \%$ bus, $19 \%$ train).

A comparison of precautions by mode shows that far more bus riders (61\%) take precautions than train riders (45\%). However, looking at the differences by mode for specific precautions, the differences are much smaller (Table 11 and Figure 20). The biggest differences by mode are avoiding a particular bus or train stop (18\% for bus vs. $11 \%$ for train) and sitting close to the driver (17\% for bus vs. $10 \%$ for train). For other specific precautions, the differences by mode are all less than five percentage points. 
For both bus and train, women were more likely than men to take almost every type of precaution (Figure 20 and Figure 21). These differences are virtually all statistically significant, and in many cases large. For bus travel, the gap between precautions that women and men take is more than 20 percentage points for limiting travel to daytime hours, waiting for transit only at well-lit places, sitting close to the driver, carrying a selfdefense spray, and holding keys to use them for self-defense. For example, $37 \%$ of women but only $12 \%$ of men said that they limited their transit use to daytime hours.

The differences in precautions taken by riders who had and had not been harassed is one of the starkest findings in the survey. For both bus and rail, riders who had not been harassed took virtually no precautions of any kind, compared to the large proportion of people who had been victimized taking precautions (Table 21).

Table 11. Types of Precautions that Riders Take during Bus and Train Trips

\begin{tabular}{lcc}
\hline Type of precaution & Bus (\%) & Train (\%) \\
\hline Take at least one precaution & 61 & 45 \\
Travel only during daytime & 24 & 20 \\
Wait for transit only at well-lit places & 24 & 20 \\
Dress a certain way & 21 & 19 \\
Hold keys so that I can use them to protect myself if attacked & 20 & 17 \\
Carry a self-defense spray & 18 & 16 \\
Avoid particular bus/train stops & 18 & 11 \\
Sit close to the driver & 17 & 10 \\
Do not wear jewelry & 15 & 11 \\
Wait for transit only if other people are around & 14 & 14 \\
Avoid carrying purses, wallets & 12 & 12 \\
Always travel with someone else & 12 & 11 \\
Avoid particular bus/train lines & 8 & 6 \\
Carry a weapon (e.g. gun or knife) & 7 & 8 \\
Other & 4 & 1 \\
\hline
\end{tabular}

Note: $\mathrm{N}=441$ for bus riders and $\mathrm{N}=386$ for train riders. 


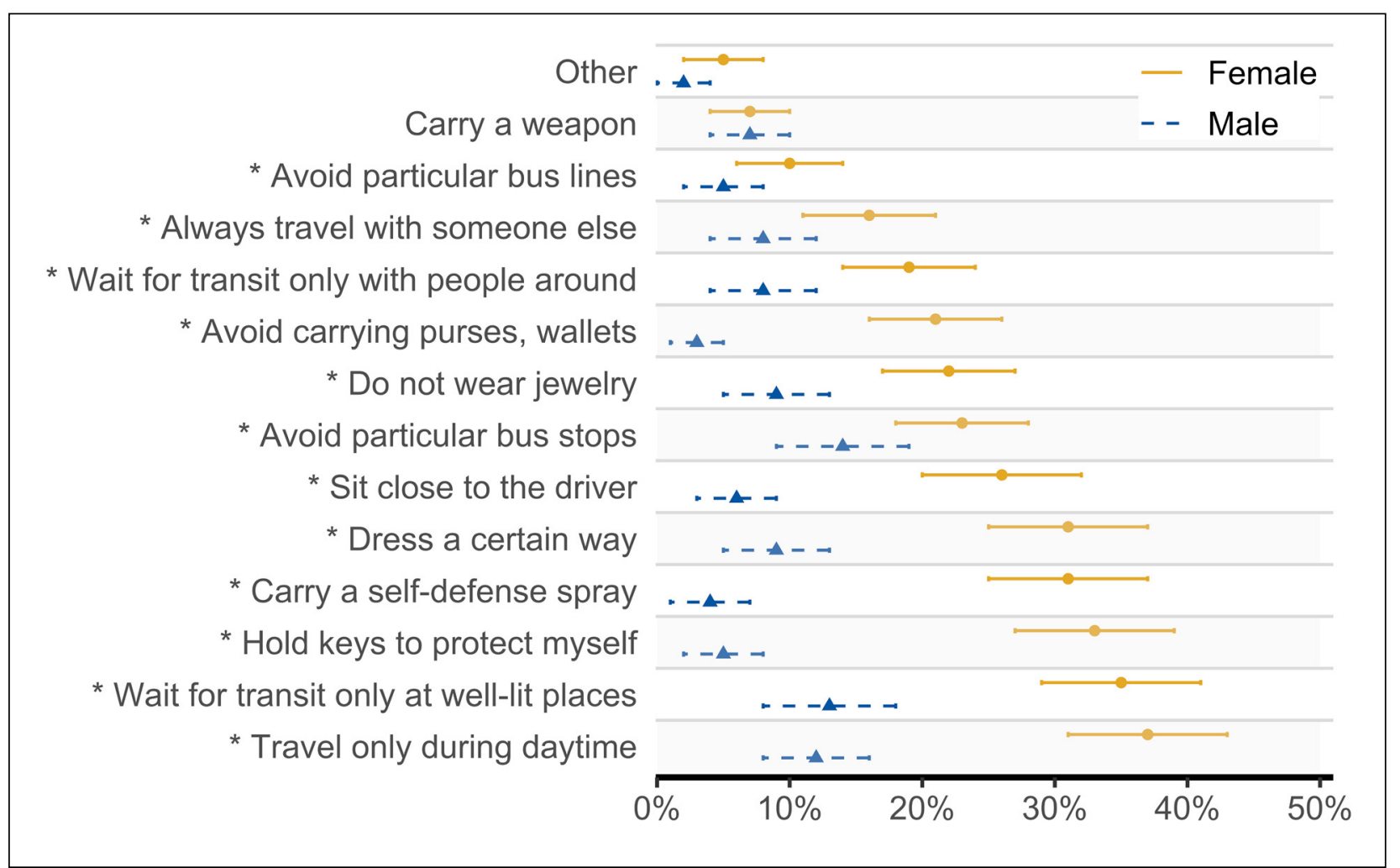

Figure 20. Precautions that Bus Riders Take, by Gender

Notes: Asterisks indicate a statistically significant difference at $p<0.05$, and the bars represent the $95 \%$ confidence intervals. There were 229 female and 212 male bus riders, and 200 female and 186 male train riders. To review the results of this analysis in table form, see Table 20 in Appendix $B$. 


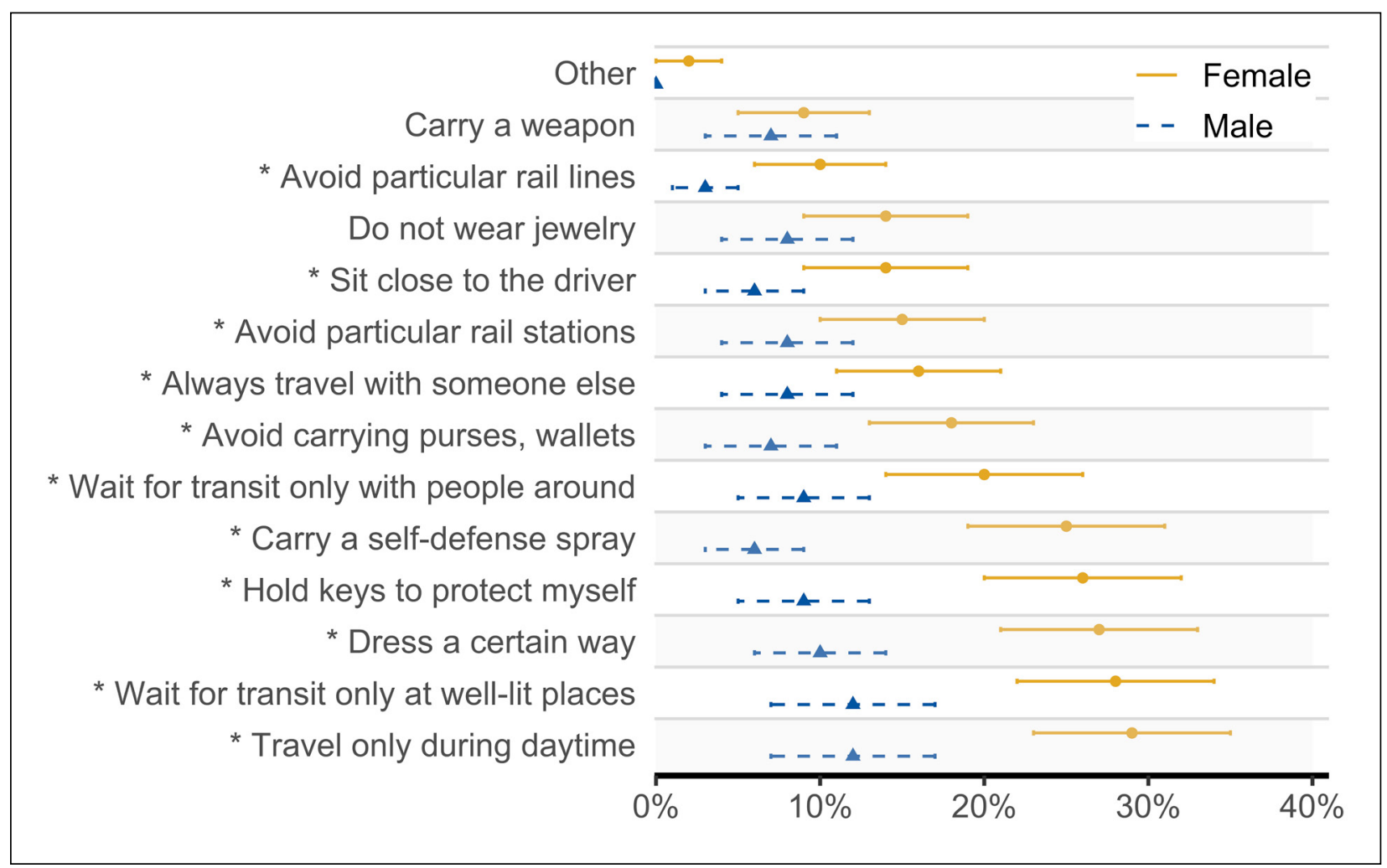

\section{Figure 21. Precautions that Train Riders Take, by Gender}

Notes: Asterisks indicate a statistically significant difference at $p<0.05$, and the bars represent the $95 \%$ confidence intervals. There were 229 female and 212 male bus riders, and 200 female and 186 male train riders. To review the results of this analysis in table form, see Table 20 in Appendix $B$.

\section{WHAT CHANGES DO STUDENTS RECOMMEND TO IMPROVE SAFETY?}

For transit riders of both genders, the most common recommendations were police patrolling platforms and train vehicles, and cameras at platforms and in vehicles. Well over one-third of respondents selected each of these four options. The least popular option suggested was "women only" wagons; just $10 \%$ of respondents supported this concept. Women-only wagons was also the only option with a statistically significant difference in the response between women (14\%) and men (6\%). (For details, see Figure 22, Table 22, and Table 23.) 


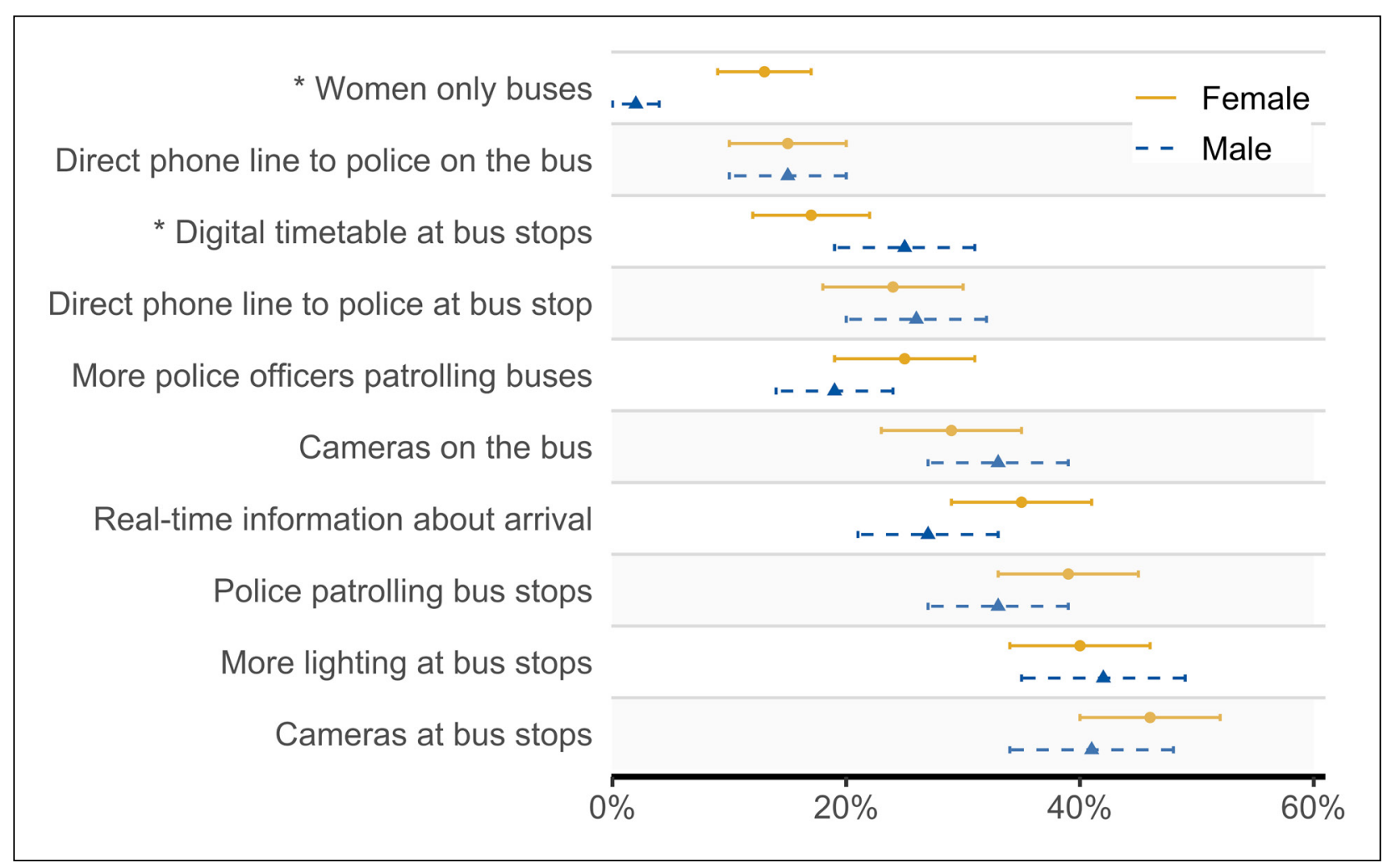

\section{Figure 22. Safety Recommendations from Bus Riders, by Gender}

Notes: Asterisks indicate a statistically significant difference at $p<0.05$, and the bars represent the $95 \%$ confidence intervals. There were 229 female and 212 male bus riders, and 200 female and 186 male train riders. To review the results of this analysis in table form, see Table 22 in Appendix B. 


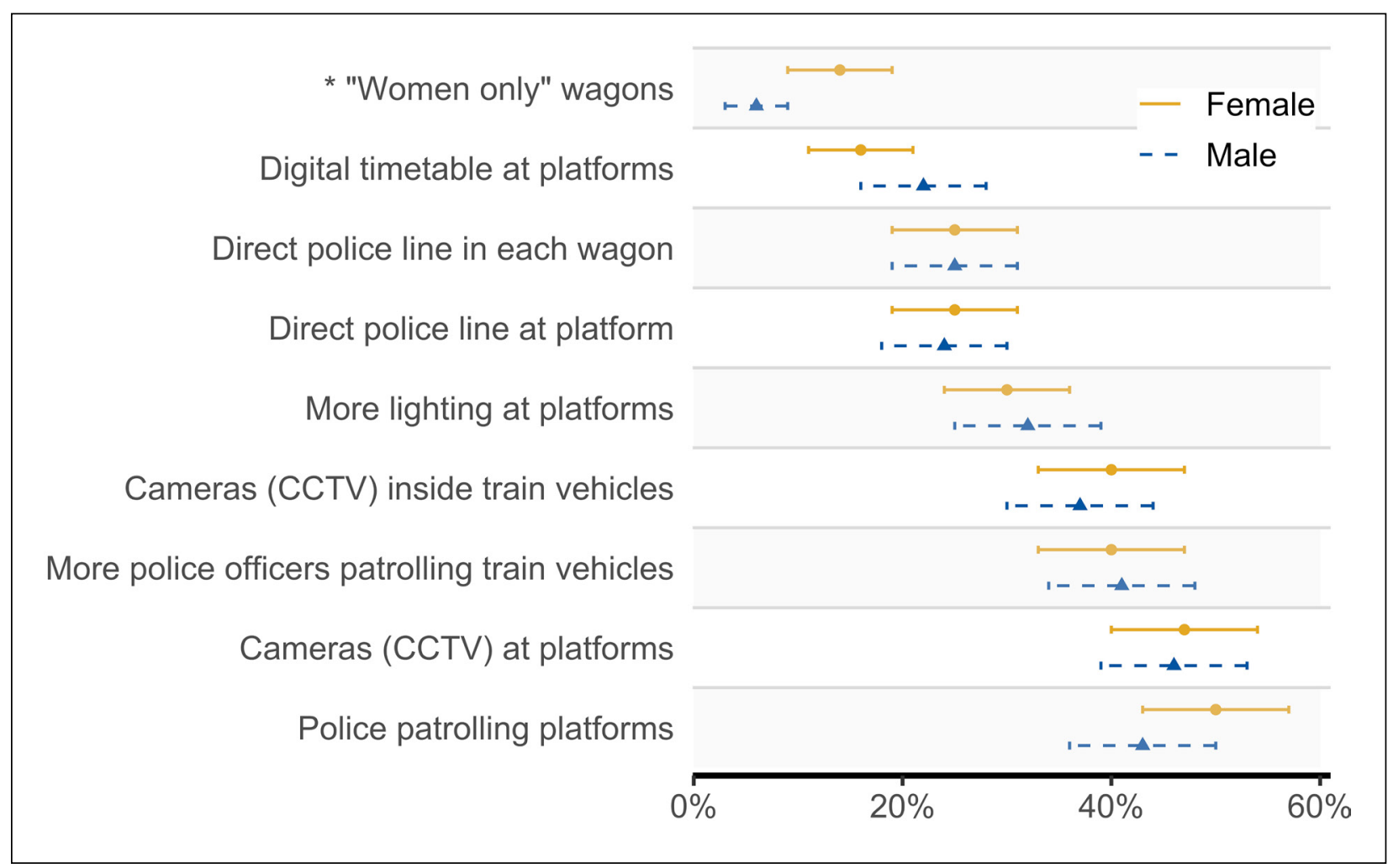

\section{Figure 23. Safety Recommendations from Train Riders, by Gender}

Notes: Asterisks indicate a statistically significant difference at $p<0.05$, and the bars represent the $95 \%$ confidence intervals. There were 229 female and 212 male bus riders, and 200 female and 186 male train riders. To review the results of this analysis in table form, see Table 23 in Appendix B. 
* Women only buses

Direct phone line to police on the bus

Digital timetable at bus stops

Direct phone line to police at bus stop

* More police officers patrolling buses

Cameras on the bus

Real-time information about arrival

Police patrolling bus stops

More lighting at bus stops

* Cameras at bus stops

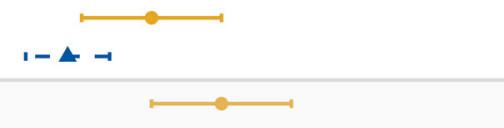

- Harassed

$1--4$

- - Not harassed

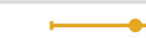

I- - - - -

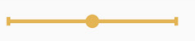

- - - - - -

$\longrightarrow$

$1--\Delta-\rightarrow$

I- - - - -

$\longmapsto$

I- $-\boldsymbol{A}--\rightarrow$

I- - $-1-\rightarrow$

$$
\text { I- - - - - }
$$

$1--\rightarrow--\rightarrow$

$20 \%$

Figure 24. Safety Recommendations from Bus Riders, by Harassed vs. Not Harassed

Notes: Asterisks indicate a statistically significant difference at $p<0.05$, and the bars represent the $95 \%$ confidence interval. There were 289 bus riders who were harassed and 183 who were not harassed. To review the results of this analysis in table form, see Table 24 in Appendix B. 


"Women only" wagons
Digital timetable at platforms
Direct police line at platform
Camerect police line in each wagon (CCTV) inside train vehicles
Police patrolling platforms
Cameras (CCTV) at platforms

\section{Figure 25. Safety Recommendations from Train Riders, by Harassed vs. Not} Harassed

Notes: Asterisks indicate a statistically significant difference at $p<0.05$, and the bars represent the $95 \%$ confidence intervals. There were 184 rail riders who were harassed and 226 who were not harassed. To review the results of this analysis in table form, see Table 25 in Appendix B. 


\section{CONCLUSIONS}

This chapter summarizes the survey findings, suggests implications for policymakers, and recommends future research that would help communities to more effectively combat the problem of sexual harassment and assault on transit.

\section{SUMMARY OF FINDINGS}

This section summarizes key findings about SJSU student transit riders' experiences with sexual harassment and assault, how concerns about harassment affect their choices about using transit, and how concerns differ by gender.

\section{Sexual Harassment is Common on Transit}

Sadly, the survey results reveal that sexual harassment is a common-even routineexperience for SJSU student transit riders, whether they ride the bus or train. Almost twothirds of respondents $(63 \%)$ had experienced some form of harassment during transit trips.

Verbal harassment was the most common form of harassment, with $41 \%$ experiencing "obscene/harassing language" and $26 \%$ being subjected to sexual comments. Among non-verbal types of harassment, $22 \%$ had been stalked and $18 \%$ had been victims of indecent exposure. Physical harassment was less common, but still $11 \%$ of students had experienced groping or inappropriate touching.

The survey also demonstrated that students do not share a common understanding of what constitutes sexual harassment. When asked directly if they had experienced "sexual assault, harassment, or other crime," $23 \%$ of riders responded affirmatively. However, when students were asked if they had experienced each of a number of specific types of harassment, $63 \%$ said they had experienced at least one type of harassing behavior. This discrepancy of 40 percentage points (63\% vs. $23 \%$ ) indicates that students may not perceive some types of harassment, particularly verbal offenses, as "sexual harassment," even though these behaviors bother them.

\section{Sexual Harassment Creates Fear and Reduces Transit Use}

The survey also found that students' fear of sexual harassment reduces their transit use. When asked if they felt safe using transit, only half of riders reported feeling always or often safe.

To reveal why students felt unsafe, the survey asked respondents whether they considered a range of environmental factors and criminal behaviors, including sexual harassment, to be significant problems on transit. Depending on the transit setting, from one-quarter to onethird of riders considered sexual harassment to be a significant problem. Finally, a quarter of riders said that sexual harassment prevented them from using transit more often. 
Unsurprisingly, many students took safety precautions when using transit. Overall, $61 \%$ of bus riders and $45 \%$ of train riders reported taking at least one safety precaution when using transit. The most common precautions that limit students' mobility include traveling only during the daytime, waiting for transit only at well-lit places, and avoiding certain bus or train stops.

The survey provides strong evidence that experiences of harassment have long-term impacts. Those students who had been prior victims of harassment were much more likely to report feeling unsafe using transit, to consider sexual harassment a problem, to report reduced use of transit, or to take precautions when riding transit. Strikingly, riders who had not been harassed took virtually no precautions of any kind.

\section{Sexual Harassment Affects Both Genders, but Far More Women}

Concern about harassment was much more common among women than men. For example, women were less likely than men to report feeling safe, twice as many women as men saw harassment as a problem, and $45 \%$ of female bus riders but only $7 \%$ of male riders said that fear of sexual harassment led them to reduce their use of the bus. Also, roughly twice as many women as men reported all three types of harassment (verbal, nonverbal, and physical).

Women were also much more likely than men to take almost every type of safety precaution when using transit: limiting travel to daytime hours, waiting for transit only at well-lit places, sitting close to the driver, carrying a self-defense spray, and holding keys to use them for self-defense. The gap between women and men bus riders taking such precautions was more than 20 percentage points.

Although sexual harassment affects more women than men, the study clearly shows that men are also affected: many male survey respondents reported having been victims and worrying about harassment. In a few cases, men also reported reducing transit use in response to that concern.

\section{Sexual Harassment Remains Largely Unreported}

Fewer than one quarter of victims reported the harassment they had experienced to anyone at all, and those students who reported the experiences mostly did so to friends or family rather than to police or transit operators.

\section{The SJSU Student Experience is a Global Experience}

The rates of victimization for SJSU bus and train riders are generally in line with the results from the surveys conducted at other cities around the world. As in most other cities, more than half of SJSU's female students experienced harassment on both the bus and train, far more women than men reported harassment, and harassment was rarely reported to authorities. However, as compared to students in the other cities in the global study, SJSU students were less likely to feel "always" or "often" safe after dark on the bus or on the train. Of the 18 cities studied, only two-Mexico City and Rio Claro, Brazil- 
had lower proportions of women than SJSU who felt safe after dark. Higher proportions of women felt safe in cities around the world, from Bogota, Colombia, to Milan, Italy, to Manila, Philippines.

\section{IMPLICATIONS FOR POLICY AND ACTION}

Although sexual harassment is a problem that stems from cultural and social factors far beyond any transit operator or single community's control, the survey findings suggest different steps that transit operators, community planners, and other policymakers can take proactively to reduce the severity of the problem.

Educate the public about sexual harassment. Transit operators, police, and other responsible public agencies can instigate widespread educational campaigns about sexual harassment. Such campaigns, through ads and posters on transit vehicles and in transit settings, can raise awareness about the problem and encourage victims and bystanders to report sexual harassment incidents. A related finding is that many victims did not explicitly identify sexual crimes as such, so awareness campaigns should also educate the public about what behaviors constitute sexual crimes.

Institutionalize collection of sexual harassment data in transit passenger surveys. Transit operators can better understand the nature and extent of harassment on their systems if they conduct systematic surveys that ask passengers about their experiences with harassment. Questions should inquire about experiences not only onboard the transit vehicle but also at transit stops and on the way to/from transit.

Make it easy to report sexual harassment. The finding that almost none of the SJSU student victims officially reported the crime underscores the need for transit operators to make reporting easy for transit riders. Smartphone apps and dedicated phone lines can help victims and bystanders report harassment and other crimes in real time. Also, in cases where operators already have reporting systems, these can be adapted to make sure that sexual harassment is offered as one of the reporting categories.

Give attention to the physical transit environment. Respondents made clear that poorly maintained and dark transit environments made them fearful, a finding that points to the value of keeping transit settings well-lit and maintained.

Safeguard against antisocial behaviors on transit. Many respondents also indicated that they would use transit more if they did not fear antisocial behaviors like drunkenness and obscene language. Survey respondents called for more police patrols and security cameras on both platforms and transit vehicles to reduce antisocial behavior.

Learn from transit industry best practices. Of course, the complexities of transit operations may require solutions that are different from those passengers recommend. To better understand feasible and tested actions, operators have a great deal to learn from the practices of transit operators that have prioritized efforts to reduce sexual crimes, including the Washington Metropolitan Area TransitAuthority (Washington, D.C.), Transport for London (England), Metro Vancouver Transit Police (Canada), and Toronto Transport 
Commission (Canada). These efforts include anti-harassment campaigns, training of transit vehicle operators, request-a-stop policies, and use of digital technologies to report harassment events.

Design safe access to transit stops. While transit operators obviously must take the lead to improve safety within the confines of their own services, other local government entities are essential partners who can work with operators to ensure passengers' safety traveling to and from transit stops. From the perspective of a potential transit rider, fear of crime when walking home from a bus stop may deter ridership just as much as fear of crime on the bus itself. Walking or cycling conditions can be improved with environmental design interventions like nighttime lighting, buildings designed with windows facing the street to provide informal protective surveillance, and protected cycle lanes. Further, some communities may find that they can improve safe access and egress from stations by coordinating transit services with shared mobility options such as taxis, ridehailing, and cycle-sharing systems.

Engage other responsible entities. Lastly, we note that the issue of sexual harassment is not only the responsibility of municipal planners or transit operators. The incidence of sexual violence against women-from domestic violence within the confines of private homes to sexual harassment in public spaces-represents a larger social problem that requires long-term and sustained responses from society. For example, the criminal justice system should also take a close look at different sexual harassment behaviors and revise the penal code to apply stricter penalties to perpetrators. Even more importantly, parents and teachers should instill in their children and pupils from early on the messages about gender equality and respect towards all human beings, regardless of gender, age, race, income, or capacities.

\section{STUDY LIMITATIONS AND RECOMMENDATIONS FOR FUTURE RESEARCH}

As with any research, the study findings point to valuable avenues for future research.

One finding from the study was that respondents often did not realize the full range of behaviors that fall under the term "sexual harassment"; many of the experiences we considered sexual harassment were not directly perceived that way by respondents. Future research is needed to better explore what behaviors people consider to be sexual harassment. Further, any future surveys or qualitative studies should be designed with care to ensure that the term is used in a way respondents will understand.

Second, this report uses relatively simple statistical analyses, aiming just to analyze the differences between male and female riders, or bus and train riders, and to measure which dependent variables significantly impacted the probability of being harassed. Future research should look at the relationships among all the variables using more advanced statistical techniques, such as by combining the exploratory data analysis techniques of multiple correspondence analysis (to explore the relationships among variables) with cluster analysis (to identify homogeneous groups among the individuals). 
Third, there is critical need for research that explores and evaluates different interventions to prevent sexual crimes in the public transit environment, as our literature review found very little evidence on this point. As an early step in identifying these best practices, there is need for research that documents what actions transit operators are currently taking (or not), from surveying passengers, to training front-line staff, to public education, to strategic collaboration with local law enforcement. Also, it would be valuable to use interviews, focus groups, or other qualitative methods to explore how agency staff and board members understand the problem of sexual harassment of riders and what role they think operators should play in combatting the problem. 


\section{APPENDIX A: SURVEY QUESTIONNAIRE AND TOPLINE RESULTS}

This appendix presents the complete survey questionnaire and topline responses.

The authors removed missing values (respondents who did not answer more than $50 \%$ of questions) from the dataset and calculated the response rates based on the applicable respondents.

Note that some categories in the tables do not sum to $100 \%$ due to rounding or because respondents could select more than one response option.

Researchers at SJSU's Mineta Transportation Institute are surveying SJSU students to learn whether or not you have had experiences with sexual assault, harassment, or other crime when using buses and trains. Your opinions are very important, even if you have not experienced assault, harassment, or other crime.

The survey results will be used to improve safety for students and others who ride buses and trains.

The survey takes about 10 minutes to complete and is confidential. Although the results of this study may be published, no information that could identify you will be shared with the researchers who analyze the survey results and write up the findings.

Your participation is completely voluntary. You can refuse to participate in the entire study, skip any question, or stop the survey at any time without any negative effect on your relations with San José State University. If you participate, there are no anticipated risks to you. The anticipated benefits are the satisfaction of sharing your views with the researchers, and the fact that the results will inform policymakers interested in providing safer transit.

Regardless of whether or not you participate, you have the option to enter yourself into a raffle to win SJSU Gold Points cards valued at $\$ 25, \$ 50$, or $\$ 100$. You have a $0.05 \%$ chance of winning.

For more information about the study, contact the researcher, Professor Asha W. Agrawal, at asha.weinstein.agrawal@sjsu.edu.

By agreeing to participate in the study, it is implied that you have read and understand the above information. Please do not write any identifying information on the survey. 
1. On a typical weekday, how long is your trip to the university, from door to door?

\begin{tabular}{lccc}
\hline Length of trip to university (minutes) & All respondents (\%) & Female (\%) & Male (\%) \\
\hline $0-15$ & 30 & 28 & 32 \\
$16-30$ & 30 & 30 & 28 \\
$31-60$ & 25 & 27 & 24 \\
$61-120$ & 12 & 11 & 12 \\
$121+$ & 3 & 3 & 3 \\
\hline
\end{tabular}

Note: $\mathrm{N}$-values are as follows: $\mathrm{N}=891$ for all respondents, $\mathrm{N}=437$ for female riders, and $\mathrm{N}=403$ for male riders.

\section{BUS/TRAVEL}

2. On a typical week, how often do you ride a public bus, like VTA or AC Transit buses? Please do not include shuttles owned/operated by SJSU.

\begin{tabular}{lccc}
\hline Days per week riding a public bus & All respondents (\%) & Female (\%) & Male (\%) \\
\hline 7 & 5 & 5 & 7 \\
$5-6$ & 9 & 8 & 8 \\
$3-4$ & 16 & 16 & 15 \\
$1-2$ & 11 & 10 & 11 \\
Less than once per week & 12 & 13 & 12 \\
Never & 47 & 48 & 47 \\
\hline
\end{tabular}

Note: $\mathrm{N}$-values are as follows: $\mathrm{N}=891$ for all respondents, $\mathrm{N}=437$ for female riders, and $\mathrm{N}=403$ for male riders.

3. During daytime, do you feel safe riding the bus?

\begin{tabular}{lccc}
\hline Feeling safe riding a public bus & All respondents (\%) & Female (\%) & Male (\%) \\
\hline Always & 24 & 17 & 33 \\
Often & 50 & 48 & 51 \\
Sometimes & 22 & 31 & 13 \\
Rarely & 2 & 3 & 2 \\
Never & 1 & 1 & 1 \\
\hline
\end{tabular}

Note: $\mathrm{N}$-values are as follows: $\mathrm{N}=472$ for all respondents, $\mathrm{N}=229$ for female bus riders, and $\mathrm{N}=212$ for male bus riders.

\section{During daytime, do you feel safe waiting at the bus stop?}

\begin{tabular}{lccc}
\hline Feeling safe riding a public bus & All respondents (\%) & Female (\%) & Male (\%) \\
\hline Always & 22 & 16 & 32 \\
Often & 43 & 39 & 45 \\
Sometimes & 28 & 36 & 18 \\
Rarely & 6 & 8 & 5 \\
Never & 1 & 1 & 32 \\
\hline
\end{tabular}

Note: $\mathrm{N}$-values are as follows: $\mathrm{N}=472$ for all respondents, $\mathrm{N}=229$ for female bus riders, and $\mathrm{N}=212$ for male bus riders. 
5. After dark, do you feel safe riding the bus?

\begin{tabular}{lccc}
\hline Feeling safe riding a public bus & All respondents (\%) & Female (\%) & Male (\%) \\
\hline Always & 3 & 0 & 7 \\
Often & 15 & 7 & 23 \\
Sometimes & 30 & 27 & 33 \\
Rarely & 19 & 24 & 14 \\
Never & 11 & 16 & 5 \\
I don't use the bus after dark & 21 & 26 & 17 \\
\hline
\end{tabular}

Note: $\mathrm{N}$-values are as follows: $\mathrm{N}=472$ for all respondents, $\mathrm{N}=229$ for female bus riders, and $\mathrm{N}=212$ for male bus riders.

6. After dark, do you feel safe walking to/from the bus stop, or waiting at the bus stop?

\begin{tabular}{lccc}
\hline Perceived safety riding a public bus & All respondents (\%) & Female (\%) & Male (\%) \\
\hline Always & 3 & 1 & 5 \\
Often & 14 & 6 & 23 \\
Sometimes & 23 & 17 & 29 \\
Rarely & 24 & 29 & 20 \\
Never & 13 & 19 & 6 \\
I don't use the bus after dark & 2 & 3 & 1 \\
\hline
\end{tabular}

Note: $\mathrm{N}$-values are as follows: $\mathrm{N}=472$ for all respondents, $\mathrm{N}=229$ for female bus riders, and $\mathrm{N}=212$ for male bus riders.

7. Which of the following prevent you from using bus more often? Mark all that apply. (The order of response options up to "other" was randomized.)

\begin{tabular}{lccc}
\hline Problems & All respondents (\%) & Female (\%) & Male (\%) \\
\hline Concern of antisocial behavior of others & 49 & 56 & 42 \\
Slow journey times & 42 & 42 & 43 \\
Fear of victimization getting to and waiting for the bus & 37 & 47 & 25 \\
Fear of victimization while on the bus & 31 & 42 & 19 \\
Dirty environment on the bus (trash, graffiti) & 31 & 30 & 33 \\
Unreliable bus service & 27 & 26 & 28 \\
Fear of sexual harassment on the bus & 27 & 45 & 7 \\
Overcrowded buses & 26 & 28 & 25 \\
Dirty environment during the walk to the bus stop & 25 & 27 & 24 \\
Many transfers & 21 & 21 & 22 \\
Lack of information about bus schedules & 19 & 18 & 19 \\
Cost of tickets & 12 & 13 & 12 \\
Fear of terrorist attack & 9 & 12 & 5 \\
Other & 9 & 7 & 11 \\
Fear of traffic crashes & 6 & 8 & 4 \\
Don't understand how to buy bus fare (ticket) & 1 & 0 & 1 \\
\hline
\end{tabular}

Note: $\mathrm{N}$-values are as follows: $\mathrm{N}=472$ for all respondents, $\mathrm{N}=229$ for female bus riders, and $\mathrm{N}=212$ for male bus riders. 
8a. Which of the following do you perceive as a significant problem on the bus you use? Mark all that apply. (The order of response options up to "other" was randomized.)

\begin{tabular}{lccc}
\hline Problems & All respondents (\%) & Female (\%) & Male (\%) \\
\hline Environmental & 38 & 38 & 37 \\
Vandalism, litter & 18 & 23 & 13 \\
Poorly designed & 18 & 18 & 17 \\
Poorly guarded/empty most of the day & 16 & 18 & 12 \\
Poorly illuminated & & & \\
Behavioral & 46 & 48 & 43 \\
Obscene language & 45 & 46 & 46 \\
Drunk people & 38 & 42 & 32 \\
Verbal/physical threats & 29 & 38 & 18 \\
Sexual harassment & 26 & 28 & 23 \\
Pickpocketing & 24 & 28 & 21 \\
Robbery & 19 & 19 & 20 \\
Drug use/sales & 19 & 21 & 17 \\
Violent crime (aggravated assault, murder) & 17 & 15 & 17 \\
Panhandling & 17 & 18 & 15 \\
Jewelry snatching & 1 & 2 & 1 \\
Other & & 48 \\
\hline Note:
\end{tabular}

Note: $\mathrm{N}$-values are as follows: $\mathrm{N}=472$ for all respondents, $\mathrm{N}=229$ for female bus riders, and $\mathrm{N}=212$ for male bus riders.

8b. Which of the following do you perceive as a significant problem at the bus stops you use? Mark all that apply. (Order of response options was randomized, up to "other.")

\begin{tabular}{lccc}
\hline Problems & All respondents (\%) & Female (\%) & Male (\%) \\
\hline Drunk people & 57 & 65 & 50 \\
Vandalism, litter & 55 & 58 & 52 \\
Poorly illuminated & 51 & 55 & 48 \\
Poorly guarded/empty most of the day & 46 & 52 & 40 \\
Obscene language & 46 & 54 & 38 \\
Poorly designed & 45 & 55 & 33 \\
Verbal/physical threats & 45 & 52 & 35 \\
Robbery & 39 & 41 & 34 \\
Drug use/sales & 36 & 44 & 27 \\
Panhandling & 35 & 38 & 32 \\
Sexual harassment & 35 & 48 & 18 \\
Violent crime (aggravated assault, murder) & 32 & 37 & 25 \\
Pickpocketing & 31 & 38 & 22 \\
Jewelry snatching & 25 & 31 & 19 \\
Other & 1 & 1 & 1 \\
\hline
\end{tabular}

Note: $\mathrm{N}$-values are as follows: $\mathrm{N}=472$ for all respondents, $\mathrm{N}=229$ for female bus riders, and $\mathrm{N}=212$ for male bus riders. 
9a. In the last 3 years, have you experienced any of the following types of harassment while traveling on, heading to, or waiting for the bus? Mark all that apply. (Order of response options was randomized, up to "other.")

\begin{tabular}{lccc}
\hline Type of harassment & All respondents (\%) & Female (\%) & Male (\%) \\
\hline Using obscene/abusive language & 27 & 29 & 22 \\
Unwanted sexual looks or gestures & 14 & 21 & 4 \\
Sexual comments (about clothing, looks) & 12 & 16 & 7 \\
Calling you babe, honey, sweetheart or something similar & 12 & 20 & 2 \\
Unwanted sexual teasing, remarks & 10 & 14 & 3 \\
Whistling & 9 & 11 & 5 \\
Stalking (a stranger following you) & 8 & 11 & 3 \\
Groping, touching inappropriately & 7 & 10 & 3 \\
Indecent exposure & 7 & 7 & 8 \\
Asking you questions of sexual nature & 7 & 9 & 6 \\
Making kissing sounds & 6 & 7 & 4 \\
Showing pornographic images & 4 & 3 & 5 \\
Masturbating in public & 4 & 5 & 4 \\
Pulling or playing with your hair & 4 & 5 & 3 \\
Unwanted kissing by a stranger & 3 & 3 & 2 \\
Asked to have sex by a stranger & 3 & 4 & 2 \\
Other & 1 & 2 & 1 \\
\hline
\end{tabular}

Note: $\mathrm{N}$-values are as follows: $\mathrm{N}=472$ for all respondents, $\mathrm{N}=229$ for female bus riders, and $\mathrm{N}=212$ for male bus riders.

$9 \mathrm{~b}$. In the last 3 years, have you experienced any of the following types of harassment while traveling on, heading to, or waiting for the bus? Mark all that apply. (Order of response options was randomized, up to "other.")

\begin{tabular}{lccc}
\hline Type of harassment & All respondents (\%) & Female (\%) & Male (\%) \\
\hline Using obscene/abusive language & 19 & 26 & 13 \\
Whistling & 17 & 29 & 3 \\
Unwanted sexual looks or gestures & 15 & 25 & 2 \\
Sexual comments (about clothing, looks) & 15 & 25 & 3 \\
Calling you babe, honey, sweetheart or something similar & 15 & 27 & 2 \\
Stalking (a stranger following you) & 14 & 18 & 8 \\
Unwanted sexual teasing, remarks & 12 & 20 & 2 \\
Making kissing sounds & 9 & 15 & 4 \\
Indecent exposure & 8 & 7 & 8 \\
Asking you questions of sexual nature & 6 & 7 & 3 \\
Asked to have sex by a stranger & 4 & 6 & 2 \\
Groping, touching inappropriately & 3 & 3 & 1 \\
Masturbating in public & 3 & 3 & 4 \\
Unwanted kissing by a stranger & 2 & 2 & 1 \\
Pulling or playing with your hair & 2 & 2 & 2 \\
Showing pornographic images & 1 & 2 & 1 \\
Other & 1 & 2 & 1 \\
\hline
\end{tabular}

Note: $\mathrm{N}$-values are as follows: $\mathrm{N}=472$ for all respondents, $\mathrm{N}=229$ for female bus riders, and $\mathrm{N}=212$ for male bus riders. 
9c. In the last 3 years, have you experienced any of the following types of harassment while traveling on, heading to, or waiting for the bus? Mark all that apply. (Order of response options was randomized, up to "other.")

\begin{tabular}{lccc}
\hline Type of harassment & All respondents (\%) & Female (\%) & Male (\%) \\
\hline Using obscene/abusive language & 28 & 31 & 22 \\
Unwanted sexual looks or gestures & 18 & 31 & 4 \\
Sexual comments (about clothing, looks) & 17 & 24 & 7 \\
Whistling & 17 & 28 & 5 \\
Calling you babe, honey, sweetheart or something similar & 16 & 28 & 2 \\
Unwanted sexual teasing, remarks & 13 & 21 & 3 \\
Stalking (a stranger following you) & 10 & 14 & 6 \\
Indecent exposure & 10 & 11 & 8 \\
Making kissing sounds & 8 & 14 & 3 \\
Asking you questions of sexual nature & 7 & 12 & 3 \\
Groping, touching inappropriately & 4 & 5 & 3 \\
Showing pornographic images & 4 & 3 & 5 \\
Asked to have sex by a stranger & 4 & 6 & 2 \\
Masturbating in public & 3 & 4 & 3 \\
Pulling or playing with your hair & 3 & 3 & 3 \\
Unwanted kissing by a stranger & 2 & 3 & 2 \\
Other & 1 & 2 & 1 \\
\hline
\end{tabular}

Note: $\mathrm{N}$-values are as follows: $\mathrm{N}=472$ for all respondents, $\mathrm{N}=229$ for female bus riders, and $\mathrm{N}=212$ for male bus riders.

10. Do you take any precautions against crime when using public buses?

\begin{tabular}{lccc}
\hline & All respondents (\%) & Female (\%) & Male (\%) \\
\hline Yes & 46 & 60 & 29 \\
No (go to question 12) & 15 & 15 & 14 \\
\hline
\end{tabular}

Note: $\mathrm{N}$-values are as follows: $\mathrm{N}=472$ for all respondents, $\mathrm{N}=229$ for female bus riders, and $\mathrm{N}=212$ for male bus riders. 


\section{Which of the following precautions do you take? Mark all that apply.} (Order of response options was randomized, up to "other.")

\begin{tabular}{lccc}
\hline Precautions taken & All respondents (\%) & Female (\%) & Male (\%) \\
\hline Travel only during daytime & 24 & 37 & 12 \\
Wait for transit only at well-lit places & 24 & 35 & 13 \\
Dress a certain way & 21 & 31 & 9 \\
Hold keys so that I can use them to protect myself if attacked & 20 & 33 & 5 \\
Avoid particular bus stops & 18 & 23 & 14 \\
Carry a self-defense spray & 18 & 31 & 4 \\
Sit close to the driver & 17 & 26 & 6 \\
Do not wear jewelry & 15 & 22 & 9 \\
Wait for transit only if other people are around & 14 & 19 & 8 \\
Always travel with someone else & 12 & 16 & 8 \\
Avoid carrying purses, wallets & 12 & 21 & 3 \\
Avoid particular bus lines & 8 & 10 & 5 \\
Carry a weapon (e.g. gun or knife) & 7 & 7 & 7 \\
Other & 4 & 7 & 2 \\
\hline
\end{tabular}

Note: $\mathrm{N}$-values are as follows: $\mathrm{N}=472$ for all respondents, $\mathrm{N}=229$ for female bus riders, and $\mathrm{N}=212$ for male bus riders.

12. In your view, what can make travelling by bus safer? Choose the three most important options from the following list.

\begin{tabular}{lccc}
\hline Recommendations using a public bus & All respondents (\%) & Female (\%) & Male (\%) \\
\hline Cameras at bus stops & 43 & 46 & 41 \\
More lighting at bus stops & 41 & 40 & 42 \\
Police patrolling bus stops & 36 & 39 & 33 \\
Phone app or other source of real-time information about when & 32 & 35 & 27 \\
buses will arrive & 30 & 29 & 33 \\
Cameras on the bus & 25 & 24 & 26 \\
Direct phone line to police at bus stop & 23 & 25 & 19 \\
More police officers patrolling buses & 21 & 17 & 25 \\
Digital timetable at bus stops & 15 & 15 & 15 \\
Direct phone line to police on the bus & 9 & 13 & 2 \\
Women-only buses & 4 & 3 & 4 \\
Other & & & 25 \\
\hline
\end{tabular}

Note: $\mathrm{N}$-values are as follows: $\mathrm{N}=472$ for all respondents, $\mathrm{N}=229$ for female bus riders, and $\mathrm{N}=212$ for male bus riders. 


\section{TRAVEL BY TRAIN (for example, VTA light rail, BART, or ACE)}

13. On a typical week, how often do you ride a train, such as VTA light rail, BART, or ACE?

\begin{tabular}{lccc}
\hline Days per week riding a public bus & All respondents (\%) & Female (\%) & Male (\%) \\
\hline 7 & 3 & 2 & 4 \\
$5-6$ & 6 & 4 & 6 \\
$3-4$ & 10 & 12 & 9 \\
$1-2$ & 10 & 11 & 8 \\
Less than once per week & 18 & 17 & 19 \\
Never & 54 & 54 & 54 \\
\hline
\end{tabular}

Note: $\mathrm{N}$-values are as follows: $\mathrm{N}=891$ for all respondents, $\mathrm{N}=437$ for female riders, and $\mathrm{N}=403$ for male riders.

14. During daytime, do you feel safe riding the train?

\begin{tabular}{lccc}
\hline Feeling safe riding a public train & All respondents (\%) & Female (\%) & Male (\%) \\
\hline Always & 30 & 25 & 37 \\
Often & 46 & 44 & 46 \\
Sometimes & 19 & 24 & 14 \\
Rarely & 3 & 4 & 2 \\
Never & 2 & 2 & 2 \\
\hline
\end{tabular}

Note: $\mathrm{N}$-values are as follows: $\mathrm{N}=410$ for all respondents, $\mathrm{N}=200$ for female train riders, and $\mathrm{N}=186$ for male train riders.

15. During daytime, do you feel safe waiting on the train platform?

\begin{tabular}{lccc}
\hline Feeling safe riding a public train & All respondents (\%) & Female (\%) & Male (\%) \\
\hline Always & 28 & 23 & 34 \\
Often & 45 & 44 & 45 \\
Sometimes & 22 & 26 & 18 \\
Rarely & 3 & 4 & 1 \\
Never & 2 & 2 & 2 \\
\hline
\end{tabular}

Note: $\mathrm{N}$-values are as follows: $\mathrm{N}=410$ for all respondents, $\mathrm{N}=200$ for female train riders, and $\mathrm{N}=186$ for male train riders.

16. After dark, do you feel safe riding the train?

\begin{tabular}{lccc}
\hline Feeling safe riding a public bus & All respondents (\%) & Female (\%) & Male (\%) \\
\hline Always & 7 & 2 & 13 \\
Often & 18 & 10 & 27 \\
Sometimes & 32 & 27 & 34 \\
Rarely & 18 & 25 & 12 \\
Never & 9 & 14 & 3 \\
I don't use the train after dark & 16 & 23 & 10 \\
\hline
\end{tabular}

Note: $\mathrm{N}$-values are as follows: $\mathrm{N}=410$ for all respondents, $\mathrm{N}=200$ for female train riders, and $\mathrm{N}=186$ for male train riders. 
17. After dark, do you feel safe walking to or waiting on the train platform?

\begin{tabular}{lccc}
\hline Feeling safe riding a public bus & All respondents (\%) & Female (\%) & Male (\%) \\
\hline Always & 6 & 0 & 12 \\
Often & 14 & 7 & 22 \\
Sometimes & 30 & 25 & 34 \\
Rarely & 20 & 24 & 16 \\
Never & 10 & 17 & 3 \\
I don't use the train after dark & 3 & 4 & 3 \\
\hline
\end{tabular}

Note: $\mathrm{N}$-values are as follows: $\mathrm{N}=410$ for all respondents, $\mathrm{N}=200$ for female train riders, and $\mathrm{N}=186$ for male train riders.

18. Which of the following prevent you from using the train more often? Mark all that apply. (Order of response options was randomized, up to "other.")

\begin{tabular}{lccc}
\hline Factor preventing train use & All respondents (\%) & Female (\%) & Male (\%) \\
\hline Fear of antisocial behavior of others (such as drinking, cursing, & 40 & 44 & 38 \\
smelling badly, etc.) & & 34 & 28 \\
Slow journey times & 30 & 38 & 19 \\
Fear of victimization waiting on the platform & 29 & 39 & 16 \\
Fear of victimization while on the train & 28 & 29 & 25 \\
Dirty environment on the train (trash, graffiti) & 27 & 38 & 13 \\
Fear of victimization walking to the station & 26 & 39 & 6 \\
Fear of sexual harassment on the train & 23 & 24 & 19 \\
Dirty environment during the walk to the train station & 22 & 21 & 22 \\
Overcrowded trains & 21 & 18 & 19 \\
Cost of tickets & 18 & 14 & 17 \\
Unreliable service & 16 & 14 & 16 \\
Lack of information about metro schedules & 16 & 10 & 12 \\
Many transfers & 11 & 12 & 6 \\
Fear of accidents & 10 & 11 & 6 \\
Fear of terrorist attack & 9 & 5 & 6 \\
Other & 6 & 2 & 6 \\
Don't understand how to buy train fare & 5 & 2 & \\
\hline
\end{tabular}

Note: $\mathrm{N}$-values are as follows: $\mathrm{N}=410$ for all respondents, $\mathrm{N}=200$ for female train riders, and $\mathrm{N}=186$ for male train riders. 
19a. Which of the following do you perceive as being a significant problem on the train? Mark all that apply. (Order of response options was randomized, up to "other.")

\begin{tabular}{lccc}
\hline Problems & All respondents (\%) & Female (\%) & Male (\%) \\
\hline Drunk people & 47 & 53 & 41 \\
Obscene language & 39 & 42 & 35 \\
Vandalism, litter & 33 & 34 & 33 \\
Verbal/physical threats & 31 & 34 & 28 \\
Poorly guarded/empty most of the day & 28 & 31 & 26 \\
Sexual harassment & 28 & 38 & 17 \\
Robbery & 21 & 21 & 20 \\
Panhandling & 19 & 18 & 17 \\
Pickpocketing & 19 & 19 & 19 \\
Drug use/sales & 18 & 16 & 19 \\
Violent crime (aggravated assault, murder) & 17 & 16 & 16 \\
Jewelry snatching & 15 & 15 & 15 \\
Poorly designed & 13 & 12 & 13 \\
Poorly illuminated & 9 & 8 & 9 \\
Other & 1 & 2 & 0 \\
\hline
\end{tabular}

Note: $\mathrm{N}$-values are as follows: $\mathrm{N}=410$ for all respondents, $\mathrm{N}=200$ for female train riders, and $\mathrm{N}=186$ for male train riders.

19b. Which of the following do you perceive as being a significant problem at the platform? Mark all that apply. (Order of response options was randomized, up to "other.")

\begin{tabular}{lccc}
\hline Problems & All respondents (\%) & Female (\%) & Male (\%) \\
\hline Drunk people & 48 & 54 & 42 \\
Poorly guarded/empty most of the day & 40 & 47 & 33 \\
Vandalism, litter & 39 & 38 & 39 \\
Obscene language & 35 & 40 & 30 \\
Verbal/physical threats & 34 & 38 & 30 \\
Panhandling & 29 & 26 & 30 \\
Sexual harassment & 28 & 34 & 21 \\
Drug use/sales & 27 & 26 & 26 \\
Robbery & 27 & 30 & 24 \\
Violent crime (aggravated assault, murder) & 24 & 26 & 20 \\
Pickpocketing & 23 & 22 & 23 \\
Poorly illuminated & 22 & 24 & 20 \\
Jewelry snatching & 20 & 20 & 18 \\
Poorly designed & 18 & 16 & 20 \\
Other & 0 & 1 & 0 \\
\hline Note:NValus
\end{tabular}

Note: $\mathrm{N}$-values are as follows: $\mathrm{N}=410$ for all respondents, $\mathrm{N}=200$ for female train riders, and $\mathrm{N}=186$ for male train riders. 
20a. In the last 3 years, have you experienced any of the following while riding on the train, heading to/from the station, or waiting at a platform? Mark all that apply. (Order of response options was randomized, up to "other.")

\begin{tabular}{lccc}
\hline Type of harassment & All respondents (\%) & Female (\%) & Male (\%) \\
\hline Using obscene/abusive language & 21 & 26 & 16 \\
Unwanted sexual looks or gestures & 12 & 19 & 3 \\
Calling you babe, honey, sweetheart or something similar & 12 & 20 & 3 \\
Whistling & 10 & 14 & 5 \\
Sexual comments (about clothing, looks) & 9 & 15 & 3 \\
Unwanted sexual teasing, remarks & 8 & 10 & 5 \\
Indecent exposure & 7 & 7 & 6 \\
Asking you questions of sexual nature & 7 & 10 & 4 \\
Stalking (a stranger following you) & 6 & 6 & 3 \\
Masturbating in public & 5 & 5 & 5 \\
Making kissing sounds & 5 & 7 & 3 \\
Groping, touching inappropriately & 4 & 4 & 3 \\
Showing pornographic images & 4 & 4 & 4 \\
Asked to have sex by a stranger & 3 & 4 & 2 \\
Pulling or playing with your hair & 3 & 3 & 2 \\
Unwanted kissing by a stranger & 2 & 2 & 1 \\
\hline
\end{tabular}

Note: $\mathrm{N}$-values are as follows: $\mathrm{N}=410$ for all respondents, $\mathrm{N}=200$ for female train riders, and $\mathrm{N}=186$ for male train riders.

$20 \mathrm{~b}$. In the last 3 years, have you experienced any of the following while riding on the train, heading to/from the station, or waiting at a platform? Mark all that apply. (Order of response options was randomized, up to "other.")

\begin{tabular}{lccc}
\hline Type of harassment & All respondents (\%) & Female (\%) & Male (\%) \\
\hline Using obscene/abusive language & 17 & 19 & 13 \\
Calling you babe, honey, sweetheart or something similar & 13 & 21 & 3 \\
Whistling & 13 & 21 & 4 \\
Stalking (a stranger following you) & 12 & 14 & 9 \\
Unwanted sexual looks or gestures & 12 & 18 & 3 \\
Unwanted sexual teasing, remarks & 11 & 17 & 4 \\
Sexual comments (about clothing, looks) & 10 & 14 & 3 \\
Asking you questions of sexual nature & 7 & 8 & 4 \\
Making kissing sounds & 7 & 12 & 2 \\
Indecent exposure & 6 & 8 & 3 \\
Masturbating in public & 5 & 6 & 2 \\
Groping, touching inappropriately & 4 & 4 & 3 \\
Asked to have sex by a stranger & 4 & 6 & 3 \\
Showing pornographic images & 3 & 3 & 4 \\
Unwanted kissing by a stranger & 3 & 2 & 2 \\
Pulling or playing with your hair & 3 & 2 & 2 \\
\hline
\end{tabular}

Note: $\mathrm{N}$-values are as follows: $\mathrm{N}=410$ for all respondents, $\mathrm{N}=200$ for female train riders, and $\mathrm{N}=186$ for male train riders. 
20c. In the last 3 years, have you experienced any of the following while riding on the train, heading to/from the station, or waiting at a platform? Mark all that apply. (Order of response options was randomized, up to "other.")

\begin{tabular}{lccc}
\hline Type of harassment & All respondents (\%) & Female (\%) & Male (\%) \\
\hline Using obscene/abusive language & 20 & 22 & 17 \\
Calling you babe, honey, sweetheart or something similar & 13 & 22 & 3 \\
Unwanted sexual looks or gestures & 12 & 16 & 4 \\
Whistling & 12 & 18 & 6 \\
Sexual comments (about clothing, looks) & 10 & 14 & 4 \\
Stalking (a stranger following you) & 9 & 10 & 6 \\
Unwanted sexual teasing, remarks & 8 & 12 & 3 \\
Indecent exposure & 7 & 8 & 5 \\
Asking you questions of sexual nature & 7 & 9 & 3 \\
Making kissing sounds & 6 & 8 & 2 \\
Masturbating in public & 5 & 6 & 3 \\
Groping, touching inappropriately & 4 & 4 & 3 \\
Showing pornographic images & 4 & 4 & 4 \\
Asked to have sex by a stranger & 4 & 5 & 2 \\
Unwanted kissing by a stranger & 3 & 4 & 3 \\
Pulling or playing with your hair & 3 & 2 & 3 \\
\hline
\end{tabular}

Note: $\mathrm{N}$-values are as follows: $\mathrm{N}=410$ for all respondents, $\mathrm{N}=200$ for female train riders, and $\mathrm{N}=186$ for male train riders.

21. Do you feel it necessary to take any precautions against crime when using the train?

\begin{tabular}{lccc}
\hline Precautions taken & All respondents (\%) & Female (\%) & Male (\%) \\
\hline Yes & 38 & 50 & 26 \\
No (go to question 23) & 7 & 6 & 8 \\
\hline
\end{tabular}

Note: $\mathrm{N}$-values are as follows: $\mathrm{N}=410$ for all respondents, $\mathrm{N}=200$ for female train riders, and $\mathrm{N}=186$ for male train riders. 
22. Which of the following precautions do you take? Mark all that apply. (Order of response options was randomized, up to "other.")

\begin{tabular}{lccc}
\hline Precautions taken & All respondents (\%) & Female (\%) & Male (\%) \\
\hline Travelling only during daytime & 20 & 29 & 12 \\
Wait for transit in well-lit places & 20 & 28 & 12 \\
Dress a certain way & 19 & 27 & 10 \\
Hold keys so I can use them to protect myself if attacked & 17 & 26 & 9 \\
Carry a self-defense spray & 16 & 25 & 6 \\
Wait for transit only if other people are around & 14 & 20 & 9 \\
Avoid carrying purses, wallets & 12 & 18 & 7 \\
Always travel with someone else & 11 & 16 & 8 \\
Avoid particular bus stations & 11 & 15 & 8 \\
Not wearing jewelry & 11 & 14 & 8 \\
Sit close to the driver & 10 & 14 & 6 \\
Carry some kind of weapon & 8 & 9 & 7 \\
Avoid particular bus lines & 6 & 10 & 3 \\
Other & 1 & 2 & 0 \\
\hline
\end{tabular}

Note: $\mathrm{N}$-values are as follows: $\mathrm{N}=410$ for all respondents, $\mathrm{N}=200$ for female train riders, and $\mathrm{N}=186$ for male train riders.

23. Of the items listed below, select the three most important things that, in your view, can make travelling by train safer. (Order of response options was randomized, up to "other.")

\begin{tabular}{lccc}
\hline Safety recommendations & All respondents (\%) & Female (\%) & Male (\%) \\
\hline Police patrolling platforms & 46 & 50 & 43 \\
Cameras (CCTV) at platforms & 46 & 47 & 46 \\
More police officers patrolling train vehicles & 40 & 40 & 41 \\
Cameras (CCTV) inside train vehicles & 38 & 40 & 37 \\
More lighting at platforms & 31 & 30 & 32 \\
Direct police line in each wagon & 25 & 25 & 25 \\
Direct police line at platform & 24 & 25 & 24 \\
Digital timetable at platforms & 19 & 16 & 22 \\
"Women only" wagons & 10 & 14 & 6 \\
Other & 2 & 2 & 3 \\
\hline
\end{tabular}

Note: $\mathrm{N}$-values are as follows: $\mathrm{N}=410$ for all respondents, $\mathrm{N}=200$ for female train riders, and $\mathrm{N}=186$ for male train riders. 


\section{CRIME REPORTING}

24. If you have been a victim of sexual assault, harassment, or other crime while riding the bus/train, at the bus/train stop, or on your way to/from the transit stop, have you reported it to anyone?

\begin{tabular}{lccc}
\hline & All respondents (\%) & Female (\%) & Male (\%) \\
\hline Yes (go to question 25) & 5 & 6 & 3 \\
No (go to question 26) & 16 & 24 & 6 \\
I have not been a victim of sexual assault or harassment in & 78 & 70 & 90 \\
a transit environment (go to question 29) & &
\end{tabular}

Note: $\mathrm{N}$-values are as follows: $\mathrm{N}=891$ for all respondents, $\mathrm{N}=437$ for female riders, and $\mathrm{N}=403$ for male riders.

25. Question asked only of people who replied "yes" to Question 24: To whom have you reported the sexual assault, harassment, or other crime? Mark all that apply.

\begin{tabular}{lccc}
\hline Person to whom victim reported the crime & All respondents $(\%)$ & Female (\%) & Male (\%) \\
\hline Friends & 16 & 15 & 16 \\
Police & 11 & 10 & 16 \\
Parents & 10 & 9 & 16 \\
Bus driver & 7 & 7 & 13 \\
Train operator & 6 & 6 & 8 \\
Transit agency & 5 & 5 & 8 \\
Spouse & 5 & 5 & 8 \\
Other family members & 5 & 5 & 5 \\
San José State University & 5 & 5 & 8 \\
Other (please explain) & 1 & 1 & 3 \\
Bus/trolley company & 0 & 0 & 0 \\
\hline
\end{tabular}

Note: $\mathrm{N}$-values are as follows: $\mathrm{N}=190$ for all victims, $\mathrm{N}=132$ for female victims, and $\mathrm{N}=38$ for male victims.

26. Question asked only of people who replied "no" to Question 24: Why did you not report the sexual assault, harassment, or other crime? Mark all that apply.

\begin{tabular}{lccc}
\hline Reason & All (\%) & Female (\%) & Male (\%) \\
\hline I did not think the crime was serious & 42 & 48 & 32 \\
To avoid more trouble & 32 & 32 & 29 \\
I did not believe that they will catch the criminal & 27 & 30 & 18 \\
I did not wish to remember this & 17 & 17 & 16 \\
I was embarrassed & 12 & 13 & 5 \\
Other (please explain) & 6 & 5 & 13 \\
I was afraid of the police & 4 & 4 & 5 \\
\hline
\end{tabular}

Note: $\mathrm{N}$-values are as follows: $\mathrm{N}=190$ for all victims, $\mathrm{N}=132$ for female victims, and $\mathrm{N}=38$ for male victims. 
27. Did anyone witness that sexual assault, harassment, or other crime?

\begin{tabular}{lccc}
\hline Witness & All (\%) & Female (\%) & Male (\%) \\
\hline Yes (go to question 28) & 25 & 26 & 29 \\
No (go to question 29) & 23 & 24 & 16 \\
I'm unsure & 48 & 48 & 53 \\
\hline
\end{tabular}

Note: $\mathrm{N}$-values are as follows: $\mathrm{N}=190$ for all victims, $\mathrm{N}=132$ for female victims, and $\mathrm{N}=38$ for male victims.

28. What was the reaction of other people witnessing that sexual assault, harassment, or other crime?

\begin{tabular}{lccc}
\hline Reactions & All (\%) & Female (\%) & Male (\%) \\
\hline They pretended not seeing what was happening & 38 & 35 & 27 \\
They watched at a distance what was happening & 19 & 21 & 18 \\
They talked to the offender & 15 & 15 & 18 \\
Other (please explain) & 15 & 12 & 27 \\
They came forward and talked to me & 13 & 15 & 9 \\
They came forward but did not say anything & 2 & 3 & 0 \\
\hline
\end{tabular}

Note: $\mathrm{N}$-values are as follows: $\mathrm{N}=190$ for all victims, $\mathrm{N}=132$ for female victims, and $\mathrm{N}=38$ for male victims.

29. In the last 3 years have seen other serious crimes (aggravated assault, robbery, rape) while on the bus or train, at the bus or train stop/platform, or while heading to/from a transit stop?

\begin{tabular}{lccc}
\hline & All respondents (\%) & Female (\%) & Male (\%) \\
\hline No (go to question \#31) & 88 & 88 & 89 \\
Yes (please explain) & 11 & 11 & 9 \\
\hline
\end{tabular}

Note: $\mathrm{N}$-values are as follows: $\mathrm{N}=891$ for all respondents, $\mathrm{N}=437$ for female riders, and $\mathrm{N}=403$ for male riders.

31. (Asked of people who answered "no" in Q29) Have you reported the serious crime(s) you saw? Mark all that apply.

\begin{tabular}{lccc}
\hline & All respondents (\%) & Female (\%) & Male (\%) \\
\hline No & 57 & 60 & 52 \\
Yes, to: & & & \\
Family or friends & 20 & 26 & 9 \\
Bus driver & 17 & 17 & 18 \\
Police & 15 & 21 & 9 \\
Transit company & 12 & 6 & 18 \\
Other & 10 & 11 & 9 \\
Train operator & 0 & 0 & 0 \\
\hline
\end{tabular}

Note: $\mathrm{N}$-values are as follows: $\mathrm{N}=86$ for all respondents, $\mathrm{N}=47$ for female riders, and $\mathrm{N}=33$ for male riders who responded to this question. 
32. In the last 3 years, have you seen theft/pickpocketing, jewelry snatching, or robbery while on the bus or train, at the bus or train stop, or while heading to or from a transit stop?

\begin{tabular}{lccc}
\hline & All respondents (\%) & Female (\%) & Male (\%) \\
\hline No & 93 & 96 & 93 \\
Yes (please explain) & 4 & 4 & 5 \\
\hline
\end{tabular}

Note: $\mathrm{N}$-values are as follows: $\mathrm{N}=891$ for all respondents, $\mathrm{N}=437$ for female riders, and $\mathrm{N}=403$ for male riders.

33. Have you reported the crime(s) you saw? Mark all that apply.

\begin{tabular}{lccc}
\hline & All respondents (\%) & Female (\%) & Male (\%) \\
\hline No & 48 & 53 & 43 \\
Yes, to: & & & \\
Other & 23 & 24 & 17 \\
Bus driver & 20 & 29 & 26 \\
Train operator & 18 & 12 & 22 \\
Transit company & 18 & 18 & 9 \\
Family or friends & 9 & 12 & \\
\hline
\end{tabular}

Note: $\mathrm{N}$-values are as follows: $\mathrm{N}=44$ for all respondents, $\mathrm{N}=17$ for female riders, and $\mathrm{N}=23$ for male riders who responded to this question.

34. In the last 3 years, has someone you know seen serious crime (aggravated assault, robbery, rape, murder) while on the bus/train, at the bus/train stop, or while heading to/ from a transit stop?

\begin{tabular}{lccc}
\hline Crime reporting & All respondents (\%) & Female (\%) & Male (\%) \\
\hline No & 91 & 92 & 93 \\
Yes (please explain) & 6 & 6 & 5 \\
\hline
\end{tabular}

Note: $\mathrm{N}$-values are as follows: $\mathrm{N}=891$ for all respondents, $\mathrm{N}=437$ for female riders, and $\mathrm{N}=403$ for male riders.

\section{PRIVATE TRANSPORTATION}

35. How often do you use a traditional taxi service (not Lyft or Uber)?

\begin{tabular}{lccc}
\hline Frequency & All respondents (\%) & Female (\%) & Male (\%) \\
\hline At least once a week & 3 & 4 & 2 \\
A few times per month & 6 & 5 & 6 \\
A few times per year & 12 & 11 & 13 \\
Never (go to question \# 37) & 78 & 79 & 79 \\
\hline
\end{tabular}

Note: $\mathrm{N}$-values are as follows: $\mathrm{N}=891$ for all respondents, $\mathrm{N}=437$ for female riders, and $\mathrm{N}=403$ for male riders. 


\section{Do you feel safe when using a taxi service?}

\begin{tabular}{lccc}
\hline Taxi safety & All respondents (\%) & Female (\%) & Male (\%) \\
\hline Always & 20 & 16 & 28 \\
Often & 35 & 32 & 36 \\
Sometimes & 36 & 43 & 30 \\
Rarely & 5 & 7 & 1 \\
Never & 5 & 5 & 5 \\
\hline
\end{tabular}

Note: $\mathrm{N}$-values are as follows: $\mathrm{N}=182$ for all respondents, $\mathrm{N}=87$ for female taxi riders, and $\mathrm{N}=83$ for male taxi riders.

37. How often do you use ride-hailing services such as Lyft and Uber?

\begin{tabular}{lccc}
\hline Ride-hailing frequency & All respondents (\%) & Female (\%) & Male (\%) \\
\hline At least once a week & 12 & 14 & 9 \\
A few times per month & 25 & 26 & 26 \\
A few times per year & 34 & 35 & 34 \\
Never (go to question \# 39) & 26 & 23 & 30 \\
\hline
\end{tabular}

Note: $\mathrm{N}$-values are as follows: $\mathrm{N}=891$ for all respondents, $\mathrm{N}=437$ for female riders, and $\mathrm{N}=403$ for male riders.

38. Do you feel safe when using a ride-hailing service?

\begin{tabular}{lccc}
\hline Ride-hailing safety & All respondents (\%) & Female (\%) & Male (\%) \\
\hline Always & 21 & 12 & 32 \\
Often & 49 & 47 & 51 \\
Sometimes & 26 & 36 & 15 \\
Rarely & 3 & 5 & 1 \\
Never & 1 & 1 & 1 \\
\hline
\end{tabular}

Note: $\mathrm{N}$-values are as follows: $\mathrm{N}=641$ for all respondents, $\mathrm{N}=331$ for female ride-hailing users, and $\mathrm{N}=278$ for male ride-hailing users. 
39. How often do you travel by private vehicle, either as the driver or as a passenger? Think of trips you take with family members, friends, colleagues, etc. Do not include trips where you pay, such as a taxi or ride-sharing trip.)

\begin{tabular}{lccc}
\hline Frequency per week & All respondents (\%) & Female (\%) & Male (\%) \\
\hline As the driver & 32 & 33 & 33 \\
7 days & 21 & 22 & 22 \\
$5-6$ days & 14 & 13 & 13 \\
$3-4$ days & 11 & 11 & 11 \\
$1-2$ days & 7 & 7 & 7 \\
Less than once & 10 & 7 & 7 \\
Never & & & \\
As the passenger & 12 & 13 & 11 \\
7 days & 13 & 13 & 17 \\
$5-6$ days & 20 & 22 & 27 \\
$3-4$ days & 28 & 29 & 23 \\
$1-2$ days & 21 & 20 & 12 \\
Less than once & 11 & 11 & \\
Never & & & 13 \\
\hline
\end{tabular}

Note: $\mathrm{N}$-values are as follows: $\mathrm{N}=891$ for all respondents, $\mathrm{N}=437$ for female riders, and $\mathrm{N}=403$ for male riders.

40. Do you feel safe in parking structures (garages/car parks)?

\begin{tabular}{lccc}
\hline Feeling of safety & All respondents (\%) & Female (\%) & Male (\%) \\
\hline Always & 9 & 4 & 15 \\
Often & 33 & 27 & 42 \\
Sometimes & 41 & 50 & 32 \\
Rarely & 10 & 13 & 6 \\
Never & 5 & 6 & 3 \\
\hline
\end{tabular}

Note: $\mathrm{N}$-values are as follows: $\mathrm{N}=891$ for all respondents, $\mathrm{N}=437$ for female riders, and $\mathrm{N}=403$ for male riders.

41. How often in a week do you use a bike?

\begin{tabular}{lccc}
\hline Frequency per week & All respondents (\%) & Female (\%) & Male (\%) \\
\hline Every day & 1 & 0 & 2 \\
$5-6$ days per week & 1 & 1 & 1 \\
3 - 4 days per week & 2 & 0 & 4 \\
1 - days per week & 3 & 2 & 5 \\
Less than once per week & 9 & 9 & 9 \\
Never (go to question \#43) & 36 & 37 & 37 \\
I don't own a bike (go to question \#43) & 45 & 50 & 42 \\
\hline
\end{tabular}

Note: $\mathrm{N}$-values are as follows: $\mathrm{N}=891$ for all respondents, $\mathrm{N}=437$ for female riders, and $\mathrm{N}=403$ for male riders. 
42. When you use a bike, do you fear being a victim of assault, harassment, or crime?

\begin{tabular}{lccc}
\hline & All respondents (\%) & Female (\%) & Male (\%) \\
\hline Always & 3 & 2 & 4 \\
Often & 4 & 5 & 2 \\
Sometimes & 23 & 27 & 19 \\
Rarely & 40 & 45 & 41 \\
Never & 28 & 20 & 34 \\
\hline
\end{tabular}

Note: $\mathrm{N}$-values are as follows: $\mathrm{N}=149$ for all respondents, $\mathrm{N}=55$ for female bike riders, and $\mathrm{N}=85$ for male bike riders.

43. Which of the following prevents you from using a bike more often? Mark all that apply.

\begin{tabular}{lccc}
\hline Concerns & All respondents $(\%)$ & Female $(\%)$ & Male $(\%)$ \\
\hline Fear that the bike will get stolen & 49 & 48 & 52 \\
Fear of traffic collision & 46 & 55 & 39 \\
Other & 29 & 25 & 34 \\
Fear of being harassed & 13 & 20 & 7 \\
\hline
\end{tabular}

Note: $\mathrm{N}$-values are as follows: $\mathrm{N}=891$ for all respondents, $\mathrm{N}=437$ for female riders, and $\mathrm{N}=403$ for male riders.

44. What is your gender?

\begin{tabular}{lccc}
\hline & All respondents (\%) & Female (\%) & Male (\%) \\
\hline Female & 51 & NA & NA \\
Male & 47 & NA & NA \\
Transgender & 0 & NA & NA \\
Other & 0 & NA & NA \\
Prefer not to say & 2 & NA & NA \\
\hline
\end{tabular}

Note: $\mathrm{N}$-values are as follows: $\mathrm{N}=864$ for all respondents, $\mathrm{N}=437$ for female riders, and $\mathrm{N}=403$ for male riders.

45. Are you LGBTQI (Lesbian/Gay/Bisexual/Transgender/Queer/Intersex)?

\begin{tabular}{lccc}
\hline & All respondents (\%) & Female (\%) & Male (\%) \\
\hline Yes & 9 & 10 & 7 \\
No & 87 & 88 & 93 \\
Prefer not to say & 5 & 4 & 3 \\
\hline
\end{tabular}

Note: $\mathrm{N}$-values are as follows: $\mathrm{N}=858$ for all respondents, $\mathrm{N}=428$ for female riders, and $\mathrm{N}=388$ for male riders. 
46. What is your race/ethnicity? Mark all that apply.

\begin{tabular}{lccc}
\hline & All respondents (\%) & Female (\%) & Male (\%) \\
\hline American Indian or Alaska Native & 0 & 1 & 0 \\
Asian or Asian-American & 45 & 43 & 49 \\
Black or African-American & 3 & 3 & 2 \\
Hispanic, Latino/a, or of Spanish origin & 20 & 23 & 18 \\
Native Hawaiian or Pacific Islander & 1 & 1 & 2 \\
White & 18 & 18 & 19 \\
Multiple & 7 & 1 & 0 \\
\hline
\end{tabular}

Note: $\mathrm{N}=852$ for Hispanic ethnicity and $\mathrm{N}=673$ for the race categories.

47. What is your age?

\begin{tabular}{lccc}
\hline Years & All respondents $(\%)$ & Female (\%) & Male (\%) \\
\hline $18-29$ & 85 & 86 & 89 \\
$30-39$ & 9 & 9 & 8 \\
$40-49$ & 2 & 3 & 2 \\
$50-59$ & 1 & 1 & 1 \\
$60+$ & 0 & 0 & 0 \\
\hline
\end{tabular}

Note: $\mathrm{N}$-values are as follows: $\mathrm{N}=891$ for all respondents, $\mathrm{N}=437$ for female riders, and $\mathrm{N}=403$ for male riders. 


\section{APPENDIX B: DATA TABLES FROM THE STATISTICAL SIGNIFICANCE TESTS}

This appendix presents the percentage and p-values for the test of two proportions used to test for statistically significant differences between women vs. men, and riders who reported that they had been harassed vs. those who had not been harassed.

DO STUDENTS FEEL UNSAFE RIDING TRANSIT, AND WHY?

Table 12. Percentage of Women vs. Men Feeling Always or Often Safe Riding Bus and Rail

\begin{tabular}{lcccccccc}
\hline & \multicolumn{4}{c}{ Bus } & & \multicolumn{3}{c}{ Train } \\
\cline { 2 - 3 } & Female (\%) & Male (\%) & P-values & & Female (\%) & Male (\%) & P-values \\
\hline Riding: Day & 65 & 84 & $\mathbf{0 . 0 0 0}$ & & 70 & 83 & $\mathbf{0 . 0 0 3}$ \\
Waiting: Day & 55 & 77 & $\mathbf{0 . 0 0 0}$ & & 68 & 79 & $\mathbf{0 . 0 1 5}$ \\
Riding: Night & 7 & 30 & $\mathbf{0 . 0 0 0}$ & & 12 & 40 & $\mathbf{0 . 0 0 0}$ \\
Waiting: Night & 7 & 27 & $\mathbf{0 . 0 0 0}$ & & 7 & 34 & $\mathbf{0 . 0 0 0}$ \\
\hline
\end{tabular}

Note: There were 472 bus riders ( 229 female and 212 male) and 410 rail riders ( 200 female and 186 male). Values in bold are statistically significant at $p<0.05$.

Table 13. Onboard Safety Concerns Identified by Female vs. Male Bus and Train Riders

\begin{tabular}{|c|c|c|c|c|c|c|}
\hline & \multicolumn{3}{|c|}{ Onboard the bus } & \multicolumn{3}{|c|}{ Onboard the train } \\
\hline & Women (\%) & Men (\%) & P-values & Women (\%) & Men (\%) & P-values \\
\hline \multicolumn{7}{|l|}{ Behavioral } \\
\hline Obscene language & 48 & 43 & 0.14 & 42 & 35 & 0.08 \\
\hline Drunk people & 46 & 46 & 0.50 & 53 & 41 & 0.01 \\
\hline Verbal/physical threats & 42 & 32 & 0.01 & 34 & 28 & 0.10 \\
\hline Sexual harassment & 38 & 18 & 0.00 & 38 & 17 & 0.00 \\
\hline Pickpocketing & 28 & 23 & 0.11 & 19 & 19 & 0.50 \\
\hline Robbery & 28 & 21 & 0.04 & 21 & 20 & 0.40 \\
\hline Drug use/sales & 19 & 20 & 0.39 & 16 & 19 & 0.22 \\
\hline Violent crime & 21 & 17 & 0.14 & 16 & 16 & 0.50 \\
\hline Panhandling & 15 & 17 & 0.28 & 18 & 17 & 0.40 \\
\hline Jewelry snatching & 18 & 15 & 0.20 & 15 & 15 & 0.50 \\
\hline \multicolumn{7}{|l|}{ Environmental } \\
\hline Vandalism, litter & 38 & 37 & 0.41 & 34 & 33 & 0.42 \\
\hline Poorly designed & 23 & 13 & 0.00 & 12 & 13 & 0.38 \\
\hline Poorly guarded/empty & 18 & 17 & 0.39 & 31 & 26 & 0.14 \\
\hline Poorly illuminated & 18 & 12 & 0.04 & 8 & 9 & 0.36 \\
\hline Other & 2 & 1 & 0.19 & 2 & 0 & 0.02 \\
\hline
\end{tabular}

Note: There were 472 bus riders (229 female and 212 male) and 410 rail riders (200 female and 186 male). Values in bold are statistically significant at $p<0.05$. 
Table 14. Safety Concerns Identified by Bus Riders Who Had vs. Had Not Been Harassed

\begin{tabular}{lcccccc}
\hline & \multicolumn{3}{c}{ Onboard } & \multicolumn{3}{c}{ At the stop } \\
\cline { 2 - 7 } & $\begin{array}{c}\text { Harassed } \\
(\%)\end{array}$ & $\begin{array}{c}\text { Not harassed } \\
(\%)\end{array}$ & $\begin{array}{c}\text { P-values } \\
\text { Poorly illuminated }\end{array}$ & $\begin{array}{c}\text { Harassed } \\
(\%)\end{array}$ & $\begin{array}{c}\text { Not harassed } \\
(\%)\end{array}$ & P-values \\
\hline Poorly designed & 12 & 12 & 0.081 & 62 & 35 & $\mathbf{0 . 0 0 0}$ \\
Poorly guarded/empty most of & 22 & $\mathbf{0 . 0 0 6}$ & 56 & 27 & $\mathbf{0 . 0 0 0}$ \\
the day & 22 & 11 & $\mathbf{0 . 0 0 2}$ & 56 & 31 & $\mathbf{0 . 0 0 0}$ \\
Panhandling & 20 & 13 & 0.050 & 43 & 22 & 0.000 \\
Drunk people & 53 & 34 & $\mathbf{0 . 0 0 0}$ & 67 & 42 & $\mathbf{0 . 0 0 0}$ \\
Vandalism, litter & 45 & 26 & $\mathbf{0 . 0 0 0}$ & 65 & 40 & $\mathbf{0 . 0 0 0}$ \\
Obscene language & 57 & 27 & $\mathbf{0 . 0 0 0}$ & 56 & 29 & $\mathbf{0 . 0 0 0}$ \\
Sexual harassment & 39 & 14 & $\mathbf{0 . 0 0 0}$ & 48 & 14 & $\mathbf{0 . 0 0 0}$ \\
Drug use/sales & 21 & 16 & 0.178 & 43 & 25 & $\mathbf{0 . 0 0 0}$ \\
Verbal/physical threats & 47 & 22 & $\mathbf{0 . 0 0 0}$ & 57 & 26 & $\mathbf{0 . 0 0 0}$ \\
Pickpocketing & 33 & 15 & $\mathbf{0 . 0 0 0}$ & 38 & 19 & $\mathbf{0 . 0 0 0}$ \\
Jewelry snatching & 21 & 11 & $\mathbf{0 . 0 0 5}$ & 31 & 15 & $\mathbf{0 . 0 0 0}$ \\
Robbery & 29 & 16 & $\mathbf{0 . 0 0 1}$ & 47 & 26 & $\mathbf{0 . 0 0 0}$ \\
Violent crime & 24 & 11 & $\mathbf{0 . 0 0 0}$ & 40 & 20 & $\mathbf{0 . 0 0 0}$ \\
\hline
\end{tabular}

Note: There were 472 bus riders (289 harassed). Values in bold are statistically significant at $p<0.05$.

Table 15. Safety Concerns Identified by Train Riders Who Had vs. Had Not Been Harassed

\begin{tabular}{lcccccc}
\hline & \multicolumn{3}{c}{ Onboard } & \multicolumn{3}{c}{ At the stop } \\
\cline { 2 - 7 } & $\begin{array}{c}\text { Harassed } \\
(\%)\end{array}$ & $\begin{array}{c}\text { Not harassed } \\
(\%)\end{array}$ & $\begin{array}{c}\text { P-values } \\
\text { (\%) }\end{array}$ & $\begin{array}{c}\text { Harassed } \\
(\%)\end{array}$ & $\begin{array}{c}\text { Not harassed } \\
(\%)\end{array}$ & P-values \\
\hline Poorly illuminated & 11 & 6 & 0.067 & 33 & 14 & $\mathbf{0 . 0 0 0}$ \\
Poorly designed & 21 & 8 & $\mathbf{0 . 0 0 0}$ & 24 & 13 & $\mathbf{0 . 0 0 4}$ \\
$\begin{array}{l}\text { Poorly guarded/ empty most } \\
\text { of the day }\end{array}$ & 38 & 19 & $\mathbf{0 . 0 0 0}$ & 55 & 27 & $\mathbf{0 . 0 0 0}$ \\
Panhandling & 28 & 12 & $\mathbf{0 . 0 0 0}$ & 45 & 16 & $\mathbf{0 . 0 0 0}$ \\
Drunk people & 64 & 33 & $\mathbf{0 . 0 0 0}$ & 64 & 35 & $\mathbf{0 . 0 0 0}$ \\
Vandalism, litter & 45 & 24 & $\mathbf{0 . 0 0 0}$ & 54 & 26 & $\mathbf{0 . 0 0 0}$ \\
Obscene language & 54 & 27 & $\mathbf{0 . 0 0 0}$ & 51 & 22 & $\mathbf{0 . 0 0 0}$ \\
Sexual harassment & 48 & 12 & $\mathbf{0 . 0 0 0}$ & 47 & 13 & $\mathbf{0 . 0 0 0}$ \\
Drug use/sales & 22 & 15 & 0.067 & 38 & 17 & $\mathbf{0 . 0 0 0}$ \\
Verbal/physical threats & 48 & 16 & $\mathbf{0 . 0 0 0}$ & 51 & 19 & $\mathbf{0 . 0 0 0}$ \\
Pickpocketing & 26 & 14 & $\mathbf{0 . 0 0 2}$ & 35 & 14 & 0.000 \\
Jewelry snatching & 22 & 9 & $\mathbf{0 . 0 0 0}$ & 33 & 9 & $\mathbf{0 . 0 0 0}$ \\
Robbery & 29 & 14 & $\mathbf{0 . 0 0 0}$ & 40 & 17 & $\mathbf{0 . 0 0 0}$ \\
Violent crime & 27 & 8 & $\mathbf{0 . 0 0 0}$ & 36 & 14 & $\mathbf{0 . 0 0 0}$ \\
\hline
\end{tabular}

Note: There were 184 rail riders who were harassed and 226 rail riders who were not harassed. Values in bold are statistically significant at $p<0.05$. 
Table 16. Factors Preventing Transit Riders from Using the Bus/Train More Often for Female vs. Male Riders

\begin{tabular}{|c|c|c|c|c|c|c|}
\hline & \multicolumn{3}{|c|}{ Bus } & \multicolumn{3}{|c|}{ Rail } \\
\hline & Female (\%) & Male (\%) & P-values & Female (\%) & Male (\%) & P-values \\
\hline $\begin{array}{l}\text { Concern of antisocial behavior of } \\
\text { others }\end{array}$ & 56 & 42 & 0.00 & 44 & 38 & 0.12 \\
\hline $\begin{array}{l}\text { Fear of victimization getting to and } \\
\text { waiting for the bus }\end{array}$ & 47 & 25 & 0.00 & -- & -- & -- \\
\hline $\begin{array}{l}\text { Fear of sexual harassment on the } \\
\text { bus/train }\end{array}$ & 45 & 7 & 0.00 & 39 & 6 & 0.00 \\
\hline Slow journey times & 42 & 43 & 0.42 & 34 & 28 & 0.10 \\
\hline $\begin{array}{l}\text { Fear of victimization while on the } \\
\text { bus }\end{array}$ & 42 & 19 & 0.00 & 39 & 16 & 0.00 \\
\hline $\begin{array}{l}\text { Fear of victimization waiting on the } \\
\text { platform }\end{array}$ & -- & -- & -- & 38 & 19 & 0.00 \\
\hline $\begin{array}{l}\text { Dirty environment on the bus (trash, } \\
\text { graffiti) }\end{array}$ & 30 & 33 & 0.25 & 29 & 25 & 0.19 \\
\hline Overcrowded buses/trains & 28 & 25 & 0.24 & 21 & 22 & 0.41 \\
\hline $\begin{array}{l}\text { Dirty environment walking to the } \\
\text { bus/train stop }\end{array}$ & 27 & 24 & 0.23 & 38 & 13 & 0.00 \\
\hline Unreliable bus/train service & 26 & 28 & 0.32 & 14 & 17 & 0.21 \\
\hline Many transfers & 21 & 22 & 0.40 & 10 & 12 & 0.27 \\
\hline $\begin{array}{l}\text { Lack of information about bus/train } \\
\text { schedules }\end{array}$ & 18 & 19 & 0.39 & 14 & 16 & 0.29 \\
\hline Cost of tickets & 13 & 12 & 0.38 & 18 & 19 & 0.40 \\
\hline Fear of terrorist attack & 12 & 5 & 0.00 & 5 & 6 & 0.33 \\
\hline Fear of traffic crashes & 8 & 4 & 0.04 & 12 & 6 & 0.02 \\
\hline Other & 7 & 11 & 0.07 & 5 & 6 & 0.33 \\
\hline $\begin{array}{l}\text { Don't understand how to buy fare } \\
\text { (ticket) }\end{array}$ & 0 & 1 & 0.07 & 2 & 6 & 0.02 \\
\hline
\end{tabular}

Note: For bus riders, $\mathrm{N}=472$ for all riders, 229 for female riders, and 212 for male riders. For train riders, $\mathrm{N}=410$ for all riders, 200 for female riders, and 186 for male riders. 
Table 17. Factors Preventing Transit Riders from Using the Bus/Train More Often for Riders Who Had and Had Not Been Harassed

\begin{tabular}{|c|c|c|c|c|c|c|}
\hline & \multicolumn{3}{|c|}{ Bus } & \multicolumn{3}{|c|}{ Rail } \\
\hline & $\begin{array}{l}\text { Harassed } \\
\quad(\%)\end{array}$ & $\begin{array}{c}\text { Not harassed } \\
(\%)\end{array}$ & P-values & $\begin{array}{l}\text { Harassed } \\
\quad(\%)\end{array}$ & $\begin{array}{c}\text { Not harassed } \\
(\%)\end{array}$ & P-values \\
\hline $\begin{array}{l}\text { Concern of antisocial behavior of } \\
\text { others }\end{array}$ & 57 & 36 & 0.00 & 50 & 32 & 0.00 \\
\hline $\begin{array}{l}\text { Fear of victimization getting to and } \\
\text { waiting for the bus }\end{array}$ & 47 & 20 & 0.00 & -- & -- & -- \\
\hline $\begin{array}{l}\text { Fear of sexual harassment on the } \\
\text { bus/train }\end{array}$ & 36 & 13 & 0.00 & 35 & 14 & 0.00 \\
\hline Slow journey times & 45 & 37 & 0.09 & 36 & 26 & 0.03 \\
\hline $\begin{array}{l}\text { Fear of victimization while on the } \\
\text { bus/train }\end{array}$ & 39 & 19 & 0.00 & 42 & 16 & 0.00 \\
\hline $\begin{array}{l}\text { Fear of victimization waiting on } \\
\text { the platform }\end{array}$ & -- & -- & -- & 39 & 21 & 0.00 \\
\hline $\begin{array}{l}\text { Dirty environment on the bus/train } \\
\text { (trash, graffiti) }\end{array}$ & 36 & 23 & 0.00 & 33 & 23 & 0.02 \\
\hline Overcrowded buses/trains & 27 & 25 & 0.63 & 22 & 19 & 0.45 \\
\hline $\begin{array}{l}\text { Dirty environment walking to the } \\
\text { bus/train stop }\end{array}$ & 29 & 19 & 0.01 & 28 & 16 & 0.00 \\
\hline Unreliable bus/train service & 30 & 22 & 0.06 & 18 & 14 & 0.27 \\
\hline Many transfers & 21 & 20 & 0.79 & 10 & 12 & 0.52 \\
\hline $\begin{array}{l}\text { Lack of information about bus/ } \\
\text { train schedules }\end{array}$ & 18 & 20 & 0.59 & 16 & 15 & 0.78 \\
\hline Cost of tickets & 12 & 11 & 0.74 & 20 & 16 & 0.29 \\
\hline Fear of terrorist attack & 9 & 8 & 0.71 & 12 & 7 & 0.08 \\
\hline Fear of traffic crashes & 8 & 4 & 0.08 & 12 & 8 & 0.18 \\
\hline Other & 7 & 12 & 0.06 & 5 & 7 & 0.40 \\
\hline $\begin{array}{l}\text { Don't understand how to buy fare } \\
\text { (ticket) }\end{array}$ & 1 & 1 & 1.00 & 5 & 4 & 0.63 \\
\hline
\end{tabular}

Note: For bus riders, $\mathrm{N}=472$ for all riders, there were 289 bus riders who were harassed and 183 bus riders who were not harassed. For train riders, $\mathrm{N}=410$ for all riders, there were 184 rail riders who were harassed and 226 rail riders who were not harassed.

\section{HOW MANY STUDENTS HAVE EXPERIENCED SEXUAL HARASSMENT RIDING TRANSIT?}

Table 18. Female vs. Male Riders Who Were Victims of Harassment during Bus/ Rail Travel, by Mode

\begin{tabular}{lcccccccc}
\hline & \multicolumn{3}{c}{ Bus } & & \multicolumn{3}{c}{ Train } \\
\cline { 2 - 3 } Type of Harassment & Female (\%) & Male (\%) & P-values & & Female (\%) & Male (\%) & P-values \\
\hline Verbal & 70 & 36 & $\mathbf{0 . 0 0 0}$ & & 51 & 27 & $\mathbf{0 . 0 0 0}$ \\
Non-verbal & 51 & 25 & $\mathbf{0 . 0 0 0}$ & & 38 & 20 & $\mathbf{0 . 0 0 0}$ \\
Physical & 16 & 8 & 0.010 & & 9 & 6 & 0.234 \\
\hline
\end{tabular}

Note: There were 472 bus riders (229 female and 212 male) and 410 rail riders (200 female and 186 male). Values in bold are statistically significant at $p<0.05$. 


\section{TO WHAT EXTENT DO VICTIMS REPORT SEXUAL HARASSMENT ON TRANSIT?}

Table 19. Percent of Women and Men Reporting Harassment

\begin{tabular}{lccc}
\hline & Female $(\%)$ & Male $(\%)$ & P-value \\
\hline Report crime & 23 & 20 & 0.076 \\
\hline
\end{tabular}

Note: There were 190 victims (132 female and 38 male).

\section{WHAT SAFETY PRECAUTIONS DO STUDENTS TAKE WHEN RIDING TRANSIT?}

Table 20. Precautions Riders Take Using Buses and Trains, by Gender

\begin{tabular}{|c|c|c|c|c|c|c|}
\hline \multirow[b]{2}{*}{ Type of Precaution } & \multicolumn{3}{|c|}{ Bus } & \multicolumn{3}{|c|}{ Train } \\
\hline & Women (\%) & Men $(\%)$ & $p$-value & Women (\%) & Men (\%) & $\mathrm{p}$-value \\
\hline Travel only during daytime & 37 & 12 & 0.000 & 29 & 12 & 0.000 \\
\hline Wait for transit only at well-lit places & 35 & 13 & 0.000 & 28 & 12 & 0.000 \\
\hline $\begin{array}{l}\text { Hold keys so I can use them to protect } \\
\text { myself if attacked }\end{array}$ & 33 & 5 & 0.000 & 26 & 9 & 0.000 \\
\hline Dress a certain way & 31 & 9 & 0.000 & 27 & 10 & 0.000 \\
\hline Carry a self-defense spray & 31 & 4 & 0.000 & 25 & 6 & 0.000 \\
\hline Always travel with someone else & 16 & 8 & 0.010 & 16 & 8 & 0.016 \\
\hline Avoid particular bus stops/train stations & 23 & 14 & 0.015 & 15 & 8 & 0.032 \\
\hline Sit close to the driver & 26 & 6 & 0.000 & 14 & 6 & 0.009 \\
\hline Do not wear jewelry & 22 & 9 & 0.000 & 14 & 8 & 0.061 \\
\hline Avoid carrying purses, wallets & 21 & 3 & 0.000 & 18 & 7 & 0.001 \\
\hline $\begin{array}{l}\text { Wait for transit only if other people are } \\
\text { around }\end{array}$ & 19 & 8 & 0.001 & 20 & 9 & 0.002 \\
\hline Avoid particular bus/train lines & 10 & 5 & 0.048 & 10 & 3 & 0.006 \\
\hline Carry a weapon (e.g., gun or knife) & 7 & 7 & 1.000 & 9 & 7 & 0.470 \\
\hline Other & 5 & 2 & 0.089 & 2 & 0 & 0.053 \\
\hline
\end{tabular}

Note: There were 472 bus riders (229 female and 212 male) and 410 rail riders (200 female and 186 male). Values in bold are statistically significant at $p<0.05$. 
Table 21. Precautions Riders Take Using Buses and Trains, by Riders Who Had and Had Not Been Harassed

\begin{tabular}{|c|c|c|c|c|c|c|}
\hline \multirow[b]{2}{*}{ Precaution Taken } & \multicolumn{3}{|c|}{ Bus } & \multicolumn{3}{|c|}{ Train } \\
\hline & $\begin{array}{l}\text { Harassed } \\
(\%)\end{array}$ & $\begin{array}{c}\text { Not } \\
\text { harassed } \\
(\%)\end{array}$ & $\mathrm{p}$-value & $\begin{array}{l}\text { Harassed } \\
(\%)\end{array}$ & $\begin{array}{c}\text { Not } \\
\text { harassed } \\
(\%)\end{array}$ & $\mathrm{p}$-value \\
\hline Travel only during daytime & 40 & 0 & 0.000 & 44 & 1 & 0.000 \\
\hline Always travel with someone else & 19 & 0 & 0.000 & 25 & 0 & 0.000 \\
\hline Avoid particular bus lines & 13 & 0 & 0.000 & 14 & 0 & 0.000 \\
\hline Avoid particular bus stops & 29 & 0 & 0.000 & 25 & 0 & 0.000 \\
\hline Sit close to the driver & 27 & 0 & 0.000 & 24 & 0 & 0.000 \\
\hline Dress a certain way & 34 & 0 & 0.000 & 27 & 0 & 0.000 \\
\hline Do not wear jewelry & 25 & 0 & 0.000 & 17 & 0 & 0.000 \\
\hline Avoid carrying purses, wallets & 20 & 0 & 0.000 & 35 & 0 & 0.000 \\
\hline Carry a weapon (e.g. gun or knife) & 12 & 0 & 0.000 & 39 & 0 & 0.000 \\
\hline Carry a self-defense spray & 30 & 0 & 0.000 & 43 & 0 & 0.000 \\
\hline $\begin{array}{l}\text { Hold keys so that I can use them to pro- } \\
\text { tect myself if attacked }\end{array}$ & 32 & 0 & 0.000 & 30 & 0 & 0.000 \\
\hline Wait for transit only at well-lit places & 40 & 0 & 0.000 & 2 & 0 & 0.000 \\
\hline $\begin{array}{l}\text { Wait for transit only if other people are } \\
\text { around }\end{array}$ & 22 & 0 & 0.000 & 22 & 0 & 0.000 \\
\hline Other & 6 & 0 & 0.000 & 42 & 0 & 0.000 \\
\hline
\end{tabular}

Note: There were 289 bus riders who were harassed and 183 bus riders who were not harassed. There were 184 rail riders who were harassed and 226 rail riders who were not harassed. Values in bold are statistically significant at $p<$ 0.05 .

\section{WHAT CHANGES DO STUDENTS RECOMMEND TO IMPROVE SAFETY ON TRANSIT?}

\section{Table 22. Recommended Safety Improvements from Bus Riders, by Gender}

\begin{tabular}{lccc}
\hline Safety Improvements & Women (\%) & Men (\%) & p-value \\
\hline Cameras at bus stops & 46 & 41 & 0.290 \\
More lighting at bus stops & 40 & 42 & 0.670 \\
Police patrolling bus stops & 39 & 33 & 0.190 \\
Phone app or other source of real-time information about when buses arrive & 35 & 27 & 0.070 \\
Cameras on the bus & 29 & 33 & 0.364 \\
More police officers patrolling buses & 25 & 19 & 0.129 \\
Direct phone line to police at bus stop & 24 & 26 & 0.628 \\
Digital timetable at bus stops & 17 & 25 & 0.039 \\
Direct phone line to police on the bus & 15 & 15 & 1.000 \\
Women-only buses & 13 & 2 & 0.000 \\
Other & 3 & 4 & 0.567 \\
\hline
\end{tabular}

Note: There were 472 bus riders, 229 female and 212 male. Values in bold are statistically significant at $p<0.05$. 
Table 23. Recommended Safety Improvements from Train Riders, by Gender

\begin{tabular}{lccc}
\hline Safety Improvements & Women (\%) & Men (\%) & p-value \\
\hline Police patrolling platforms & 50 & 43 & 0.168 \\
Cameras (CCTV) at platforms & 47 & 46 & 0.844 \\
More police officers patrolling train vehicles & 40 & 41 & 0.841 \\
Cameras (CCTV) inside train vehicles & 40 & 37 & 0.545 \\
More lighting at platforms & 30 & 32 & 0.671 \\
Direct police line at platform & 25 & 24 & 0.819 \\
Direct police line in each wagon & 25 & 25 & 1.000 \\
Digital timetable at platforms & 16 & 22 & 0.132 \\
"Women only" wagons & 14 & 6 & $\mathbf{0 . 0 0 9}$ \\
Other & 2 & 3 & 0.528 \\
\hline
\end{tabular}

Note: there were 410 rail riders, 200 female and 186 male train riders. Value in bold is statistically significant at $\mathrm{p}<0.05$.

Table 24. Recommended Safety Improvements from Bus Riders Who Had vs. Had Not Been Harassed

\begin{tabular}{lccc}
\hline Safety Improvements & Harassed (\%) & Not harassed (\%) & p-value \\
\hline Cameras at bus stops & 47 & 37 & 0.033 \\
More lighting at bus stops & 40 & 43 & 0.519 \\
Police patrolling bus stops & 37 & 34 & 0.508 \\
Phone app or other source of real-time information about & 35 & 27 & 0.069 \\
$\quad$ when buses will arrive & & & \\
Cameras on the bus & 27 & 34 & 0.105 \\
More police officers patrolling buses & 26 & 18 & 0.044 \\
Direct phone line to police at bus stop & 25 & 27 & 0.628 \\
Digital timetable at bus stops & 18 & 24 & 0.115 \\
Direct phone line to police on the bus & 16 & 14 & 0.556 \\
Women only buses & 11 & 5 & 0.024 \\
Other & 4 & 3 & 0.571 \\
\hline
\end{tabular}

Note: There were 289 bus riders who were harassed and 183 bus riders who were not harassed. Values in bold are statistically significant at $p<0.05$. 
Table 25. Recommended Safety Improvements from Rail Riders Who Had vs. Had Not Been Harassed

\begin{tabular}{lccc}
\hline Safety Improvements & Harassed (\%) & Not harassed (\%) & p-value \\
\hline Police patrolling platforms & 46 & 46 & 1.000 \\
More police officers patrolling train vehicles & 47 & 35 & $\mathbf{0 . 0 1 4}$ \\
Cameras (CCTV) inside train vehicles & 40 & 37 & 0.534 \\
Cameras (CCTV) at platforms & 50 & 42 & 0.106 \\
Direct police line at platform & 26 & 23 & 0.481 \\
Direct police line in each wagon & 30 & 22 & 0.065 \\
More lighting at platforms & 33 & 30 & 0.515 \\
Digital timetable at platforms & 16 & 22 & 0.126 \\
"Women only" wagons & 12 & 9 & 0.321 \\
Other & 3 & 1 & 0.140 \\
\hline
\end{tabular}

Note: There were 184 rail riders who were harassed and 226 rail riders who were not harassed. Value in bold is statistically significant at $p<0.05$. 


\section{APPENDIX C: DATA TABLES FROM THE REGRESSION MODELING}

Appendix $\mathrm{C}$ presents the detailed findings of the regression modeling.

\section{LIKELIHOOD OF BEING VICTIMIZED}

Table 26 and Table 27 present the results from models exploring the likelihood that bus and train riders had been a victim of sexual harassment or assault. The dependent variables for both modes include victims who had been verbally, non-verbally, and/or physically harassed, or who had been the victim of at least one type of crime.

Table 26. Logistic Regression for Model of Bus Riders Who Had Been Victimized, by Type of Victimization

\begin{tabular}{|c|c|c|c|c|}
\hline \multirow[b]{2}{*}{ Independent Variables } & \multicolumn{4}{|c|}{ Type of Victimization } \\
\hline & Any & Verbal & Non-verbal & Physical \\
\hline \multicolumn{5}{|l|}{ Sociodemographic } \\
\hline Being female & $4.76^{\star * *}$ & $5.00^{* * *}$ & $3.30^{* * *}$ & $2.17^{*}$ \\
\hline \multicolumn{5}{|l|}{ Being LGBTQI } \\
\hline \multicolumn{5}{|l|}{ Race and ethnicity } \\
\hline \multicolumn{5}{|l|}{ Age } \\
\hline \multicolumn{5}{|l|}{ Travel behavior } \\
\hline \multicolumn{5}{|l|}{ Frequent bus rider ${ }^{a}$} \\
\hline \multicolumn{5}{|l|}{ Commute time ${ }^{b}$} \\
\hline Do not take bus at night & $0.43^{* *}$ & $0.55^{\star}$ & & \\
\hline Pseudo R square $^{c}$ & 0.13 & 0.13 & 0.11 & 0.08 \\
\hline
\end{tabular}

Notes: Blue text indicates a lower likelihood of being victimized.

* Statistically significant at $p<0.05$.

** Statistically significant at $p<0.01$.

*** Statistically significant at $p<0.0001$.

${ }^{a}$ Bus riders who travel four or more times a week.

${ }^{\mathrm{b}}$ Categorical variable indicating the length of commute time, ranging from 0 - 15 minutes to more than 121 minutes.

c Pseudo R square is only used to compare the models. 
Table 27. Logistic Regression for Model of Train Riders Who Had Been Victimized, by Type of Victimization

\begin{tabular}{|c|c|c|c|c|}
\hline \multirow[b]{2}{*}{ Independent Variables } & \multicolumn{4}{|c|}{ Type of Victimization } \\
\hline & Any & Verbal & Non-verbal & Physical \\
\hline \multicolumn{5}{|l|}{ Sociodemographic } \\
\hline Being female & $2.44^{\star * *}$ & $2.86^{\star \star *}$ & $2.32^{* *}$ & \\
\hline \multicolumn{5}{|l|}{ Being LGBTQI } \\
\hline \multicolumn{5}{|l|}{ Race and ethnicity } \\
\hline \multicolumn{5}{|l|}{ Age } \\
\hline \multicolumn{5}{|l|}{ Travel behavior } \\
\hline \multicolumn{5}{|l|}{ Frequent bus rider ${ }^{\mathrm{a}}$} \\
\hline Long commute time (61 - 120 minutes) & & & $0.31^{*}$ & \\
\hline Very long commute time $(121+$ minutes $)$ & & & & $7.6^{*}$ \\
\hline Do not take bus at night & & & $0.39^{* *}$ & \\
\hline pseudo R square ${ }^{b}$ & 0.08 & 0.09 & 0.13 & 0.16 \\
\hline
\end{tabular}

Notes: Blue text indicates a lower likelihood of being victimized.

* Statistically significant at $p<0.05$.

** Statistically significant at $p<0.01$.

*** Statistically significant at $p<0.0001$.

a Bus riders who travel four or more times a week.

${ }^{\mathrm{b}}$ Pseudo R square is only used to compare the models.

\section{PERCEIVED SAFETY}

Table 28 and Table 29 present the results from models exploring the likelihood that bus and train riders feel "always" or "often" safe.

Table 28. Ordered Logistic Regression Model for Safety Perception on the Bus, Showing Odds Ratios for Significant Explanatory Variables

\begin{tabular}{|c|c|c|c|c|}
\hline \multirow[b]{2}{*}{ Independent Variables } & \multicolumn{2}{|c|}{ On the bus } & \multicolumn{2}{|c|}{ Waiting for the bus } \\
\hline & Day & Night & Day & Night \\
\hline Have been harassed ${ }^{a}$ & $0.43^{* * *}$ & & $0.38^{*}$ & \\
\hline Being male & $1.24^{\star * *}$ & $3.57^{* \star \star}$ & $1.27^{* \star *}$ & $3.12^{*}$ \\
\hline \multicolumn{5}{|l|}{ Being LGBTQI } \\
\hline Age $2^{b}$ & $1.22^{* *}$ & $1.59^{*}$ & & \\
\hline Age $3^{b}$ & $1.25^{\star *}$ & & $0.52^{*}$ & \\
\hline Age $4^{b}$ & $2.07^{*}$ & & & $0.61^{*}$ \\
\hline \multicolumn{5}{|l|}{ Age $5^{b}$} \\
\hline Take precautions ${ }^{\mathrm{c}}$ & & & & \\
\hline
\end{tabular}

Notes: Blue text indicates a lower likelihood of being victimized.

a Binary variable indicating whether or not the respondent had been harassed.

${ }^{\mathrm{b}}$ Age is a categorical value.

c This is a binary variable.

* Statistically significant at $p<0.05$.

** Statistically significant at $p<0.01$.

*** Statistically significant at $p<0.0001$. 
Table 29. Ordered Logistic Regression Model for Safety Perception on the Train, Showing Odds Ratios for Significant Explanatory Variables

\begin{tabular}{|c|c|c|c|c|}
\hline \multirow[b]{2}{*}{ Independent Variables } & \multicolumn{2}{|c|}{ On the train } & \multicolumn{2}{|c|}{ Waiting for the train } \\
\hline & Day & Night & Day & Night \\
\hline Have been harassed ${ }^{a}$ & $0.43^{* * *}$ & $0.61^{* *}$ & $0.38^{* * *}$ & $0.45^{\text {*** }}$ \\
\hline \multicolumn{5}{|l|}{ Frequent bus rider } \\
\hline Being male & & $3.57^{\star \star \star}$ & & $3.12^{\star \star *}$ \\
\hline \multicolumn{5}{|l|}{ Age $2^{b}$} \\
\hline \multicolumn{5}{|l|}{ Age $3^{b}$} \\
\hline \multicolumn{5}{|l|}{ Age $4^{\mathrm{b}}$} \\
\hline \multicolumn{5}{|l|}{ Age $5^{b}$} \\
\hline Take precautions $^{\mathrm{c}}$ & & & & \\
\hline
\end{tabular}

Notes: Blue text indicates a lower likelihood of being victimized.

a Binary variable indicating whether or not the respondent had been harassed.

${ }^{\mathrm{b}}$ Age is a categorical value.

${ }^{c}$ This is a binary variable.

* Statistically significant at $p<0.05$.

** Statistically significant at $p<0.01$.

*** Statistically significant at $p<0.0001$. 


\section{ABBREVIATIONS AND ACRONYMS}

\begin{tabular}{ll}
\hline AC Transit & Alameda-Contra Costa Transit District \\
SJSU & San José State University \\
VTA & [Santa Clara] Valley Transportation Agency \\
\hline
\end{tabular}




\section{BIBLIOGRAPHY}

Abenoza, Roberto F., Vania Ceccato, Yusak O. Susilo, and Cats Oded. "Individual, Travel, and Bus Stop Characteristics Influencing Travelers' Safety

Perceptions." Transportation Research Record 2672 (2018): 19-28. https://doi. org/10.1177/0361198118758677.

Agrawal, A., and A. Sharma. "Gender Contests in the Delhi Metro: Implications of Reservation of a Coach for Women." Indian Journal of Gender Studies 22 (2015): 421-436.

Ball, Krista S., and Caroline J. Wesson. "Perceptions of Unwanted Sexual Behaviour on Public Transport: Exploring Transport Density and Behaviour Severity." Crime Prevention and Community Safety 19 (2017): 199-210.

Beller, Anne, Sanford Garelik, and Sydney Cooper. "Sex Crimes in the Subway." Criminology 18 (1980): 35-52.

Best, A. "Transit Violations: Locating the 'Bus Rape' in L.A. and Other Public Geographies of Violence." The Feminist Wire, 2013. http://thefeministwire. com/2013/02/transit-violations-locating-the-bus-rape-in-l-a-and-otherpublicgeographies-of-violence/.

British Transport Police Authority. "Fear of Crime and Concerns about Personal Safety on the Rail Network. Summary of Findings from Existing Research: 2008 Update." London: British Transport Police Authority, 2008. https://btpa.police.uk/livesite/ wp-content/uploads/2012/01/2008-update-BTPA-Passenger-fear-of-crime-paperFINAL.pdf.

Ceccato, Vania, and Anastasia Loukaitou-Sideris, eds. Transit Crime and Sexual Violence in Cities: International Evidence and Prevention. Routledge, forthcoming.

Ceccato, Vania, and Y. Paz "Crime in São Paulo's Metro System: Sexual Crimes against Women." Crime Prevention and Community Safety 19, n3 (2017): 211-226.

Cozens, Paul, Richard Neale, Jeremy Whitaker, and David Hillier. "Managing Crime and the Fear of Crime at Railway Stations-A Case Study in South Wales (UK)." International Journal of Transport Management 1 (2003): 121-132.

Cox, D.R. "The Regression Analysis of Binary Sequences (with Discussion)." Journal of the Royal Statistical Society B 20 (1958): 215-242.

Crime Concern. "People's Perceptions of Personal Security and Their Concerns about Crime on Public Transport." London: Department for Transport, 2004. https://webarchive.nationalarchives.gov.uk/+/http:/www.dft.gov.uk/pgr/crime/ps/ perceptions/researchfindings. 
Dunckel Graglia, A. "Finding Mobility: Women Negotiating Fear and Violence in Mexico City's Public Transit System." Gender, Place \& Culture 23 (2016): 624-460.

End Violence Against Women. "Poll Reveals 1/4 Women Don't Feel Safe on London Public Transport." March 30, 2012. http://www.endviolenceagainstwomen.org.uk/ news/14/poll-reveals-14-womendont-feel-safe-on-london-public-transport.

FiA Foundation. Safe and Sound: International Research on Women's Safety on Public Transport. London: FiA Foundation, 2016.

Gardner, Natalie, Jianqiang Cui, and Eddo Coiacetto. "Harassment on Public Transport and Its Impacts on Women's Travel Behaviour." Australian Planner 54 (2017): 8-15.

Gekoski, A., et al. 'What Works' in Reducing Sexual Harassment and Sexual Offences on Public Transport Nationally and Internationally: A Rapid Evidence Assessment. London: Middlesex University London, 2015. http://eprints.mdx.ac.uk/15219/1/ Gekoski\%2C\%20Gray\%2C\%20Horvath\%2C\%20Edwards\%2C\%20Emirali\%20 \%26\%20Adler\%202015.pdf.

Gekoski, Anna, Jacqueline M. Gray, Joanna R. Adler, and Miranda A.H Horvath. "The Prevalence and Nature of Sexual Harassment and Assault against Women and Girls on Public Transport: An International Review." Journal of Criminological Research, Policy and Practice 3 (2017): 3-16.

Gordon, M., and S. Riger. The Female Fear. New York: Free Press, 1989.

Goldsmith, Belinda. "Exclusive: Safety and Time Are Women's Biggest Concerns about Transport - Global Poll." REUTERS, November 14, 2018. https://www.reuters. com/article/us-transport-women-poll/exclusive-safety-and-time-are-womensbiggest-concerns-about-transport-global-poll-idUSKCN1NK04K.

Hartgen, D., G. Ingalls, and T. Owens. Public Fear of Crime and its Role in Public Transit Use. Raleigh: University of North Carolina, Center for Interdisciplinary Transportation Studies, 1993.

Hsu, Hsin-Ping. "How Does Fear of Sexual Harassment on Transit Affect Women's Use of Transit?" In Women's Issues in Transportation: Summary of the 4th International Conference 2 (2011): 85-94.

Hsu, Hsin-Ping, D. Houston, and M. Boarnet. "Gender and Rail Transit Use: Influence of Environmental Beliefs and Safety Concerns." Transportation Research Record 2673 (2019): 327-338.

Irvin-Erickson, Yasemin, and Nancy La Vigne. "A Spatio-Temporal Analysis of Crime at Washington, DC Metro Rail: Stations' Crime-Generating and Crime-Attracting Characteristics as Transportation Nodes and Places." Crime Science 4 (2015): 14. 
Islam, A., and T. Amin. "Eve Teasing in Bangladesh: An Overview." IOSR Journal of Humanities and Social Science (IOSR-JHSS) 21, no. 11, version 5 (2016): 1-6.

Ito, S. "Stop It! Tokyo Police Anti-Groper App Becomes Smash Hit in Japan." The Japan Times, May 23, 2019.

ludici, Antonio, Laura Bertoli, and Elena Faccio. "The 'Invisible' Needs of Women with Disabilities in Transportation Systems." Crime Prevention and Community Safety 19 (2017): 264-275.

Jubainville, d'Arbois, H., and C. Vanier. "Women's Avoidance Behaviours in Public Transport in the lle-de-France Region." Crime Prevention and Community Safety 19 (2017): 183-198.

Keane, Carl. "Evaluating the Influence of Fear of Crime as an Environmental Mobility Restrictor on Women's Routine Activities." Environment and Behavior 30 (1998): 60-74.

Khanna, Meghna. “Sexual Harassment on Public Transit.” Planning, May 2018.

Kim, Sungyop, and Ulfarsson F Gudmundur. "Commitment to Light Rail Transit Patronage: Case Study for St. Louis MetroLink." Journal of Urban Planning and Development 138 (2012): 227-34. https://doi.org/10.1061/(ASCE)UP.19435444.0000115.

Koskela, Hille, and Rachel Pain. "Revisiting Fear and Place: Women's Fear of Attack and the Built Environment." Geoforum 31 (2000): 269-280.

Levine, Ned, and Martin Wachs. "Bus Crime in Los Angeles: Il-Victims and Public Impact." Transportation Research Part A: General 20 (1986): 285-293.

Los Angeles Metro. Metro On-Board Passenger Survey. Los Angeles: Los Angeles County Metropolitan Transportation Authority, 2018.

Los Angeles Metro. Understanding How Women Travel. August 30, 2019. http://libraryarchives.metro.net/DB_Attachments/2019-0294/ UnderstandingHowWomenTravel_FullReport_FINAL.pdf.

Loukaitou-Sideris, Anastasia. "Is It Safe to Walk Here?" Research on Women's Issues in Transportation Conference Proceedings, Vol. 2, Washington DC: Transportation Research Board, 2005.

-----. How to Ease Women's Fear of Transportation Environments: Case Studies and Best Practices. San José: Mineta Transportation Institute, 2009.

----. "Safe on the Move: The Importance of the Built Environment." In Ceccato, V. (Ed.) Urban Fabric of Crime and Fear. Berlin, London, and New York: Springer, 2012, pp. 85-110. 
-----. "Fear and Safety in Transit Environments from the Women's Perspective." Security Journal 27 (2014): 242-256.

-----. "Intimidated Riders: US Women's Perspectives about Safety in Transit Settings." In Ceccato, V. and Newton, A, (Eds.) Safety and Security in Transit Environments, 291-308. Berlin, London, and New York: Springer, 2015.

----. "A Gendered View of Mobility and Transport." Town Planning Review 87 (2016): 547-565.

Loukaitou-Sideris, A. and C. Fink. "Addressing Women's Fear of Victimization in Transportation Settings: A Survey of US Transit Agencies." Urban Affairs Review 44 (2009): 554-587.

Lynch, Gary, and Atkins, Susan. "The Influence of Personal Security Fears on Women's Travel Patterns.” Transportation 15 (1988): 257-277.

Manville, Michael, Brian Taylor, and Evelyn Blumenberg. Falling Transit Ridership: California and Southern California. UCLA: Institute for Transportation Studies, 2018.

McCullagh, Peter. "Regression Models for Ordinal Data." Journal of the Royal Statistical Society B 42 (1980): 109-142.

Natarajan, Mangai, Margaret Schmuhl, Susruta Sudula, and Marissa Mandala. "Sexual Victimization of College Students in Public Transport Environments: A Whole Journey Approach." Crime Prevention and Community Safety 19 (2017): 168182.

Newton, Andrew. 2014. "Crime on Public Transport." Encyclopedia of Criminology and Criminal Justice. 2014. pp. 709-720.

Powers, M. "Why the \#MeToo Movement is a Public Transportation Issue." Washington Post, October 20, 2017. https://www.washingtonpost.com/news/dr-gridlock/ wp/2017/10/20/why-the-metoo-movement-is-a-public-transportation-issue/?utm _ term=.ca4f43f6e 972 .

Rahman, M.S.U. "Bus Service for Women Only in Dhaka City: An Investigation." Journal of Bangladesh Institute of Planners 3 (2010): 17-32.

R Development Core Team. R: A language and environment for statistical computing. Vienna, Austria: R Foundation for Statistical Computing, Vienna, Austria, 2016. ISBN 3-900051-07-0, http://www.R-project.org.

Romero, S.. "Public Rapes Outrage Brazil, Testing Ideas of Image and Class. New York Times, May 25, 2013. http://nytimes.com/2013/05/25/world/americas/rapes-inbrazil-spur-class-and-gender-debate.html. 
Rotaris, L., and R. Danielis. "Commuting to College: The Effectiveness and Social Efficiency of Transportation Demand Management Policies." Transport Policy, 44 (2015): 158-168.

Rubin, D. B. Multiple Imputation for Nonresponse in Surveys. Vol. 81. John Wiley \& Sons, 1987.

San José State University. "Student Quick Facts." http://www.iea.sjsu.edu/Students/ QuickFacts/default.cfm?version=graphic (visited April 17, 2019).

Smith, Martha J., and Ronald V. Clarke. "Crime and Public Transport." Crime and Justice 27 (2000): 169-233.

Smith, Martha J., and D.B. Cornish. Secure and Tranquil Travel: Preventing Crime and Disorder on Public Transport. London: Jill Dando Institute of Crime Science, 2006.

Solymosi, R., K. Cella, and A. Newton. "Did They Report It to Stop It? A Realist Evaluation of the Effect of an Advertising Campaign on Victims' Willingness to Report Unwanted Sexual Behaviour." Security Journal 31 (2018): 570-590.

Stark, Juliane, and Michael Meschik. "Women's Everyday Mobility: Frightening Situations and their Impacts on Travel Behaviour." Transportation Research Part F: Traffic Psychology and Behaviour 54 (2018): 311-323.

Stringer, Scott M. Hidden in Plain Sight: Sexual Harassment and Assault in the New York City Subway System. Office of the Manhattan Borough President, 2007. http://www.nytimes.com/packages/pdf/nyregion/city_room/20070726_ hiddeninplainsight.pdf.

Twyford, R. Report: Project Guardian- Public Awareness Campaign Rationale. London: Project Guardian, 2013.

UK Department of Transport. A Bulleting of Transport Statistics: Great Britain. 2004.

UK Department for Transport. 2008. "Experience and Perceptions of Anti-Social Behaviour and Crime on Public Transport." London: Department for Transport. https://webarchive.nationalarchives.gov.uk/20090103072146/http://www.dft.gov. uk/pgr/statistics/datatablespublications/trsnstatsatt/antisocialcrime.

U.S. Census Bureau. "QuickFacts: San Jose City, California." April 17, 2019. https:// www.census.gov/quickfacts/fact/table/sanjosecitycalifornia/PST045218.

Van Buuren, S., and K. Groothuis-Oudshoorn. "mice: Multivariate Imputation by Chained Equations in R." Journal of Statistical Software 45 (2011): 1-67.

Warr, M. 1984. "Fear of Victimization: Why Are Women and the Elderly More Afraid?" Social Science Quarterly 65 (3): 681-702. 
Washington Metropolitan Area Transit Authority. "Understanding Sexual Harassment on Public Transportation - 2008." April 11, 2018. https://www.wmata.com/about/news/ upload/2018-Sexual-Harassment-Report-Final.pptx.

Yanuz, N., and E.W. Welch. "Addressing Fear of Crime in Public Space: Gender Differences in Reaction to Safety Measures in Train Transit." Urban Studies 47 (2010): 2491-2515. 


\section{ENDNOTES}

1. M. Powers, "Why the \#MeToo Movement is a Public Transportation Issue," Washington Post, October 20, 2017, https://www.washingtonpost.com/news/dr-gridlock/ wp/2017/10/20/why-the-metoo-movement-is-a-public-transportation-issue/?utm_ term=.ca4f43f6e 972 .

2. Ceccato and Loukaitou-Sideris, forthcoming.

3. M. Powers, "Why the \#MeToo Movement is a Public Transportation Issue," Washington Post, October 20, 2017, https://www.washingtonpost.com/news/dr-gridlock/ wp/2017/10/20/why-the-metoo-movement-is-a-public-transportation-issue/?utm_ term=.ca4f43f6e972.

4. Los Angeles Metro, Understanding How Women Travel (2019), p. 99.

5. Gekoski A., Gray, J.M., Adler, J.R., and Horvath, M.A.H., "The Prevalence and Nature of Sexual Harassment and Assault against Women and Girls on Public Transport: An International Review," Journal of Criminological Research, Policy and Practice 3 (2017): 3-16, p.4.

6. Ceccato, V. and Loukaitou-Sideris, A. (forthcoming), Transit Crime and Sexual Violence in Cities: International Evidence and Prevention (New York: Routledge).

7. Michael Manville, Brian Taylor, and Evelyn Blumenberg, Falling Transit Ridership: California and Southern California (Los Angeles: UCLA Institute for Transportation Studies, 2018).

8. Gary Lynch and Susan Atkins, "The Influence of Personal Security Fears on Women's Travel Patterns," Transportation 15 (1988): 257-277; Anastasia Loukaitou-Sideris, "How to Ease Women's Fear of Transportation Environments: Case Studies and Best Practices" (San José: Mineta Transportation Institute, 2009).

9. Hartgen, D., Ingalls, G., and Owens, T., Public Fear of Crime and its Role in Public Transit Use, Raleigh: University of North Carolina, Center for Interdisciplinary Transportation Studies, 1993; UK Department of Transport 2004, A Bulleting of Transport Statistics: Great Britain.

10. A. Loukaitou-Sideris, "Fear and Safety in Transit Environments from the Women's Perspective," Security Journal 27 (2014): 242-256.

11. M.J. Smith, and D.B. Cornish, Secure and Tranquil Travel: Preventing Crime and Disorder on Public Transport (London: Jill Dando Institute of Crime Science, 2006); and A. Loukaitou-Sideris, "Safe on the Move: The Importance of the Built Environment," in V. Ceccato, ed., Urban Fabric of Crime and Fear (Berlin, London, and New York: Springer, 2012), pp. 85-110. 
12. A. Best, "Transit Violations: Locating the 'Bus Rape'in L.A. and OtherPublic Geographies of Violence," The Feminist Wire (2013), http://thefeministwire.com/2013/02/transitviolations-locating-the-bus-rape-in-l-a-and-otherpublic-geographies-of-violence/; S. Romero, "Public Rapes Outrage Brazil, Testing Ideas of Image and Class," New York Times (May 25, 2013), http://nytimes.com/2013/05/25/world/americas/rapes-in-brazilspur-class-and-gender-debate.html.

13. Anastasia Loukaitou-Sideris and Camille Fink, "Addressing Women's Fear of Victimization in Transportation Settings: A Survey of US Transit Agencies," Urban Affairs Review 44 (2009): 554-587.

14. Anastasia Loukaitou-Sideris, "A Gendered View of Mobility and Transport," Town Planning Review 8 (2016): 547-565.

15. Ceccato and Loukaitou-Sideris, forthcoming.

16. Smith, Martha J. and Clarke, Ronald V. "Crime and Public Transport," Crime and Justice 27 (2000): 169-233.

17. Irvin-Erickson, Yasemin and La Vigne, Nancy, "A Spatio-Temporal Analysis of Crime at Washington, DC Metro Rail: Stations' Crime-Generating and Crime-Attracting Characteristics as Transportation Nodes and Places," Crime Science 4 (2015): 14.

18. M. Gordon and S. Riger, The Female Fear (New York: Free Press, 1989); and M. Warr, "Fear of Victimization: Why Are Women and the Elderly More Afraid?" Social Science Quarterly 65 (1984): 681-702.

19. Loukaitou-Sideris, 2012.

20. Anne Beller, Sanford Garelik, and Sydney Cooper, "Sex Crimes in the Subway," Criminology 18 (1980): 35-52; and Lynch and Atkins, 1988.

21. Smith and Clarke, 2000; Loukaitou-Sideris, 2009; Andrew Newton, 2014, "Crime on Public Transport," Encyclopedia of Criminology and Criminal Justice, 709-720; Loukaitou-Sideris, Anastasia, 2015, "Intimidated Riders: US Women's Perspectives about Safety in Transit Settings," in Safety and Security in Transit Environments, 291-308, Springer; Goldsmith, Belinda, "Exclusive: Safety and Time Are Women's Biggest Concerns about Transport - Global Poll," REUTERS, November 14, 2018, https://www.reuters.com/article/us-transport-women-poll/exclusive-safety-and-timeare-womens-biggest-concerns-about-transport-global-poll-idUSKCN1NK04K.

22. Islam, A. and Amin, T., "Eve Teasing in Bangladesh: An Overview," IOSR Journal Of Humanities And Social Science (IOSR-JHSS), 21, 11 (2016): 1-6.

23. FiA Foundation, Safe and Sound: International Research on Women's Safety on Public Transport, London: FiA Foundation, 2016. 
24. Gardner, Natalie, Cui, Jianqiang, and Coiacetto, Eddo, "Harassment on Public Transport and Its Impacts on Women's Travel Behaviour," Australian Planner 54 (2017): 8-15; Gekoski et al., 2017.

25. Stringer, Scott M., Hidden in Plain Sight: Sexual Harassment and Assault in the New York City Subway System, Office of the Manhattan Borough President, 2007, http:// www.nytimes.com/packages/pdf/nyregion/city_room/20070726_hiddeninplainsight. pdf.

26. Natarajan, Mangai, et al., "Sexual Victimization of College Students in Public Transport Environments: A Whole Journey Approach," Crime Prevention and Community Safety 19 (2017): 168-182.

27. Los Angeles County Metropolitan Transportation Authority, Metro On-Board Passenger Survey (2018).

28. Washington Metropolitan Area Transit Authority, Collective Action for Safe Spaces, and Stop Street Harassment (2018, April 11), "Understanding Sexual Harassment on Public Transportation - 2008," https://www.wmata.com/about/news/upload/2018Sexual-Harassment-Report-Final.pptx.

29. End Violence Against Women (EVAW) (2012, March 30), Poll reveals 1/4 women don't feel safe on London public transport [web post], retrieved from: http://www. endviolenceagainstwomen.org.uk/news/14/poll-reveals-14-womendont-feel-safe-onlondon-public-transport.

30. R. Twyford, Report: Project Guardian- Public Awareness Campaign Rationale (London: Project Guardian, 2013).

31. Washington Metropolitan Area Transit Authority, 2018.

32. Juliane Stark and Michael Meschik, "Women's Everyday Mobility: Frightening Situations and their Impacts on Travel Behaviour," Transportation Research Part F: Traffic Psychology and Behaviour 54 (2018): 311-323.

33. Natarajan et al., 2017.

34. Hille Koskela and Rachel Pain, "Revisiting Fear and Place: Women's Fear of Attack and the Built Environment," Geoforum 31 (2000): 269-280.

35. Stringer, 2007.

36. British Transport Police Authority, Fear of Crime and Concerns about Personal Safety on the Rail Network. Summary of Findings from Existing Research: 2008 Update, London: British Transport Police Authority, 2008, https://btpa.police.uk/livesite/ wp-content/uploads/2012/01/2008-update-BTPA-Passenger-fear-of-crime-paperFINAL.pdf; UK Department for Transport, Experience and Perceptions of Anti-Social 
Behaviour and Crime on Public Transport, London: Department for Transport, 2008, https://webarchive.nationalarchives.gov.uk/20090103072146/http://www.dft.gov.uk/ pgr/statistics/datatablespublications/trsnstatsatt/antisocialcrime

37. Crime Concern, People's Perceptions of Personal Security and Their Concerns about Crime on Public Transport, London: Department for Transport, $2004 \mathrm{https} / / /$ webarchive.nationalarchives.gov.uk/+/http:/www.dft.gov.uk/pgr/crime/ps/perceptions/ researchfindings.

38. Keane, Carl, "Evaluating the Influence of Fear of Crime as an Environmental Mobility Restrictor on Women's Routine Activities," Environment and Behavior 30 (1998): 60-74; Cozens, Paul, et al., "Managing Crime and the Fear of Crime at Railway Stations-a Case Study in South Wales (UK)," International Journal of Transport Management 1 (2003): 121-132; Loukaitou-Sideris, Anastasia 2005, "Is It Safe to Walk Here," Research on Women's Issues in Transportation Conference Proceedings, Vol. 2, Washington D.C.: Transportation Research Board, 102; Loukaitou-Sideris, 2009; Loukaitou-Sideris, 2015; Abenoza, Roberto F., et al., 2018, "Individual, Travel, and Bus Stop Characteristics Influencing Travelers' Safety Perceptions," Transportation Research Record, https://doi.org/10.1177/0361198118758677; Stark and Meschik, 2018.

39. Gekoski et al., 2017

40. Loukaitou-Sideris, 2005

41. Levine, Ned and Wachs, Martin, "Bus Crime in Los Angeles: Il-Victims and Public Impact," Transportation Research Part A: General 20 (1986): 285-293; LoukaitouSideris, 2005.

42. Iudici, Antonio, Bertoli, Laura, and Faccio, Elena, "The 'Invisible' Needs of Women with Disabilities in Transportation Systems," Crime Prevention and Community Safety 19 (2017): 264-275.

43. Keane, C., "Evaluating the Influence of Fear of Crime as an Environmental Mobility Restrictor on Women's Routine Activities," Environment and Behavior 30 (1998): 60-74; Crime Concern, 2004. "People's Perceptions of Personal Security and Their Concerns about Crime on Public Transport." London: Department for Transport, 2004, ,https://webarchive.nationalarchives.gov.uk/+/http:/www.dft.gov.uk/pgr/crime/ps/ perceptions/researchfindings; Loukaitou-Sideris, 2005; Loukaitou-Sideris, A. 2009, "How to Ease Women's Fear of Transportation Environments: Case Studies and Best Practices"; Loukaitou-Sideris, 2015; Abenoza, et al., 2018; Stark, J. and Meschik, M., 2018.

44. Koskela, H. and Pain R., "Revisiting Fear and Place: Women's Fear of Attack and the Built Environment," Geoforum 31 (2000): 269-280. 
45. Yanuz, N. and Welch, E.W., "Addressing Fear of Crime in Public Space: Gender Differences in Reaction to Safety Measures in Train Transit," Urban Studies 47 (2010): 2491-2515.

46. Kim S. and Ulfarsson, G.F., "Commitment to Light Rail Transit Patronage: Case Study for St. Louis MetroLink," Journal of Urban Planning and Development 138 (2012): 227-34, https://doi.org/10.1061/(ASCE)UP.1943-5444.0000115.

47. H.-P. Hsu, D. Houston, and Marlon Boarnet, "Gender and Rail Transit Use: Influence of Environmental Beliefs and Safety Concerns," Transportation Research Record 2673 (2019): 327-338.

48. Jubainville, d'Arbois, H. and Vanier, C., "Women's Avoidance Behaviours in Public Transport un the lle-de-France Region," Crime Prevention and Community Safety 19 (2017): 183-198

49. Ibid.

50. Koskela and Pain. 2000.

51. Hsu, H-P, "How Does Fear of Sexual Harassment on Transit Affect Women's Use of Transit?" in Women's Issues in Transportation: Summary of the 4th International Conference 2 (2011): 85-94.

52. Stark and Meschik, 2018.

53. Lynch and Atkins, 1988.

54. Hsu et al., 2019; Jubainville and Vanier, 2017.

55. Beller et al., 1980.

56. British Transport Police Authority, 2008

57. Khanna, Meghna, "Sexual Harassment on Public Transit," Planning, May 2018.

58. Stringer, 2007.

59. Loukaitou-Sideris, 2005.

60. Beller et al., 1980.

61. Ball, Krista S., and Wesson, Caroline J., "Perceptions of Unwanted Sexual Behaviour on Public Transport: Exploring Transport Density and Behaviour Severity," Crime Prevention and Community Safety 19 (2017): 199-210.

62. FiA Foundation, 2016. 
63. Gekoski, A., et al., 2015, "What Works' in Reducing Sexual Harassment and Sexual Offences on Public Transport Nationally and Internationally: A Rapid Evidence Assessment," http://eprints.mdx.ac.uk/15219/1/Gekoski\%2C\%20Gray\%2C\%20 Horvath\%2C\%20Edwards\%2C\%20Emirali\%20\%26\%20Adler\%202015.pdf.

64. Ito, S., "Stop It! Tokyo Police Anti_Gropper App Becomes Smash Hit in Japan," The Japan Times, May 23, 2019.

65. FiA Foundation, 2016

66. Ibid.

67. Gekoski et al., 2015

68. Ibid.

69. Ibid.

70. Solymosi, R., Cella, K., and Newton, A. 2018. "Did They Report It to Stop It? A Realist Evaluation of the Effect of an Advertising Campaign on Victims' Willingness to Report Unwanted Sexual Behaviour," Security Journal 31 (2): 570-590.

71. Ceccato, V. and Paz, Y., "Crime in São Paulo's Metro System: Sexual Crimes against Women." Crime Prevention and Community Safety 19 (2017): 211-226.

72. Dunckel Graglia, A. 2016. "Finding Mobility: Women Negotiating Fear and Violence in Mexico City's Public Transit System." Gender, Place \& Culture 23(5): 624-460; Rahman, M. S. U. 2010. "Bus Service for 'Women Only in Dhaka City: An Investigation." Journal of Bangladesh Institute of Planners. 3: 17-32.

73. Agrawal, A. and Sharma, A. 2015. "Gender Contests in the Delhi Metro: Implications of Reservation of a Coach for Women." Indian Journal of Gender Studies 22(3): 421436.

74. Loukaitou-Sideris, A. 2009.

75. San José State University, "Student Quick Facts," http://www.iea.sjsu.edu/Students/ QuickFacts/default.cfm?version=graphic (visited October 14, 2019).

76. San José State University, 2019.

77. U.S. Census Bureau, "QuickFacts: San Jose City, California," https://www.census. gov/quickfacts/fact/table/sanjosecitycalifornia/PST045218 (visited April 17, 2019).

78. Ceccato and Loukaitou-Sideris, A. forthcoming.

79. Questions 3 to 6 for bus riders and 14 to 17 for train riders. 
80. Cox, D.R., 1958. "The Regression Analysis of Binary Sequences (with Discussion)." Journal of the Royal Statistical Society B (1958): 215-242.

81. McCullagh, P., "Regression Models for Ordinal Data." Journal of the Royal Statistical Society B 42 (1980): 109-142.

82. Rubin, D. B., Multiple Imputation for Nonresponse in Surveys. Vol. 81. (John Wiley \& Sons, 1987).

83. S. van Buuren and K. Groothuis-Oudshoorn, "mice: Multivariate Imputation by Chained Equations in R," Journal of Statistical Software, 45, no. 3 (2011), 1-67.

84. San José State University, "Student Quick Facts," http://www.iea.sjsu.edu/Students/ QuickFacts/default.cfm?version=graphic (visited October 14, 2019). 


\section{ABOUT THE AUTHORS}

\section{ASHA WEINSTEIN AGRAWAL, PH.D.}

Dr. Agrawal is Professor of Urban and Regional Planning at San José State University. Her research and teaching interests in transportation policy and planning include bicycle and pedestrian planning, travel survey methods, and transportation finance policy. She also works in the area of transportation history. She has a BA from Harvard University in Folklore and Mythology; an MSc from the London School of Economics and Political Science in Urban and Regional Planning; and a PhD from the University of California, Berkeley, in City and Regional Planning.

\section{ANASTASIA LOUKAITOU-SIDERIS, PH.D.}

Dr. Loukaitou-Sideris is Associate Dean of the UCLA Luskin School of Public Affairs, and Professor of Urban Planning. Her area of specialization is urban design, physical and land use planning. She has served as a consultant to the Transportation Research Board, Federal Highway Administration, Southern California Association of Governments, South Bay Cities Council of Government, Los Angeles Neighborhood Initiative, Mineta Transportation Institute, Robert Wood Johnson Foundation, the Greek government, and many municipal governments on issues of urban design, land use and transportation. She has published more than 100 articles and chapters and has co-authored or co-edited eight books: Urban Design Downtown: Poetics and Politics of Form (UC Press 1998); Jobs and Economic Development in Minority Communities (Temple University Press 2006); Sidewalks: Conflict and Negotiation over Public Space; Companion to Urban Design (MIT Press 2009); and The Informal American City: Beyond Taco Trucks and Day Labor (MIT Press 2014). Transit-Oriented Displacement or Community Dividends? (MIT Press 2019), and The New Companion to Urban Design (Routledge 2019).

\section{CRISTINA TORTORA, PH.D.}

Dr. Tortora is Assistant Professor in the Department of Mathematics and Statistics at San José State University. She completed her PhD in Statistics at the University of Naples Federico II in 2012. She has previously held postdoctoral positions at McMaster University, the University of Guelph, and Stazione Zoologica Anton Dohrn of Naples. Her research focuses on data analysis methods that use advanced clustering techniques, such as to find homogeneous groups of units within the data. Recent work focuses on methods that can detect clusters of different shapes, are robust in presence of outliers, and can cluster big data sets. She also collaborates with experts in different applied fields, including environmental science, transportation, and industrial engineering.

\section{YAJING HU, PH.D.}

Dr. Hu received her Ph.D. in Microbiology from the University of Massachusetts at Amherst in 2008. Since then, she has worked at Stanford University and a private biotech company focusing on translational biomedical research and developing molecular diagnostic assays. She recently received an M.S. in Statistics from San José State University and joined Abbott as a Senior Scientist in global data science and analytics. 


\section{PEER REVIEW}

San José State University, of the California State University system, and the MTI Board of Trustees have agreed upon a peer review process required for all research published by MTI. The purpose of the review process is to ensure that the results presented are based upon a professionally acceptable research protocol. 


\author{
Founder, Honorable \\ Norman Mineta (Ex-Officio) \\ Secretary (ret.), \\ US Department of Transportation \\ Chair, \\ Abbas Mohaddes (TE 202I) \\ President \& COO \\ Econolite Group Inc. \\ Vice Chair, \\ Will Kempton (TE 2022) \\ Retired \\ Executive Director, \\ Karen Philbrick, PhD \\ (Ex-Officio) \\ Mineta Transportation Institute \\ San José State University \\ Richard Anderson \\ (Ex-Officio) \\ President \& CEO \\ Amtrak \\ David Castagnetti (TE 202 I) \\ Co-Founder \\ Mehlman Castagnetti \\ Rosen \& Thomas \\ Maria Cino (TE 202 I) \\ Vice President \\ America \& U.S. Government \\ Relations Hewlett-Packard Enterprise
}

\author{
Grace Crunican* \\ (TE 2022) \\ Retired
}

Donna DeMartino (TE 202I)

General Manager \& CEO

San Joaquin Regional Transit District

Nuria Fernandez* (TE 2020)

General Manager \& CEO

Santa Clara Valley

Transportation Authority (VTA)

John Flaherty (TE 2020)

Senior Fellow

Silicon Valley American

Leadership Form

Rose Guilbault (TE 2020)

Board Member

Peninsula Corridor

Joint Powers Board

Ian Jefferies (Ex-Officio)

President \& CEO

Association of American Railroads

Diane Woodend Jones

(TE 2022)

Principal \& Chair of Board

Lea + Elliott, Inc.
Therese McMillan

(TE 2022)

Executive Director

Metropolitan Transportation

Commission (MTC)

Bradley Mims (TE 2020)

President \& CEO

Conference of Minority

Transportation Officials (COMTO)

Jeff Morales (TE 2022)

Managing Principal

InfraStrategies, LLC

Dan Moshavi, PhD

(Ex-Officio)

Dean, Lucas College and

Graduate School of Business

San José State University

Takayoshi Oshima (TE 202 I)

Chairman \& CEO

Allied Telesis, Inc.

Toks Omishakin

(Ex-Officio)

Director

California Department of

Transportation (Caltrans)
Paul Skoutelas (Ex-Officio)

President \& CEO

American Public Transportation

Association (APTA)

Dan Smith (TE 2020)

President

Capstone Financial Group, Inc.

Beverley Swaim-Staley (TE 2022)

President

Union Station Redevelopment

Corporation

\section{Jim Tymon (Ex-Officio)}

Executive Director

American Association of

State Highway and Transportation

Officials (AASHTO)

\section{Larry Willis (Ex-Officio)}

President

Transportation Trades

Dept., AFL-CIO

$(\mathrm{TE})=$ Term Expiration

* = Past Chair, Board of Trustees

\section{Directors}

Karen Philbrick, Ph.D.

Executive Director

Hilary Nixon, Ph.D.

Deputy Executive Director

\section{Asha Weinstein Agrawal,}

\section{Ph.D.}

Education Director

National Transportation Finance

Center Director

\section{Brian Michael Jenkins}

National Transportation Security

Center Director

\title{
Research Associates Policy Oversight Committee
}

Jan Botha, Ph.D.

Civil \& Environmental Engineering

San José State University

Katherine Kao Cushing,

\section{Ph.D.}

Enviromental Science

San José State University

Dave Czerwinski, Ph.D. Marketing and Decision Science San José State University
Frances Edwards,

Ph.D.

Political Science

San José State University

Taeho Park, Ph.D.

Organization and Management

San José State University

\section{Christa Bailey}

Martin Luther King, Jr. Library

San José State University

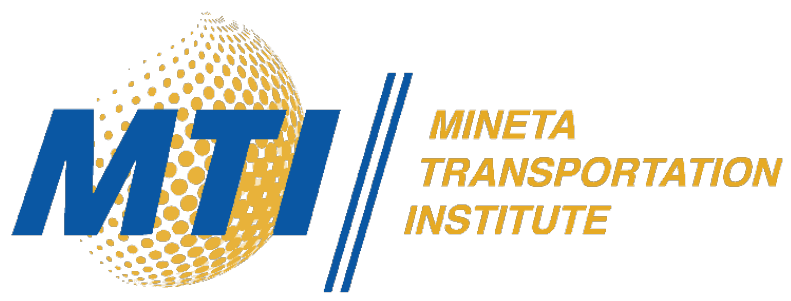

